\title{
Economic evaluation of stroke
}

Citation for published version (APA):

Evers, S. M. A. A. (2001). Economic evaluation of stroke. [Doctoral Thesis, Maastricht University]. Datawyse / Universitaire Pers Maastricht. https://doi.org/10.26481/dis.20011207se

Document status and date:

Published: 01/01/2001

DOI:

10.26481/dis.20011207se

Document Version:

Publisher's PDF, also known as Version of record

\section{Please check the document version of this publication:}

- A submitted manuscript is the version of the article upon submission and before peer-review. There can be important differences between the submitted version and the official published version of record.

People interested in the research are advised to contact the author for the final version of the publication, or visit the DOI to the publisher's website.

- The final author version and the galley proof are versions of the publication after peer review.

- The final published version features the final layout of the paper including the volume, issue and page numbers.

Link to publication

\footnotetext{
General rights rights.

- You may freely distribute the URL identifying the publication in the public portal. please follow below link for the End User Agreement:

www.umlib.nl/taverne-license

Take down policy

If you believe that this document breaches copyright please contact us at:

repository@maastrichtuniversity.nl

providing details and we will investigate your claim.
}

Copyright and moral rights for the publications made accessible in the public portal are retained by the authors and/or other copyright owners and it is a condition of accessing publications that users recognise and abide by the legal requirements associated with these

- Users may download and print one copy of any publication from the public portal for the purpose of private study or research.

- You may not further distribute the material or use it for any profit-making activity or commercial gain

If the publication is distributed under the terms of Article $25 \mathrm{fa}$ of the Dutch Copyright Act, indicated by the "Taverne" license above, 
Economic Evaluation of Stroke 
The studies described in this thesis were performed at the department of Health Organisation, Policy and Economics of the Maastricht University and the department of Neurosurgery of the University Hospital Maastricht. These studies are in part supported by grants from the Dutch Fund for Investigative Medicine, Health Insurance Executive Board, (on behalf of the SICHPA-trial), and the Maastricht Health Research Institute for Prevention and Care (HEALTH).

Economic evaluation of stroke. Silvia Evers. Thesis. Maastricht University With references - With summary in Dutch.

MeSH subject headings: Cerebrovascular Accident, Cost-Benefit Analysis, Cost of Illness.

ISBN: $90-52783292$

(C) 2001, Silvia MAA Evers, Maastricht University, Department of Health Organisation, Policy and Economics, PO Box 616,6200 MD Maastricht, 6200 MD Maastricht, The Netherlands; tellephone +31-43-3881602/81560; e-mail S.Evers@beoz.unimaas.nl or Secretariaat@beoz.unimaas.nl.

Lay out: Isel Bosma-van Noppen

Cover Design and Printed by: Datawyse/Universitaire Pers Maastricht. 


\title{
Economic Evaluation of Stroke
}

\author{
Academisch Proefschrift \\ ter verkrijging van de graad van doctor \\ aan de Universiteit Maastricht, \\ op gezag van de Rector Magnificus, \\ Prof. dr. A.C. Nieuwenhuijzen Kruseman, \\ volgens het besluit van het College van Decanen, \\ in het openbaar te verdedigen \\ op vrijdag 7 december 2001 om 12.00 uur \\ door
}

Sibilla Mechtildes Antonia Adolph Evers 


\section{Promotores:}

Prof. dr. I.A.M. Maarse

Prof. dr. T.L.C.M. Groot (Vrije Universiteit Amsterdam)

\section{Co-promotores:}

Dr. A.J.H.A. Ament

Dr. G. Blaauw

\section{Beoordelingscommissie:}

Prof. dr. W.N.J. Groot (voorzitter)

Prof, dr. G.A.M. van den Bos (Universiteit van Amsterdam, RIVM)

Prof. dr. K. Kesteloor (Katholieke Universiteit Leuven)

Dr. J. Lodider

Prof. dr. C.P. van Schayck

\section{Paranimfen:}

Marielle Goossens.

Nathalie Janssen

Financial support by the Netherlands Heart Foundation for the publication of this thesis is gratefully acknowledged. 
Voor Tiny" en Piet 



\section{Contents}

1 General Introduction: Economic Evaluation in Stroke

1.1 General Introduction and Aim of the Thesis 13

$\begin{array}{lll}1.2 & \text { Stroke } & 13\end{array}$

1.3 Epidemiology of Stroke $\quad 14$

1.4 Stroke Careers 14

1.5 Economic Burden of lliness 15

1.6 Economic Evaluation in Stroke 16

1.7 Objectives and Outline of the Thesis 17

References 18

2 Economic Evaluation in Stroke Research: An Introduction

Summary 25

2.1 Introduction 25

2.2 Study Frame $\quad 27$

2.3 Outcome Measurement 30

2.4 Costs Measurement $\quad 33$

2.5 Adjustments 37

2.6 Adaptation \& Utilisation 38

2.7 Conclusion 40

Acknowledgements 40

References 41

3 Economic Evaluation in Stroke Research:

A Systematic Review

Summary 49

3.1 Introduction 49

3.2 Economic Evaluation Designs 50

3.3 Methods 51

3.4 Results $\quad 52$

3.5 Economic Quality of the Studies 59

3.6 Conclusions 63

Acknowledgements 65

References 65 
4 The Usefulness of Ratios for Allocation Decisions: The Case of Stroke

$\begin{array}{ll}\text { Summary } & 71\end{array}$

$\begin{array}{lll}4.1 & \text { Introduction } & 71\end{array}$

4.2 CEA Or CUA 73

4.3 Measuring Effects $\quad 73$

4.4 Illustrations $\quad 75$

4.5 Conclusion $\quad 80$

References $\quad 81$

5 Cost of Stroke in The Netherlands from a Societal Perspective

$\begin{array}{ll}\text { Summary } & 85\end{array}$

5.1 Introduction $\quad 85$

$\begin{array}{ll}5.2 \text { Methods } & 86\end{array}$

5.3 Data, Analysis and Results by Cost Category 87

$\begin{array}{ll}5.4 \text { Results } & 93\end{array}$

5.5. Conclusion 96

$\begin{array}{ll}\text { Acknowledgments } & 98\end{array}$

References 98

6 The Use of Mental Health Care by Stroke Patients: A Cost - Analysis

$\begin{array}{ll}\text { Summary } & 105\end{array}$

$\begin{array}{ll}6.1 \text { Introduction } & 105\end{array}$

6.2 Psychiatric Morbidity Related to Stroke 106

$\begin{array}{ll}6.3 \text { Methodological Aspects } & 108\end{array}$

$\begin{array}{ll}6.4 \text { Results } & 112 \\ 6.5 \text { Conclusion and Discussion } & 117\end{array}$

$\begin{array}{ll}\text { 6.5 Conclusion and Discussion } & 117\end{array}$

$\begin{array}{ll}\text { Acknowledgements } & 120\end{array}$

$\begin{array}{ll}\text { References } & 120\end{array}$ 
7 Predicting the Cost of Hospital Stay for Stroke Patients: The Use of Diagnosis Related Groups

Summary

7.1 Introduction

7.2 Diagnosis Related Groups

7.3 Factors Predicting Utilisation of Stroke

7.4 Methods

7.5 Results

7.6 Conclusion

7.7 Discussion

Acknowledgments

References

8 Discussion: The Future Challenge of Economic Evaluation in Stroke: Integrated Care

8.1 Introduction

8.2 Recommendation for Policy Making 156

8.3 Major Problems in Economic Evaluation Research on Stroke 157
8.4 Changing Stroke Care

8.5 Evaluation of Integrated Care: A new Challenge for Future Reserach 160 References 



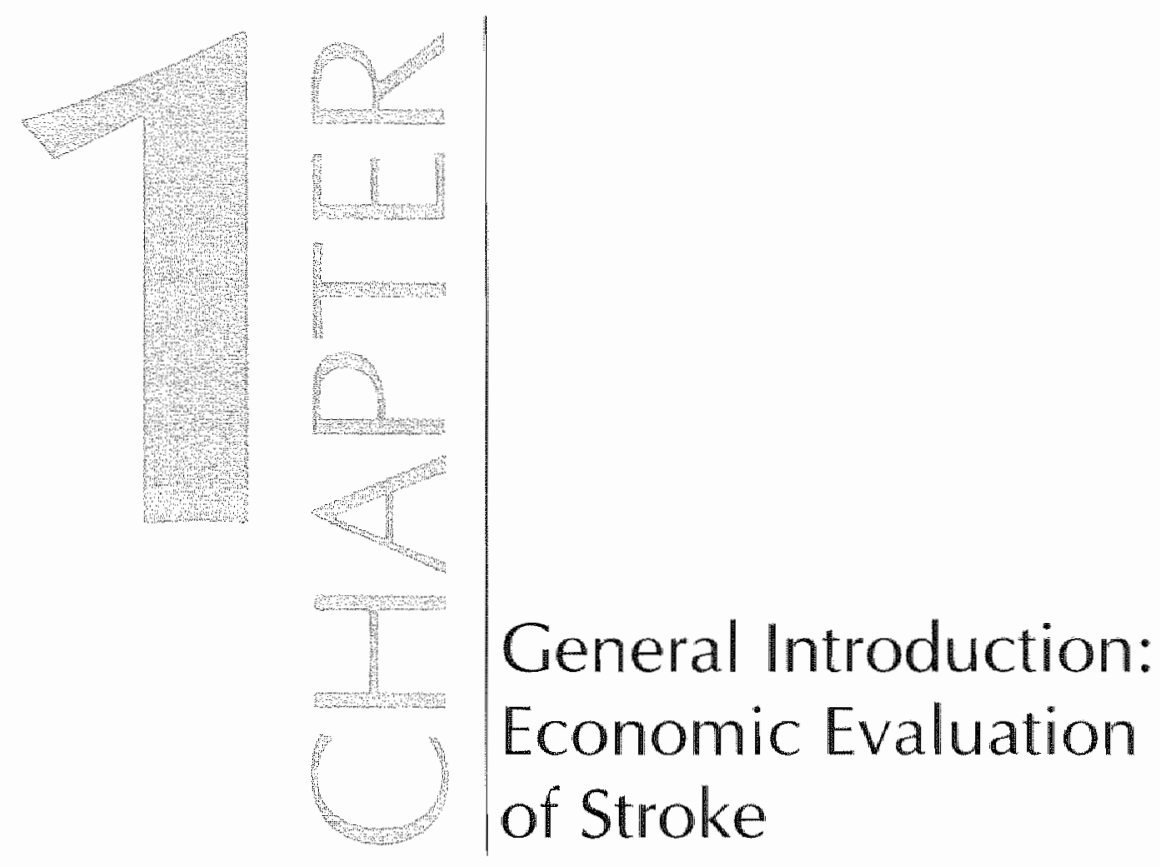




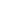




\subsection{General introduction and aim of the thesis}

The topic of this thesis is the economic evaluation of stroke interventions. Stroke is an important disease in both medical and economic terms. The main purpose of this thesis is to assess the quality of (methodological) aspects of economic evaluation studies of stroke, and to highlight some important economic aspects regarding stroke in Dutch society.

The introductory chapter outlines the background of both economic evaluation and stroke. Initially, stroke as a disease is introduced, and some major epidemiological aspects of stroke are described. Following this, the overall health care utilisation based on an average stroke patient's career is described, and there is a discussion of the economic burden of stroke, as well as of the concept of economic evaluation. Finally, the thesis is summarised in outline.

\subsection{Stroke}

From a health economics perspective, it is important to take into account stroke, or Cerebrovascular Diseases (CVD). Stroke is a vascular disease that affects the blood vessels supplying blood to the brain. Stroke is defined by the World Health Organisation (WHO) as "rapidly developed clinical signs of focal (or global) disturbance of cerebral function, lasting more than 24 hours or leading to death, with no apparent cause other than vascular origin"1. In the last decade, numerous risk and prognostic factors of stroke have been identified, such as. alcohol, blood haematocrit, blood pressure, coagulability, diet, family history of stroke, lack of exercise, oestrogens, serum cholesterol, smoking, stress, uric acid and weight ${ }^{206}$.

For the most part, strokes are ischaemic $(80 \%)$, and less often involve haemorhage $(20 \%)^{\%}$. However, the distinction between an ischaemic stroke and a haemorhagic stroke cannot be determined by clinical signs and symptoms. Haemorrhage damages or destroys brain tissue, whereas blood clots cause ischaemic stroke. The consequences of stroke can be devastating, both physically and psychologically ${ }^{3,9}$. It is assumed that the consequences of stroke depend on the size and the location of the lesion, although this is not always shown in the patients' quality of life measure ${ }^{10}$. In minor cases, symptoms can disappear within a few minutes or hours, a condition called transient ischaemic attack (TIA). 


\subsection{Epidemiology of stroke}

There is no recent population-based registration in the Netherlands to give insight into the prevalence and incidence of stroke. The most recent populationbased resource is the Tilburg Stroke Study", which estimates the annual incidence at 1.7 per 1,000, of which 1.5 per 1,000 are first ever strokes. The incidence and prevalence figures for stroke in the Netherlands are often based on GP-registrations. In 1994, the average incidence is estimated to be 1.7 per 1,000 for men and 2.0 per 1,000 for women; the average prevalence in 1994 ranges from 5.6 per 1,000 for men and 5.4 per 1,000 for women ${ }^{12}$. Stroke is a disease of old age. The prevalence rate above 55 years is estimated to be 25.2 per 1,000 for men and 27.7 per 1,000 for women. The incidence and prevalence rates have been relatively stable in recent years ${ }^{12}$. Stroke is the leading cause of death for women and the third cause of death for men ${ }^{13}$. In the Netherlands, the annual age-adjusted stroke mortality dropped between 1972 and $1986^{14}$, after which the decline in mortality leveled off. Overall in 1999, $9 \%$ of deaths were caused by stroke $^{13}$.

\subsection{Stroke careers}

For the most part, stroke patients are admitted to hospital immediately following the stroke ${ }^{15-17}$. In recent years, stroke patients have accounted for approximately $2 \%$ of hospital admissions and for $4 \%$ of inpatient hospital days ${ }^{18,19}$. The length of stay within hospital has decreased for stroke patients, from 28 days in 1980 to 23 days in $1998^{19}$. During the same period, the average length of stay for all patients also decreased, from 14 days to 9 days ${ }^{19}$. As a result, stroke patients in Dutch thospitals still stay relatively long ${ }^{20}$. Several studies have shown that the relatively long length of hospital stay for stroke patients is mostly due to nonmedical reasons, e.g. blocked beds ${ }^{2123}$. A study showed that for stroke patients, in the period from 1992 to 1994, about 10 out of 25 days of hospital stay were due to non-medical reasons, such as waiting for placement in a nursing home $(28 \%)$, in a rehabilitation center $(5 \%)$, or waiting for home care facilities $(3 \%)^{2 .}$. Considering that only 15 days are actually necessary for medical reasons, one could argue that the length of hospital stay in the Netherlands can be reduced considerably without compromising the quality of care ${ }^{23}$. Consequently, in recent years many hospitals have emphasised the continuity of care after stroke, by implementing hospital stroke units and regional stroke services ${ }^{24 \cdot 2 \pi}$. A regional 
stroke service is a chain of care providers, which in a joint network guarantee an integral, professional and integrated treatment and care for stroke patients in all stages of the disease. The members of the network have joint responsibility for the adequate and quick transfer of patients between the various health care facilities, and have joint responsibility for the quality of the care chain at large. Coaching of the informal caregiver is a main feature of the medical treatment in each link of the chain. A hospital stroke unit is part of the stroke service ${ }^{25}$. These integrated heath care arrangements are directly tailored to care demand, and it is generally expected that these facillities will enhance the continuity and efficiency of care. The cooperative harmonization of the financial and administrative organization among the various health care professionalls in one region is essential for the success of this system of care ${ }^{25,29,30}$.

While the majority of stroke patients $(60 \%)$ return to the home situation after being hospitalised for stroke, $17 \%$ of stroke patients die within the hospital, and $11 \%$ go to a nursing home 3 . This means that most patients who do not die of refurn to the home are likely to go to a nursing home. In recent years the number of stroke patients in the somatic department of nursing homes has increased from $28 \%$ to $35 \%$. The importance of nursing homes as facilities for stroke patients can also be illustrated by the fact that $50 \%$ of lifetime costs are due to nursing. home care ${ }^{3}$. In studying the stroke patients' career for up to 5 years it appears. that $63 \%$ of all stroke patients die ${ }^{34}$. Stroke survivors mostly stay in the home situation, with only a relatively small percentage staying in a nursing home or in a rehabilitation center ${ }^{2234}$. In the home situation, stroke patients depend on informal care over a long period of time, sometimes leading to high levels of burden both for the patients and their caregivers ${ }^{35.37}$.

\subsection{Economic burden of illness}

As in other countries, stroke in the Netherlands accounts for about $3 \%$ of health care costs ${ }^{13.38}$. Looking at the top 10 diseases in terms of costs of all diseases in the Netherlands in 1994, stroke is ranked in seventh place in all age groups and second in the oldest age groups $\geq 65$ years ${ }^{39}$, For a large part, costs are due to home nursing services (district nursing etc.) ( $16 \%$ ), hosplal costs (20\%), and nursing home care costs $(37 \%)^{13}$. Looking at lifetime cosis, it appears that longterm care facilities are in the long run more expensive than acute care facilities ${ }^{13,3}$. Regarding other costs, the problem is that for some costs few national data are available, such as stroke prevention costs, mental health care 
costs, and caregivers' $\operatorname{costs}^{13,41,42}$. A recent study, however, illustrates that psychiatric comorbidity is a relevant problem in stroke, inducing additional costs $^{4 !}$. Looking at the future, the cost of stroke will be an increasingly important issue. It is expected that, mainly due to an ageing population, the number of stroke patients and related costs will increase substantially until $2015^{45-46}$. Depending on the scenario applied, the increase in these costs will vary between $33 \%$ and $48 \%$, 35 ,

\subsection{Economic evaluation in stroke}

In recent years more and more emphasis has been put on cost, next to the effectiveness of new and existing treatment modalities. Economic evaluation studies as a part of medical technology assessment incorporate a range of techniques that can be used to investigate the costs and consequences of different procedures and programs. A good (full) economic evaluation consists of finding both the costs and benefits of comparable health care services. The results of economic evaluation studies can be used as a tool to inform policy makers, health care insurers, health care providers and patients on the value of an intervention compared with another intervention. The results of an economic evaluation study can be expressed in cost per effect-measure, the so-called ratio. The preferred effect measure is Quality-Adjusted Life Years (QALY), resulting in a cost-utility ratio. A QALY is an outcome measure that combines the number of life years saved (mortality), adjusted for quality. The number of economic evaluation studies in stroke has increased during recent years ${ }^{36}$. However, a systematic review of trial-based full economic evaluation stroke studies from 1966 until 1998 shows that only a few full economic evaluations have been undertaken in the domain of stroke $e^{4 ?}$. in most of these full economic evaluation studies, the methodology and technical execution were limited. Besides that, although using the concept of QALY is preferable from a theoretical point of view, for practical reasons cost-effectiveness analysis (CEA) rather than costutility analysis (CUA) is more often applied in stroke evaluation studies ${ }^{43}$. One of the main limitations of CEA is that the results can only be compared with the results of other CEAs using the same effect parameter. In addition, ratios are often not methodologically well-constructed, which may be misleading if the results are to be used for resource allocation. Part of this limitation can be explained by the fact that economic evaluation is sometimes hampered because stroke is not a homogeneous disease-entity. Stroke is a chronic disease with an acute onset 
leading to a broad scale of limitations varying from full health to long-term substantial impairment or death. Consequently, stroke patients make use of a wide variety of health care facilities and programs?. An economic evaluator, therefore, has to reckon with a broad spectrum of costs and outcome possibilities. That is why in economic evaluation studies modeling is often used as an addition or substitute for trial-based economic evaluation studies.

\subsection{Objectives and outline of the thesis}

This thesis consists of a number of studies that analyse aspects of economic evaluation regarding stroke. The thesis gives insight into the methodological state of the art of economic evaluation regarding stroke and is the first to highlight some aspects, such as psychiatric comorbidity, which are in general not regarded in economic evaluation studies. The main conclusion of the thesis is that the quality of economic evaluation studies in stroke can be improved by using sound methodologies and by applying a broader perspective to the evaluation.

Chapter 2 addresses crucial aspects in economic evaluation research. The purpose of this chapter is to provide some insight into the principles of economic evaluation studies in the field of stroke, so that these studies become easier for a non-expert to understand.

Chapter 3 reviews the literature of available economic evaluation studies in the field of stroke between 1966 and 1998 , based on a methodological checklist ${ }^{49,50}$. The chapter gives a detailed description of the methodological quality of these economic evaluation studies.

Chapter 4 addresses the usefulness of ratios as a tool for allocation decisions, with stroke as an example. The chapter illustrates that ratios based on economic evaluation studies may sometimes be misleading and for these reasons are not useful for resource allocation decisions.

Chapter 5 presents a cost-of-illness study in which the costs of stroke in the Netherlands in 1993 are calculated from a societal perspective, including both the cost of medical consumption as well as production losses.

One of the striking problems in Chapter 5 is that no national data are available for mental health care costs. These costs are calculated in Chapter 6 , providing a clear illustration of psychiatric comorbidity as a relevant problem which induces additional costs in stroke.

Chapter 7 is concerned with inpatient costs for stroke and analyses whether a Diagnosis. Related Groups (DRG) classification system can provide a satisfactory 
prediction of the variance of costs in stroke patients. The results of this chapter suggest that future implementation of output pricing based on the DRG case-mix measures is reasible, but only if it enhances information on complications and the level of functioning.

The thesis ends with discussion and conclusions in Chapter 8 , in which integrated care is considered as a future challenge for economic evaluation in stroke.

\section{References}

1. World Health Organization (WHO). Stroke 1989 Recommendations on Stroke Prevention, Diagnosis and Therapy. Report of the WHO task force on stroke and Other Cerebrovascular Disorders. Stroke 1989;20:1407-31.

2. Bronner $L \mathrm{~L}$, Kanter DS, Manson JE. Primary prevention of stroke. N Eng I Med $1995 ; 333: 1392-400$.

3. Goldstein LB, Matchar DB. The Stroke P.O.R.T.: secondary and tertiary prevention of ischeamic stroke. Stroke Prevention Patient Outcomes Research Team. Health Rep $1994 ; 6: 154-9$.

4. Keli SO. Epidemiology of stroke, the role of blood pressure, alcohol and diet. Wageningen: Landbouwuniversiteit Wageningen; 1995 [Thesis].

5. Verschuren WMM, Smir HA, van Leer EM, Berns MPH, Blokstra A, Steenbrink-van Woerden IA. Prevalentie van risicofactoren voor hart- en vaatziekten en veranderingen daarin in de periode 1987-1991. Eindrapportage Peilstationsproject Hart-en Vaatziekten 1987-1991. Billhoven: Rijksinstituut voor Volksgezondheid en Milieuhygiene; 1994.

6. Voko Z. Etiology and prevention of stroke: The Rottendam Study. Rotterdam: Erasmus Unversiteit Rotterdam: 2000 |Thesis|.

7. Meyboom-de long B, Buis J. Zorg na een beroerte; een publikatie van de Nederlandse Hartstichling over de gevolgen en de daamee samenhangende zorg: bevindingen, knelpunten en aanbevelingen. Den Haag. Nederlandse Hartstichting: 1995.

8. de Haan Rl. Clinimetrics in stroke. Amsterdam: University of Amsterdam: 1994 |rhesis!.

9. Hochstenbach $\mathbf{B H}$. The cognitive, emotional and behavioral consequences of stroke. Nijmegen: Katholieke Universiteit Nijmegen; 1999 [Thesis].

10. de Haan RJ, Limburg M, Van der Meulen $\mathrm{H}$, Jacobs HM, Aaronson NK. Quality of life after stroke. Impact of stroke type and lesion location. Stroke 1995:26:402-8. 
11. Herman B, Leyten AC, van Luijk IH, Frenken CW, Op de Coul AA, Schulte BP. Epidemiology of stroke in Tilburg, the Netherlands. The population-based stroke incidence register: 2. Incidence, initial clinical picture and medical care, and threeweek case fatality. Stroke 1982;13:629-34.

12. Rijksinsituut voor Volksgezondheid en Milieu (RIM). Volksgezondheid Toekomst Verkenning. Maarssen: Elsevier/De Tijdsstroom; 1997.

13. Centraal Bureau voor de Statistiek (CBS-statline). Overledenen naar doodsoonaak en geslacht. In: hitp:/statline cbs.nl/statweb/index.stm.

14. Reitsma JB, Limburg $M$, Kleijnen J, Bonsel G), Tiissen JG. Epidemiology of stroke in The Netherlands from 1972 to 1994: the end of the decline in stroke mortality. Neuroepidemiology $1998 ; 17: 121-31$.

15. Bots ML, Looman SJ, Koudstaal PI, Hofman A, Hoes AW, Grobbee DE. Prevalence of stroke in the general population. The Rotterdam Study. Stroke 1996;27:1499-501.

16. Franke CL. Intracerebral hemorrhage. Heeten: De Wever Zirkenhuis, Department of neurology; 1991 [Thesis].

17. Rijkuniversiteit Groningen Vakgroep Huisartsgeneeskunde. De patient met een cerebrovasculair accident en de huisarts. Groningen: Rijkssuniversiteit Groningen, vakgroep huisartsgeneeskunde; 1992.

18. Evers SM, Engel GL, Ament Al. Cost of stroke in The Netherlands from a societal perspective Stroke 1997;28:1375-81.

19. SIG/Prismant. Gegevens over algemene ziekenhuizen. Utrecht: SIG/Prismant; 19801998.

20. SIG. Kenninformatie diagnosegroepen, kliniek en dagverplleging, Nederland totaal 1998. In http:/www.sig.nl.

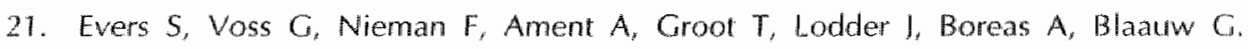
Predicting the Cost of Hospital for Stroke Patients: The Use of Diagnosis Related Groups. Health Policy 2001; accepted for publication.

22. Hermans E. In het verkeerde bed; hel zorgtraject van een cohort CVA-patienten na ziekenhuisopname. Maastricht: Universiteit Maastricht; 2000 Thesisl.

23. van Straten $A$, van der Meulen $1 H$, van den Bos GA, Limburg M. Length of hospital stay and discharge delays in stroke patients. Stroke 1997:28:137-40.

24. Limburg M, Tuut MK. CBO-richtlijn 'Betoerte' (herziening). Ned Tijdschr Geneeskd $2000 ; 144: 1058-62$.

25. Nederlandse Hartstichting. Stappenplan stroke sevice; een zeven-stappenmdel om te komen tot regionale samenwerking in de CWA-zorg. Den Haag: Nederlandse Hantstichting; 1999.

26. Nederlandse Hartstichting. CVAStroke Services Nieuwsbrief. Den Haag: Nederlandse Hartstichting: 2000. 
27. Nederlandse Hartstichting Commissie Ontwikkeling Richtlinnen Stroke Unit (CORSU). Advies Opzet Stroke Unit. Den Haag: Nederlandse Hartstichting; 2001.

28. Nederlandse Hartstichting Commissie Ontwikkeling Richtlinen TIA-POli (CORTIP). Adwies Opzet Tia-Poli. Den Haag: Nederlandse Hartstichting; 2001.

29. Jorgensen $H S_{2}$ Nakayama $H$, Raaschou HO, Larsen $K$, Hubbe P, Olsen TS. The effect of a stroke unit: reductions in mortality, discharge rate to nursing home, length of hospital stay and cost. A community-based study. Stroke 1995;26:1178-82.

30. Nederlandse Hartstichting, CBO kwaliteitsinstituut voor de gezondheidszorg. Beroerte. Alphen aan den Rijn: 2000 Van Zuiden Communications BV; 2000.

31. Nederlandse Hartstichting. Hart en Vaatziekten in Nederland 1999; Cijfers over ziekte en sterke. Den Haag: Nederlandse Hartstichting; 1999.

32. SIG informatiecentrum voor de gezondheidszorg. SIVIS-jaarboeken 1986-1997. Utrech: $51 \mathrm{G}$ informatiecentrum voor de gezondheidszorg; 1986-1996.

33. Bergman L, van der Meulen $\mathrm{H}$, Limburg M, Habbema JD. Costs of medical care after first-ever stroke in The Netherlands. Stroke 1995;26:1830-6.

34. Scholte op Reimer W. Long-term care after stroke: studies on care utilisation, quality of care and burden of caregiving. Amsterdam: University of Amsterdam; 1999 [Thesis].

35. Low IT, Payne $S$, Roderick P. The impact of stroke on informal carers: a literature review. Soc Sci Med 1999;49:711-25.

36. Scholte op Reimer WJ, de Haan RJ, Rijnders PT, Limburg M, van den Bos GA. The burden of caregiving in partners of long-term stroke survivors. Stroke 1998;29:160511.

37. Sicholte op Reimer WJ, de Haan RJ, Pijnenborg $J M$, Limburg $M$, van den Bos GA. Assessment of burden in partners of stroke patients with the sense of competence questionnaire. Stroke 1998;29:373-9.

38. Evers SMAA, Goossens MEJB, Ament AlHA, Maarse IAM. Economic evaluation in stroke research: an introduction. Cerebrowasc Diseases 2001;11:82-91.

39. Polder II. Meerding WI, Koopmanschap MA, Bonneux L, van der Maas PI. Kosten van ziektten in Nederland 1994. Rotterdam: Instituut Maatschappelijke Gezondheidszong Instituut voor Medical Technology Assessment Erasmus Universiteit Rotterdam; 1997.

40. Meerding WI, Bonneux L, Polder J, Koopmanschap MA, van der Maas PJ. Demographic and epidemiological determinants of health care costs in Netherlands: cost of illness study. BMJ 1998;317:111-5.

41. Evers SMAA, Ament AJHA, Driessen CAM. The use of mental health care by stroke patients: a cost-analysis. Int I Tech Assess Health Care 2001: accepted for publication. 
42. Evers SMAA, Ament AJHA, Groot TLCM. Valuation of Informal Care; the Case of Informal Care in the Netherlands. 16th Annual Mecting of the International Society of Technology Assessment in Health Care, The Hagwe, The Netherlands, 2000;32.

43. Lodder 1, Bouter LM. Toekomstige aantallen CVA patiènten in Nederland. Ned Tijdschr Geneeskd 1992:136:425-8.

44. Niessen LW, Barendregt II. Bonneux L, Koudstaall PI. Stroke trends in ar aging population. The Technology Assessment Methods Project Team. Stroke $1993 ; 24: 931-9$.

45. Struijs IN. Scenario-onderzoek naar het zorggebruik en de kosten van de zong wan CVA patienten in Nederlands tot en met het jaar 2015. Mastricht: Universiteit Maastricht; 1999 [MSC-thesis].

46. Struijs IN, van Genugten MLL, Evers SMAA, lager IC. Future prevalence and costs of stroke in the Netherlands. In: 16th Annual Meeting of the International Society of Technology Assessment in Health Care; 2000; The Hague, The Netherlands; 2000; 99.

47. Evers SM, Ament Al, Blaauw G. Economic evaluation in stroke research : a systematic review. Stroke 2000;31:1046-53.

48. Ament AlHA, Evers SMAA. The usefulness of ratios for allocation decisions: the case of stroke. Cerebrovasc Diseases 2000;10:283-8.

49. Evers SMAA, Wijk van AS, A. Ament AJHA. Economic evaluation of mental health care interventions, a review. Maastricht: University of Limburg, Department of Health Economics, Working Paper WP 94.03; 1994.

50. Evers SMAA, van Wijk AS, Ament AlHA. Economic evaluation of mental health care interventions: a review. Health Econ 1997;6:161-77. 



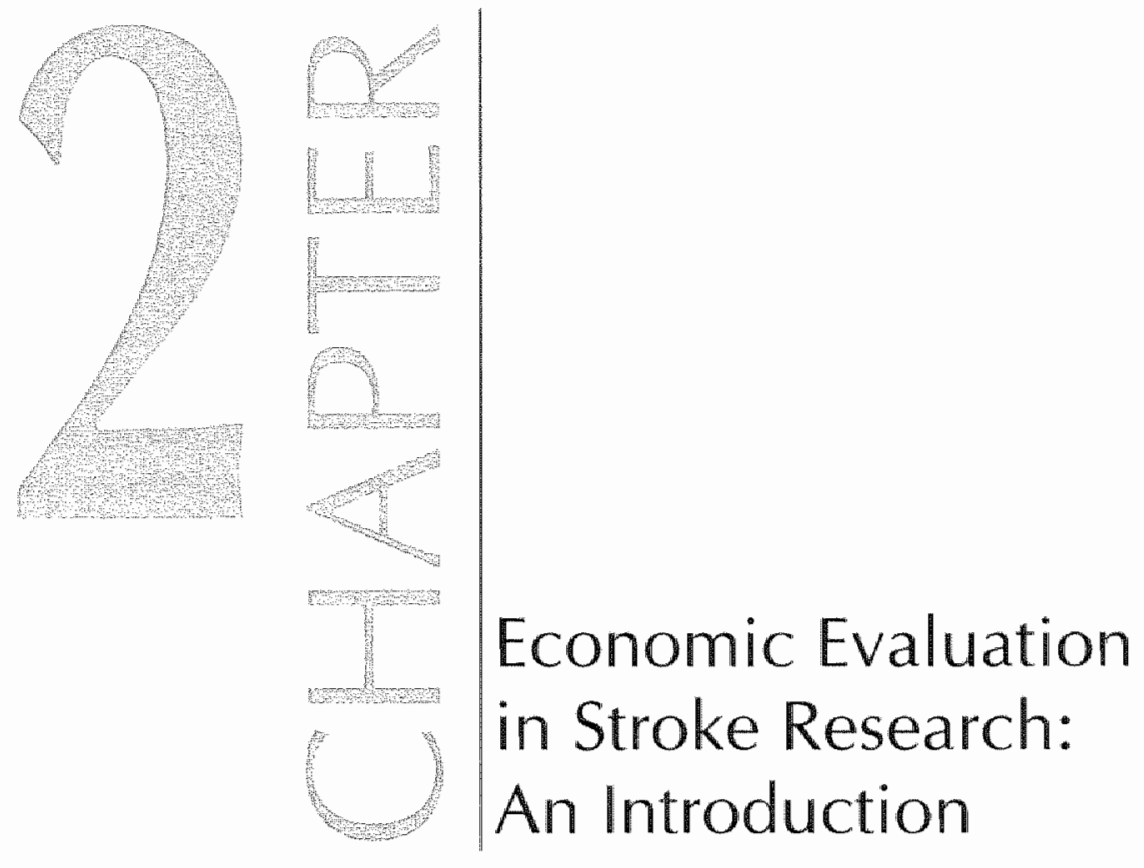





\section{Summary}

Before developing new medical facilities or adapting existing facilities in the field of stroke, it is desirable to assess not only the medical, but also the economic consequences of such facilities. Economic evaluation studies differ from other outcome studies in the way that costs are compared with effects. The purpose of this chapter is to provide insight into economic evaluation studies in the field of stroke, so that these studies become easier for physicians to understand and to apply.

Crucial aspects in economic evaluation research are addressed successively, such as the techniques used and how the results can be influenced by the perspective of the study. The chapter also considers the inclusion of costs and consequences in economic evaluation research. At the end of this chapter, special issues in economic evaluation studies are presented, such as discounting, sensitivity analysis, incremental analysis and ratios.

Although neurologists have no direct responsibility for allocating scarce resources in the field of stroke, they are confronted with the results of these decisions in their work every day. Because of this, it might be useful to have a clear understanding of economic evaluation studies.

\subsection{Introduction}

In western countries, $2-4 \%{ }^{1-9}$ of total health care costs are due to stroke. In stroke management, several developments have led to increased concern about the amount of money spent on stroke. On one hand, governments want to cut down health care expenditures, while on the other the health care sector is facing an increased demand for stroke interventions, due to demographic changes (an aging population) and changing attitudes toward health care. Demand is also growing due to new developments in stroke medicines and the changing preferences of stroke patients. The assumption underlying Health Economics is that resources (physicians, beds) are scarce, and choices have to be made regarding the allocation of these resources. Economics is the science of choices - the science that explains the choices that we make and how those choices change as we cope with scarcity. In economics, it is assumed that actors (physicians, patients, and health care insurers) have objectives and tend to choose a rational way to achieve these objectives. Decisions in health care involve committing resources to one use instead of another. To make a rational 
choice between relevant alternatives, the systematic analysis of economic aspects is needed.

The field of study that incorporates economic aspects (among others) in its assessments is termed Medical Technology Assessment or Health Technology Assessment (MTA or HTA). HTA is an interdisciplinary, scientifically-based assessment of technologies in health care, including drugs, devices, medical and surgical procedures, as well as organizational, administrative and support systems. Economic evaluation is a branch of HTA, as are, for instance, epidemiological, judicial, ethical and social aspects. In economic evaluation the question of reimbursement, i.e., who pays the cost of intervention (government, insurance companies, patients, etc.), is mot regarded as the central issue. Moreover, in economic evaluation the total costs and consequences of an intervention are studied at a societal level.

In stroke research more and more studies include an economic evaluation. A MEDLINE-search combining 'Cerebrovascular-disorders' and 'Costs-and-costanalysis' shows that since 1968 the number of stroke studies including costs have increased in both absolute and relative terms. Figure 1 gives an indication of the growth in quantity and does not give any indication whatsoever of the enlargement in quality. The importance of economic evaluation studies can also be illustrated by the fact that some governments have developed guidelines for the economic evaluation of pharmaceutical products before listing and pricing a drug ${ }^{10-12}$.

In recent years physicians have had to concern themselves increasingly not only with the efficacy of care and its acceptability to patients, but also with its economic efficiency". This chapter provides an introduction to economic evaluation and discusses issues in the design of such studies in the field of stroke, so that these studies become easier for physicians to understand and apply. 
Figure 1. Number of economic evaluation stroke studies

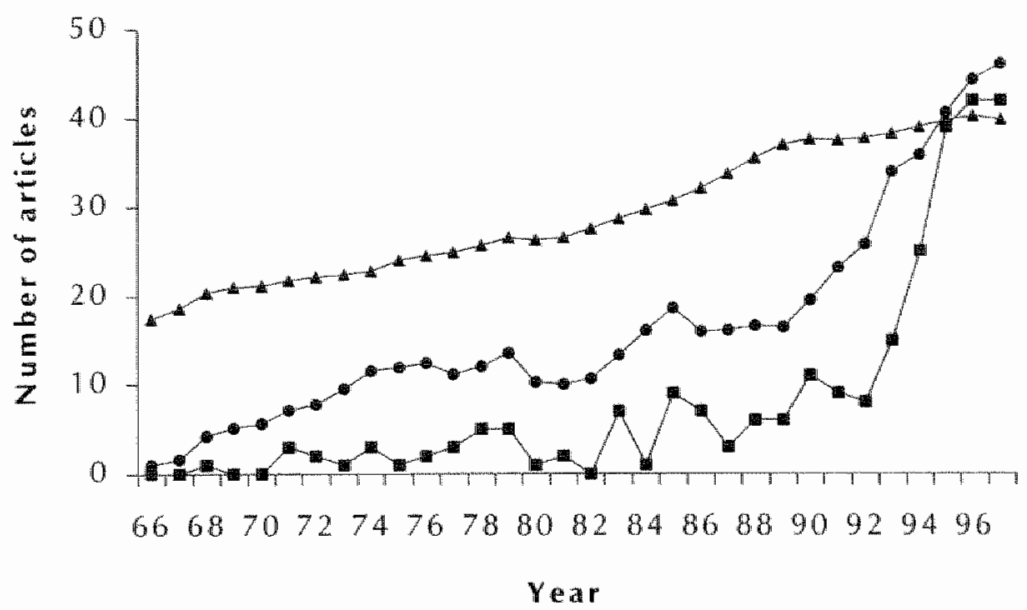

- Costs-and-cost-analysis'/all subheadings and 'Cerebrovascular-disorders'all subheadings (absolute figures): 'Costs-and-cost-analysis'all subheadings ( 100$)$; 1 'Cerebrovasculardisorder'; all subheadings ( $\times 10.000)$.

Source: MEDLINE

\subsection{Study frame}

\subsubsection{ANALMTIC PERSPECTIVE}

For economic evaluation and especially for the interpreblion of the results of a study, it is essential to ascertain the perspective of the analysis ${ }^{14}$. The analytic perspective is the viewpoint from which the study is conducted, e.g., principal, financiers, performer. The perspective determines which costs and consequences will be examined and the conclusions that can be drawn from a study in the field of stroke.

Ideally, the resulls of economic evaluation studies are to be used for resource allocation on the societal level; therefore, it is preferable to perform economic evaluation studies from the perspective of society ${ }^{75-1 \%}$. In addition, several other narrower viewpoints can be takem: for example, that of the third-party payer, of the health care provider, or of the patient. When using economic evaluation studies in stroke management, one should be aware of the viewpoint of 
analysis, as the results of the study differ depending on the analytic perspective. However, when reviewing the literature, only rarely does one discover studies in which the perspective is explicitly mentioned ${ }^{12-27}$.

Sometimes the perspective can be deduced from the sponsor of the study. Thus, one should be aware of a potential conflict of interest between researchers and their funding sources, as the introduction of some stroke interventions, such as drugs, may have financial implications ${ }^{22,27}$.

\section{2 .2 STUDY DESIGN}

In an economic evaluation study it is assumed that epidemiological aspects are as important as economic aspects. Only studies with a good epidemiological design, in which a comparison is made with the best alternative, can isolate the observed effect of an intervention. Some guidelines recommend that the health intervention of interest should be compared to existing practice ${ }^{24}$. Economic evaluation studies are often referred to as "piggyback' studies in which economic and additional health outcomes are 'piggybacked' on - added to - randomised controlled trials (RCTs) ${ }^{16,24}$. A problem with these studies is that it is often difficult to achieve statistical significance for the economic results, because the study power is calculated using a clinical endpoint. Only in a few instances are studies specially designed to determine the economic significance.

RCTs, however, though often considered to be the gold standard for economic evaluation, should not be considered as representative of or generalisable to the real world situation; they do not address issues on a more aggregate level. Additional biases in stroke research are that new therapies are often tested using a 'young' population in which the interaction with other diseases is ignored. Because of this, the results may not be representative of stroke in the elderly. For generalisation of the results to a real world situation, it is often necessary to perform (additionally) more naturalistic studies, such as modelling and observational studies ${ }^{25}$.

\subsubsection{MODELIING}

In general, guidelines ${ }^{12}$ recommend the use of trial-based data, supplemented by modelling, in order to replicate (long-term) effects of the actual practice conditions. A model is a simplified version of reality that is used to describe the essential clements of a real situation, such as the economic implications of 
using a particular stroke therapy. One of the major limitations of modelling is the interdependence of the validity of the input data. The point of such a model is to describe enough of the essential elements of reality to enable costeffective decision making. Modelling plays a central role in economic evaluation, and is used both as a substitute for trial-based-studies and as a complementary exercise to adapt trial-based data to a reall world situation ${ }^{16,263}$. In this last view, models and trials are complementary. In some instances trials may not be suitable, for instance when studying long-term costs and outcomes. For example, in the United States the long-term effects of stroke prevention have been studied by the Stroke Patient Outcome Research Team (Stroke PORT) ${ }^{27,20}$. The team has developed a comprehensive model of the nature of stroke, the so-called Stroke Prevention Policy Model (SPPM) ${ }^{29,30}$. The SPPM incorporates component models for the natural history of stroke, implication of prevention strategies, patient preference, and costs. The input in the model is based on RCTs, epidemiological studies, administrative data, patient preference data and expert opinions ${ }^{23,30}$. The team showed that treatments that produce even subtle improvements in the patterns of outcomes after stroke are likely to be cost-effective. This is because stroke patients are in general highly disabled and consequently induce high per diem costs. Furthermore, by using the SPPM as a model, the Stroke PORT study had the opportunity to extend the follow-up period, and thus could show that even small differences in shortterm effects can generate sizzeable long-term differences in outcomes ${ }^{30}$.

\subsubsection{TYPE OF ANALYSIS}

Figure 2 presents a flow chart for several categories of economic evaluation studies. The gray-shaded boxes in this figure refer to full economic evaluation studies that are considered to be the 'gold' standard. Furthermore, by means of two questions, "Is there a comparison of two or more alternatives?" and "Are both costs (inputs) and consequences (outputs) of alternatives examined?", a subdivision between partial and full economic evaluation studies can be easily achieved"s. One can speak of a full economic evaluation only if the answer to both questions is yes. There are four main types of analysis in full economic evaluations: cost-minimization analysis (CMA), cost-effectiveness analysis (CEA), cost-benefit analysis (CBA), and cost-utility analysis (CUA). Sometimes a cost-consequence analysis, in which the costs and consequences of alternative programs are computed and listed, without any attempt to aggregate these results, is added to this list ${ }^{24}$. 


\subsection{Outcome measurement}

\subsubsection{CONSEQUENCES}

As shown in Figure 2, the identification of consequences determines which type of full economic evaluation study is under consideration. In a CMA, the effects of the altermatives do not differ and consequently they are not valued. The evaluation in a CMA is essentially a search for the least costly alternative. The effects are measured differently in CEA, CUA, and CBA - in natural units, utilities (e.g. quality-adjusted-life-years), or pecuniary units respectively.

Stroke outcomes are particularly difficult to measure because of the heterogeneity of stroke signs and symptoms ${ }^{31}$. The outcome measures used in CEA studies mainly include stroke scales that concentrate on neurological impairments such as hemiparesis and level of consciousness. These stroke scales, such as the NIH Stroke Scales, the Canadian Stroke Scales, and the Scandinawian Stroke Scale, are related to each other, but the results cannot be compared directly as some of the items and the weights of the items are different 32.34 . In stroke research, functional disability is usually measured with the Glasgow Outcome Scale, the Barthel Activities of Daily Living Index, the Rankin Scale or the modified Rankin Scale. A problem is that the different versions of the Rankin Scale are not interchangeable.

Another limitation of a CEA using stroke scales and disability scales is that this analysis gives no information about the effects of the impairment on the patients' functional abilities. To overcome this problem one could use Healthrelated Quality of Life (HRQOL) measures. These are a more holistic way of measuring effects, including physical, emotional, and social aspects of life" such as the (stroke-adapted) Sickness Impact Profile, the Short Form-36, and EuroQol that are increasingly being used in stroke research ${ }^{3.44}$. Even so, a major limitation of CEA studies is that they do not permilt comparisons with interventions evaluated by other effects, as the outcome measures may be difterent. 
Figure 2. Decision three for applied studies with an economic aspect

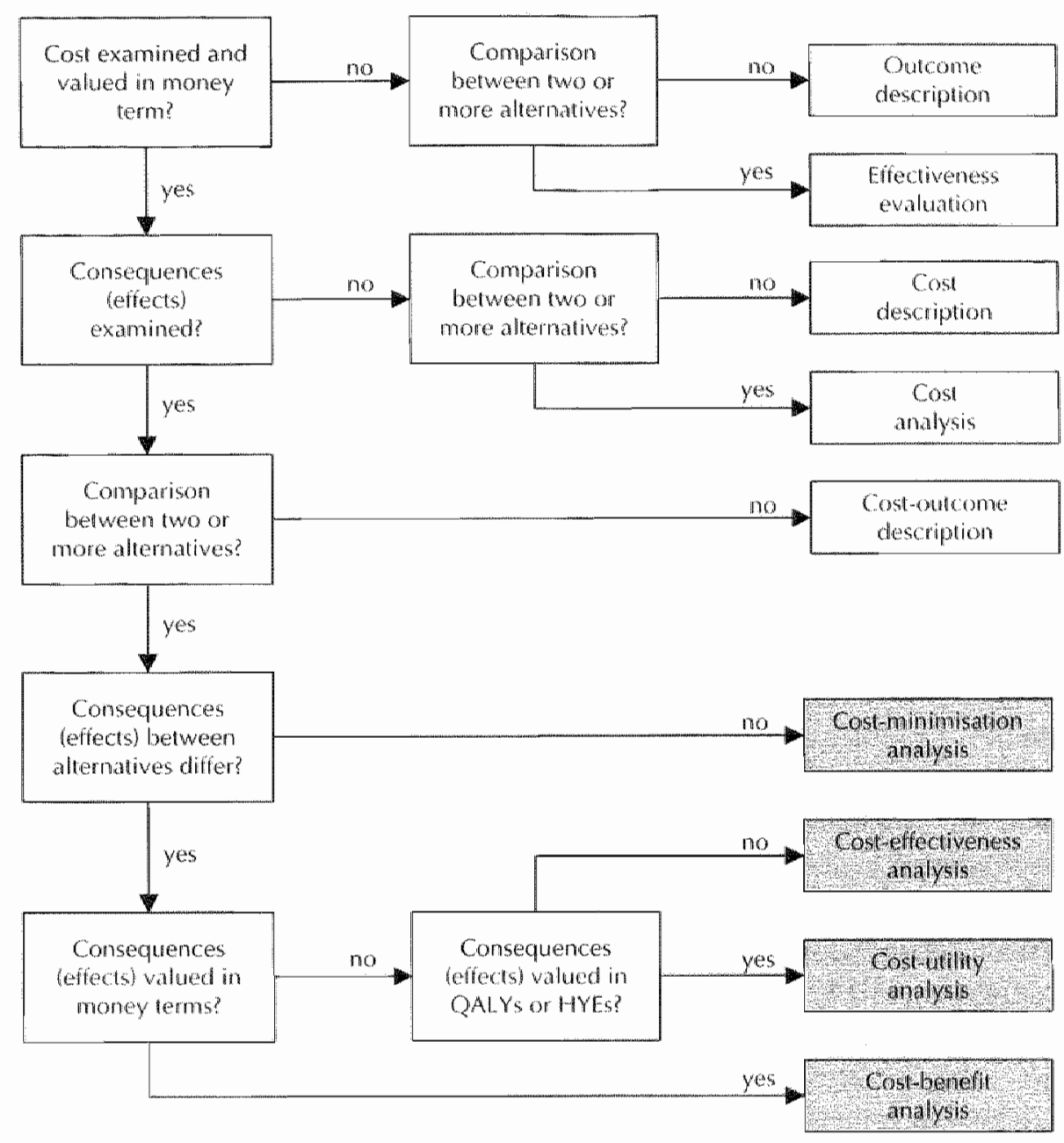

In a CUA, benefits are measured in utilities, i.e. the (stroke) patient's preference for a specific level of health status or a specific health outcome. In general, in a CUA the effects are measured in QALYs or HYEs, which rate both the quantity (stroke survival) and the quality of life of the stroke patients ${ }^{4 !}$. Quality-Adjusted Life Year (QALY) combines a Quality of Life measure (QOL) with mortality. The outcome measure in these types of study is life-years 
gained, adjusted for the quality of life. A common approach is to allocate a lower weight to a year of life that has low quality than to a year of higher quality. The EuroQol is frequently used for the measurement of utilities in stroke $35,40,48,43$. Another measure used in a CUA is a Health Years Equivalent (HYE), which gives a hypothetical number of years spent in perfect health that could be considered equivalent to the actual number spent in a defined imperfect state of health. The CUA is considered superior from an economic viewpoint, as this method takes patients' preferences into account when evaluating treatments.

Finally, a $C B A$ tries to express the health improvement in monetary terms. Costs and benefits are then measured in the same monetary unit, and one can see immediately whether the benefits outweigh the costs of a stroke intervention. However, the possibility of a CBA may be limited, as only a small number of benefits can be valued in monetary terms.

\subsubsection{Problems in OUTCOME MEASUREMENT}

Apart from the general pitfalls in neuroepidemiological research ${ }^{46}$, performing outcome measurements in the field of stroke will always lead to some additional problems. First, stroke has an acute onset. Consequently, data on the quality-of-life before stroke and before starting the treatment are not available. Another point that may especially influence the quality of life measurement is that stroke patients, like other chronically ill patients, have a remarkable capacity to adapt to their bad health. Both problems make it difficult to measure the improvement caused by (acute) stroke interventions. This may be solved by using a retrospective pretest or so-called then-test ${ }^{\prime 47}$. In the then-test, stroke patients are asked to provide a judgement about the health care status prior to the stroke. In addition to this, a large number of stroke patients die, which may lead to non-random missing values: i.e. the most severely disabled stroke patients are excluded from follow-up. It is still unclear how one can best value the costs and QoL aspects of these groups of patients in economic evaluation studies. Furthermore, many stroke survivors have cognitive and communicative disorders, so that self-reported information on a patient's quality of life cannot always be obtained. One solution is to use proxy measurements to avoid excluding this group of patients from the study. In addition, the instruments used in economic evaluation research are usually not very sensitive to small changes in health status. Therefore, the effects of stroke interventions may not be proven using the tools of economic evaluation. 


\subsection{Costs measurement}

Economic evaluation studies differ from other stroke outcome studies in the way that costs are compared with effects. To gain some insight into the performance of the costing within a study, the following questions are important: "Which costs-items are included in the stroke study?" "How are these costs measured?", and finally "How is each cost component valued?". In economic evaluation studies in the field of stroke, costs should not be restricted to the health care sector itself. Non-health care costs, such as the costs of informal care provided by relatives of the stroke patient, transportation costs of the stroke patient, and out-of-pocket expenses, should also be included, especially in stroke studies performed from a societal perspective.

\subsubsection{IDENTIFICATION}

Although it may not be possible to measure and value all the costs and consequences of stroke interventions under comparison, a full identification of important and relevant costs should be provided ${ }^{16}$. Broadly, three general categories of costs are used in an economic evaluation: direct costs, indirect costs and intangible cost $\mathrm{s}^{4.8}$.

Direct costs include all actual changes in resource use that are attributable to stroke, whether medical or non-medical. The direct medical costs which are overall identified in all stroke studies are the costs of hospital and professional care, medication and diagnostic tests ${ }^{49}$. Direct non-medical costs are associated with the provision of medical services outside the health care sector. In stroke studies this may include transportation of a patient to a medical service, out-of-pocket expenses, and the cost of informal care provided by family and friends.

Indirect costs are the value of reduced productivity resulting from stroke or mortality due to stroke. There may be some discussion about whether indirect costs should be taken into account at all in economic evaluation studies in the field of stroke. Inclusion of indirect costs might be relevant as stroke patients may recover sooner using one program compared to another program. However, if a program evaluates a disease with a high frequency in the nonproductive age group, such as stroke, this might not result in changes in the indirect costs. Although stroke is such a disease, several studies show that indirect costs should not be neglected (see Table 1). Furthermore, indirect costs may be relevant for family members and other stroke caregivers, who 
may have to leave their job or reduce their working hours. Given the controversy surrounding the inclusion of indirect costs, it is suggested that productivity changes, both in quantity and in price, should be reported separately"

Intangible costs are costs that cannot be expressed easily in monetary terms, such as pain, changes in social functioning, changes in the ability to pertorm nomal daily activities and changes in mobility due to stroke.

The above subdivision in costs is frequently used, but sometimes induces certain problems. Therefore Drummond" has suggested another division of costs, e.g. health care sector costs, costs for patient and family and costs in other sectors.

\subsubsection{MEASUREMENT}

In the context of economic evaluation in the field of stroke, data can be obtained using patient records, databases from insurance companies, hospital or providers databases, interviews, questionnaires and diaries ${ }^{50}$. Generally, stroke patients have to deal with multiple health care prowiders, medical consumption not covered by medical insurance, and all kinds of expenses outside the health care sector.

Because there is no single database that includes all cost information relevant to the stroke patient, information often has to be obtained from self-reported channels, such as interviews, questionnaires or cost-diaries ${ }^{50}$.

\subsubsection{VALUATION}

Valuation means the assignment of prices to the quantities of cost components measured. The basic idea of ecomomic evaluation studies is to add up the costs and benefits of wo or more stroke treatments, and pick the best alternative. However, choosing the best alternative leaves no resources to be spent on the next-best alternative. At the heart of economic analysis is the assumption that the true costs of a stroke program are equal to the value of the benefits from the next-best alternative. These opportunity costs are the cost of using resources for some purpose (best alternative), measured as their value in the next-best alternative use. In a truly competitive market, prices will equal opportunity costs. In the health care market, prices are distorted by a variety of forces, including cross-subsidization and cost-shifting. 
Because of the difficulty in estimating opportunity costs, charges or prices are used as a proxy for the costs in economic evaluation studies ${ }^{5}$. Charges or tariffs are not market prices associated with a product or service and are often 'negotiated prices'. This cannot be considered the optimal method of valuing health care costs, since charges do not usually reflect the true cost of providing a product or service ${ }^{52}$. There is considerable consensus that the cost callculation in HTA should be valued at opportunity costs ${ }^{24}$. If no prices are available, it is sometimes possible to calculate shadow prices using modelling techniques.

There is still much discussion about the proper way to value indirect costs. There are several ways of valuing the production losses in stroke research, such as the Human Capital (HC) approach and the Friction Cost (FC) method. The HC approach is a method of valuing indirect costs based on the expected economic productivity of the individual. In the HC approach the amount of production losses is valued by (market) earnings. A few years ago the FC method ${ }^{53,54}$ for estimating the indirect costs was introduced. According to the FC method, production losses will be confined to the period needed to replace a sick worker: the so-called friction period. Estimates based on the FC method are about $10 \%$ to $20 \%$ lower as compared to cost estimates according to the HC approach. Although it is not frequently used, we would like to refer to the Willingness-to-Pay method, in which both the direct and the indirect costs are included. The WTP approach is an evaluation method used to determine the maximum amount of money an individual is willing to pay to avert or to reduce health risks. WTP is measured either directly or indirectly. In direct measurement (contingent valuation), the person interviewed, after receiving detailed explanations of hypothetical scenarios (e.g. conditions of illness). indicates the maximum amount of money he/she would be willing to pay to change the situation using certain interventions, or at least not to make it any worse. In the case of indirect methods (revealed preferences) of measuring WTP, an individual's willingness to pay is deduced by drawing conclusions from his/her behaviour. The WTP is consistent with the framework of health economics. One of the basic ideas in health economics is that people who gain from certain health care interventions are willing to sacrifice a certain amount of money. This would render the WTP the most powerful technique from a theoretical point of view. One of the difficulties, however, is making the WTP realistic for the respondent. Another difficulty is that some persons might be more willing to spend money than others because they are more wealthy (ability to pay). Furthermore, if questions are asked regarding treatments with 
an uncertain outcome, risk-averse persons may react differently from riskseeking persons.

\subsubsection{COST-OF-HLLNSSSTUDIES}

One of the frequently performed partial economic evaluation analyses, studying only costs, is a cost-of-illness (COl) study. A COl study estimates and evaluates the direct and indirect costs of stroke. In addition to the most epidemiological estimates of morbidity and mortality, COI studies give additional information regarding the economic burden of stroke ${ }^{55}$.

As Table $\pi$ shows, there are several approaches to estimating the costs of stroke. The most widely employed are the prevalence method and the incidence method. The underlying idea of the prevalence method is that all stroke costs should be assigned to the year in which they are borne or with which they are directly associated. Using this approach, direct costs and productivity losses resulting from stroke are assigned to the year in which they occur. Expected future earnings in the life years lost as a result of premature stroke mortality are assigned to the year of death. The incidence method is based on the principle that the flow of costs associated with stroke should be assigned to the year in which that flow begins. All costs, both direct costs and productivity losses due to morbidity and mortality, are discounted to present value and assigned to the year in which the disease first appears ${ }^{56}$.

Another consideration is whether one is going to perform a bottom-up or a top-down cost-of-illness study. The top-down method calculates the national costs of stroke using databanks and statistics. In the bottom-up method a group of stroke patients are asked, by means of a questionnaire, what the costs of their disease are. The results of this questionnaire are extrapolated to a population level.

A COI study is limited, as it only takes into account the cost and does not relate the costs of a certain intervention to the effects. A general problem of the various COl studies of stroke is that they consider stroke in general. As noticed by Porsdal et al, stroke is not one but several distinct diseases, and each of these diseases has a unique epidemiological profile ${ }^{57}$. Another problem is that comparison of the various COI studies is difficult due to the different methods used (incidence vs. prevalence, bottomup vs. wop-down), the lack of transferability of health care costs, and different timing of the COI studies. Although the methodological differences between the studies are comparable, 
the overall results (see Table 1) show that in the western world about 2 to $4 \%$ of the costs are spent on stroke.

Table 1. Cost of stroke studies in different countries

\begin{tabular}{|c|c|c|c|c|c|}
\hline Author & $\begin{array}{l}\text { Nature } \\
\mathrm{COl}^{3}\end{array}$ & Country & Year of estimate & $\begin{array}{l}\text { Costs } \\
\text { (\% of totall) }\end{array}$ & $\begin{array}{l}\text { Direct \% } \\
\text { health care }\end{array}$ \\
\hline Bergman' & $\mathrm{ib}, \mathrm{b}$ & Netherlands & 1991 Uifetime costs & $d$ & $4 \%$ \\
\hline Dobkin?" & $\mathrm{pb}, \mathrm{t}$ & USA & 1993 & $d(57 \%) i(43 \%)$ & $2 \%$ \\
\hline Drummond ${ }^{\overline{3}}$ & $p b, t$ & England & $1984 / 1985$ & $\mathrm{~d}$ & $3 \%$ \\
\hline Evers $^{4}$ & $p b_{i} t$ & Netherlands & 1993 & $\mathrm{~d}(78 \%)$ i $(32 \%)$ & $3 \%$ \\
\hline Forbes/lsand & $\mathrm{pb}, \mathrm{t}$ & Scotland & 1988 & $d$ & $4 \%$ \\
\hline Scott" & $\mathrm{pb}, \mathrm{t}$ & New Zealand & 1992 & $d(92 \%)$ i $(8 \%)^{b}$ & $3 \%$ \\
\hline Smurawska ${ }^{5.3}$ & $i b, b$ & Canada & 1991-1992 per admission & $d$ & $-x$ \\
\hline Taylor $^{8}$ & $i b, t$ & USA & 1990 lifetime costs & $d(42 \%) ;(5 B \%)$ & $3 \%$ \\
\hline Terent ${ }^{6 \mathrm{~A}, 6.5}$ & $\mathrm{pb}, \mathrm{t}$ & Sweden & 1991 & $d(76 \%) ;(24 \%)$ & -5 \\
\hline Thorngren ${ }^{\text {his }}$ & $i b, b$ & Sweden & 1986 1987 first year & $d$ & $\ldots$ \\
\hline Weill ${ }^{\circ}$ & $\mathrm{pb}, \mathrm{t}$ & France & 1982 & $d$ & $2 \%$ \\
\hline
\end{tabular}

"Only most recent incidence-based and prevalence-based COI per country included.

buerage of the low $(d(94 \%)$ and $i(6 \%))$ and a high $(d(91 \%)$ and $i(9 \%))$ variant.

"Percentages calculated by the authors using the OECD statistical compendium".

Not possible to calculate a percentage as the study is not extrapolated to a national level.

" Internationally, study results are not comparable due to different approaches ${ }^{\text {tit }}$.

\section{Nature $\mathrm{COI}$}

$\mathrm{b}=$ incidence based

$\mathrm{pb}=$ prevalence based

$$
\begin{aligned}
& b=\text { bottom-up } \\
& t=\text { top-down }
\end{aligned}
$$

\subsection{Adjustments}

Stroke is a chronic disease and patients may require care over a period of several years. Costs and benefits occurring in different years should not just be added or subtracted, but rather expressed as their equivalent values at one time. Discounting is an adjustment for the different timing of costs and effects. The costs and outcomes of health care interventions will accrue over time. An individual will usually prefer benefits today to benefits tomorrow, and costs tomorrow rather than costs today. This time preference has to be built into estimates of both costs and outcomes to reflect their current values. Discounting is the process of calculating the present value of future costs and benefits. Where the expenditures and benefits of the intervention arise at different times in the future, the costs and benefits have to be discounted at 
some rate to find their present value. In general, programs that require current investments to achieve benefits far into the future are most strongly affected by the choice of discount rate. Discounting is not rellevant if the study period is less than one year. Several published studies have used a discount rate of $5 \%$ per year ${ }^{24}$ "Given currently availlable data on real economic growth and corresponding estimates of real consumption rates of interest, a discount rate of $3 \%$ per year was regarded as the most appropriate ${ }^{24}$. For sensitivity analysis a reasonable range of discount rates from $0 \%$ to $7 \%$ per year should be used ${ }^{24}$. The information needed for a good economic evaluation is sometimes limited. therefore estimates have to be made on very little information. Furthermore, each study should perform a sensitivity analysis to show the influence of its assumptions on the results of the study. A sensitivity analysis is a process in which different values of critical variables are used for the analysis, in order to assess the impact of changing these values:. It is often the case that precise data are not available for certain variables required in an evaluation. Researchers then have to make an estimation, based on information that is. available, and sensitivity analysis can be useful in testing the importance of the assumptions behind these estimates. It may show the dependency of a conclusion on a particular assumption, suggesting that the overall analysis cannot be viewed as definitive, but it may also show that changing the parameter of the assumption does not significantly alter the study's conclusions ${ }^{5.1}$.

\subsection{Adaptation \& Utilisation}

Decision-makers are especially interested in the additional costs and additional benefits of an intervention compared with an alternative intervention. An incremental analysis provides this intormation. At the end of the analysis the results are expressed in one ratio. Depending on the type of analysis this can be either a cost-effectiveness, a cost-benefit or a cost-utility ratio. In recent years thas become fashionable to express the results of a study in a cost-per-quality adjusted lire year. In a league table, a kind of ranking chart, the results of the studies can be compared with other interventions. As Table 2 shows, cholesterol testing and diet therapy cost 500 times less in order to produce one QALY compared with neurosurgical interventions for malignant intracranial tumors ${ }^{5 *}$. 
Table 2. QALYS of interventions relevant for neurosciences

\begin{tabular}{|c|c|}
\hline Intervention & $\begin{array}{l}\text { Cost/QAL'L } \\
\text { Aug } 1990\end{array}$ \\
\hline Cholesterol testing and diret therapy only lalt adults, aged $40-69$ ) & 220 \\
\hline Neurosurgical intervention for head injury & 240 \\
\hline GP advice to stop snoking. & 270 \\
\hline Neurosurgical intervention for subarachnoid hemorrhage & 490 \\
\hline Anti-hypertensive therapy to prevent stroke & 940 \\
\hline Cholesterol testing and treatment & 1.480 \\
\hline Coronary Artery Bypass Craft (left main wessel disease, severe angina) & 2,090 \\
\hline Cholesterol testing and treatment (incrementally) of all adults aged 25-39 years & 14,150 \\
\hline Coronary Artery Bypass Grati (1 vessel disease, moderate angina) & 18,830 \\
\hline Neurosurgical interventions for thalignant intracranial tumors & 107,780 \\
\hline
\end{tabular}

Source: Adapted from Drummond et al..$^{\text {st }}$

Based on a league table, decisions can be made, incorporating both costs and outcomes. To make the adaptation more transparent, Laupacis ${ }^{59}$ suggested dividing new technologies into five grades based on the level of evidence (completeness of the data available) and on the incremental analysis. For example, grade A technology is both more effective and cheaper than the existing one, whereas a grade $E$ technology is less or equally effective and more costly.

Furthermore, a number of countries ${ }^{12,60,63}$ have created guidelines, in most instances initiated by the government. In general, these guidelines try to improve the use of economic evaluation for both reimbursement and listing purposes. The purpose is also to define methodological standards and thus to increase the validity (reliability and relevance) of economic evaluation studies. Broadly, these guidelines incorporate common features mentioned in this chapter. Although there are several differences, all guidelines underline the importance of using and reporting transparent methods so that readers can easily understand what calculations are being performed on which data elements, minimizing bias, and providing justification for the methods and assumptions used ${ }^{12,60}$.

To enable clear national standards of what patients can expect to receive from the National Health Service, the United Kingdom set up the National Institute of Clinical Excellence (NICE) which gives advice upon the appraisal of health technologies. As stated on their website, "NICE may... advise that certain new treatments, although offering limited clinical benefits, would not be cost 
effective - that is, that the National Health Service (NHS) could achieve much greater health benefits by using its resources in other ways." As a consequence. NICE may, in some instance, prevent access to effective new treatments, as some of these new technologies are not cost-effective.

\subsection{Conclusion}

The field of economic evaluation research is expanding rapidly. This chapter gives basic insight into the use of economic evaluation studies in stroke research. For further details we refer to various guides ${ }^{16,24}$.

Although attempts have been made to standardise economic evaluation studies, we would like to point out that there is no single way of performing an economic evaluation study. This stresses the need for transparent reporting of research methodology in economic evaluation studies and careful interpretation of these results when using them for decision making.

Economic evaluation studies are going to be used more and more by policy makers as a basis for their decisions. In addition, these economic evaluation studies will have an increasing impact on clinical practice, in terms of pricing, coverage, and reimbursement. In some instances, there may be tension between those who wish to maximise effectiveness for the individual patient (e.g. the clinicians) and those who wish to reduce costs at a macro level (e.g. the policy makers) ${ }^{6}$. But these clinicians are also facing, to an increasing extent, a 'llifeboat scenario', where a growing number of stroke patients are demanding a larger amount of care while available resources remain scarce. Information on both the costs and effectiveness of several programs can be helpful when making these decisions.

\section{Acknowledgements}

We thank Dr. Gerhard Blaauw (neurosurgeon, University Hospital Maastricht), Professor Tom Groot (Department of Accounting, the Vrije Universiteit Amsterdam), and Dr. Jan Lodder (neurologist, University Hospital Maastricht) for their comments on draft versions of this chapter. This does not necessarily mean that they endorse all elements of our analysis and the conclusion. 


\section{References}

1. Bergman L, van der Meuten I, Limburg M, Habbema DF. Cost of Medical Care After First-Ever Stroke in the Netherlands. Stroke 1995;26:1830-6.

2. Dobkin B. The economic impact of stroke. Neurology $1995 ; 45: 56-9$.

3. Drummond MF, Ward GH. The financial burden of stroke and the economic evaluation of treatment alternatives. In: Clifford Rose F, editor. Stroke: epidemiological, therapeutic and socio-economic aspects. London: Royal Society of Medicine Services Limited; 1986.

4. Evers SMAA, Engel GL, Ament AJHA. Cost of stroke in the Netherlands. Stroke 1997;28:1375-81.

5. Forbes IF. Cost of stroke. Scott Med 1 1993;38:S4-5.

6. Isard PA, Forbes JF. The cost of stroke to the national service in Scotland. Cerebrovasc Dis 1992:47-50.

7. Scott WG, Scott H. Ischaemic stroke in New Zealand: an economic study. NZ Med | 1994;107:443-6.

8. Taylor TN, Davis PH, Torner JC, Holmes 1, Meyer IW, Jacobson MF. Lifetime cost of stroke in the United States. Stroke 1996:27:1459-66.

9. Weill $C$, Schneider $T$. The cost of cerebtovascular accidents in France in 1982. In: Clifford Rose F, editor. Stroke: epidemiological, therapeutic and socio-economic aspects. London: Royal Society of Medicine Services Limited; 1986.

10. Detsky AS. Guidelines for economic analysis of pharmaceutical products: a draft document for Ontario and Canada. PharmacoEconomics 1993;3:354-61.

11. Drummond M. Australian guidelines for cost-effectiveness studies: the tin end of the boomerang? York: University of York, Centre for Health Economics; 1991.

12. Jacobs $P$, Bachynsky I. Baladi J-F. A comparative rewiew of pharmacoeconomic guidelines. PharmacoEconomics 1995;8:182+9.

13. Maynard A, Sheldon TA. Health economics: has it fulfilled its potential? In: Maynard A, Chalmers I, editors. Non-random reflections on health serwices. research: on the 25th anniversary of Archie Cochrane's Effectiveness and Efficiency. London: BMJ Publishing Group; 1997.

14. Davidoff Al, Powe NR. The role of perspective in defining economic measures for the ewaluation of medical technology. Int J Technol Assess Health Care 1996; 12:9-21.

15. Warner KE, Hutton RC. Cost-benefit and cost-effectiveness analysis in health care. Growth and composition of the literature. Med Care 1980;18:1069-84. 
16. Drummond MF, OBrien B, Stoddart GL. Torrance GW. Methods for economic evaluation of health care programmes. Second edition ed. Oxford: Oxford University Press; 1997.

17. Weinstein MC. Principles of cost-effective resource allocation in health care organization. Int $\$ Technol Assess Health Care 1990;6:93-103.

18. Udvarhelyi 1S, Colditz GA, Rai A, Epstein AM. Cost-effectiveness and cost-benefit analyses in the medical literature. Are the methods being used correctly? Ann intern Med 1992:116:238-44.

19. Coossens MICB, Evers SMAA. Economic assessment of back pain interventions. J Occup Rehabil 1997;7:15-32.

20. Fvers SMAA, Wijk van AS, Ament AlHA. Economic evaluation of mental health care interventions, a review. Maastricht: University of Limburg, department of Health Economics, Working Paper WP 94.03; 1994.

21. Evers SMAA, Wijk van AS. Ament AJHA. Economic evaluation of mental health care interventions, a review. Health Econ 1997;6:161-77.

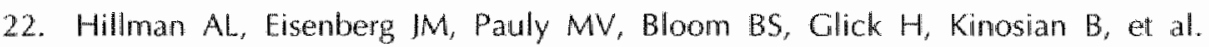
Avoiding bias in the conduct and reporting of cost-effectiveness research sponsored by pharmaceutical companies. N Engl) Med 1991;324:1362-5.

23. Freemantle $N$, Maynard A. Something rotten in the state of clinical and economic evaluations? Health Econ 1994;3:63-7.

24. Gold MR, Siegel $\ E$, Russell LB, Weinstein MC. Cost-effectiveness in health and medicine. New York/Oxlord: Oxford University Press; 1996.

25. Baltussen R, Ament A, Leidl R. Making cost assessments based on RCTs more useful to decision-makers. Health Policy 1996;37:163-83.

26. Rittenhouse B. Uses of models in economic evaluations of medicines and other health trechnologies. London: Office of Heatth Economics; 1996.

27. Matchar DB, Duncan PW, Samsa GP, Whismant IP, DeFriese GH, Ballard DI, et al. The Stroke Prevention Patient Outcomes Research Team. Goals and methods. Stroke 1993:24:2135-42.

28. Goldstein LB. Matchar DB. The Stroke P.O.R.T.: secondary and tertiary prevention of ischemic stroke. Stroke Prevention Patient Outcomes Research Team. Health Rep 1994;6:15449.

29. Matchar DB, Samsa GP, Matthews IR, Ancukiewicz M, Parmigiani G, Hasselblad V. et al. The Stroke Prevention Policy Model: linking evidence and clinical decisions. Ann Intern Med 1997;127:704-11.

30. Samsa GP, Reutter RA, Parmigiani $G$, Ancukiewicz $M$, Abrahamse P, Lipscomb J. et al. Performing cost-effectiveness analysis by integrating randomized trial data 
with a comprehensive decision model: application to treatment of acute ischemic stroke. I Clin Epidemiol 1999;5:2:259-71.

31. Williams LS. Health-related quality of life autcomes in stroke. Neuroepidemiology $1998 ; 17: 116-20$.

32. de Haan R, Horn J, Limburg M, van der Meullen J, Bossuyt P. A comparison of five stroke scales with measures of disability, handicap, and quality of life. Stroke 1993:24:1178-81.

33. de Haan $R$, Limburg $M$, van der Meulen J. Jacobs HM, Aaronson NK. Quality of life after stroke. Impact of stroke type and lesion location. Stroke 1995:26:402-8.

34. de Haan $R$, Aaronson $N$, Limburg $M$, Hewer RL, van Crevel H. Measuring quality of life in stroke. Stroke 1993;24:320-7.

35. Dorman PI, Waddell F, Slattery J, Dennis M, Sandercock P. Is the EuroQol a vallid measure of health-related quality of life after stroke? Stroke 1997;28:1876-82.

36. O. Mahony P, Rodgers $H$, Thomson RG, Dobson R, James OF. Is the SF-36 suitable for assessing health status of older stroke patients? Age Ageing 1998; 27:19-22.

37. Hop IW, Rinkel G), Algra A, van Gijn 1. Quality of life in patients and partners after aneurysmal subarachnoid hemorrhage. Stroke 1998;29:798-804.

38. Dorman P, Slattery I, Farrell B. Dennis M, Sandercock P. Qualitative comparison of the reliability of health status assessments with the EuroQol and SF-36 questionnaires after stroke. United Kingdom Collaborators in the Internationall Stroke Trial. Stroke 1998;29:63-8.

39. van Straten $A$, de Haan RI, Limburg $M$, Schuling J, Bossuyt PM, van den Bos GA. A stroke-adapted 30-item version of the Sickness Impact Profile to assess quality of life (SA-SIP30). Stroke 1997;28:2155-61.

40. Dorman PI, Waddell F, Slattery I, Dennis M, Sandercock P. Are proxy assessments of health status after stroke with the EuroQol questionnaire feasible, accurate, and unbiased? Stroke 1997:28:1883-7.

41. Dorman PI, Slattery I, Farrell B. Dennis MS, Sandercock PA. A randomised comparison of the EuroQol and Shor Form-36 after stroke. United Kingdom collaborators in the International Stroke Trial. BM] 1997:315:461.

42. Sneeuw KC, Aaronson NK, de Haan RJ Limburg M. Assessing quality of life after stroke. The value and limitations of proxy ratings. Stroke 1997;28:1541-9.

43. Hobson P. Bhowmick B, Meara J. Use of the SF-36 questionnaire in cerebrovascular disease. Stroke 1997:28:464-5.

44. Anderson C, Laubscher S, Burns R. Validation of the Short Form 36 (SF-36) health survey questionnaire among stroke patients. Stroke 1996;27:1812 6. 
45. Johannesson $M$. Jónsson $B$, Karlsson $C$. Outcome measurement in economic evaluation. Health Econ 1996;5:279-96.

46. Anderson DW, Rocca WA, Rosário. Pitfalls in Neuroepidemiologic Research. Neuroepidemiology 1998; 17:55-62.

47. Sprangers MAC. Response-shifte bias: a challenge to the assessment of patients' quality of life in cancer clinical trials. Cancer Treat Rev 1996;22:55-62.

48. Luce B, Elixhauser A. Estimating costs in the economic evaluation of medical technologies, Int \ Technol Assess Health Care 1990;6:57-75.

49. Dunbabin, D.. Cost-effective intervention in stroke. PharmacoEconomics 1992; 2:468-99.

50. Goossens MEIB, Rutten-van Molken MPMH, Waeyen IWS, wan der Linden SMIP. The cost diary; a method to measure the direct and indirect costs in a cost effectiveness research. I Clin Epidemiol 2000;53: 688-95.

51. Luce B, Elixhauser A. Standards for socioeconomic evalluation of health care products and services. Berlin: Springer; 1990.

52. Finkler A. The distinction between cost and charges. Ann Intern Med 1982:96:102-9.

53. Koopmanschap MA, Ineveld van BM. Towards a new approach for estimating indirect costs of disease. Soc Sci Med 1992;34:1005-10.

54. Koopmansichap MA, Rutten FFH, van Ineveld BM, van Roijen $L$. The friction cost method for measuring indirect cost of disease. I Health Econ 1995;14:171-89.

55. Drummond MF. Cost-of-Illness Studies A Major Headache? PharmacoEconomics $1992 ; 2: 1-4$

56. Hodgson TA, Meiners MR. Cost-of-illness methodology: a guide to current practices and procedures. Milbank Mem Fund Q Health Soc 1982;60:429-62.

57. Porsdal V, Boysen G. Cost-of-illness studies of stroke. Cerebrovasc Dis $1997: 7: 258-63$.

58. Drummond $M$, Torance $G$, Mason J. Cost-ffectiveness league tables: more harm than good? Soc Sci Med 1993:37:33-40.

59. Laupacis A, Feeny D, Detsky AS, Tugwell PX. How attractive does a new technology have to be to warrant adoption and utilization? Tentative guidelines. for using clinical and economic evaluations. CMAl 1992;146:473-81.

60. College voor Zorgverzekeringen. Ridhtijnen voor farmaco-economisch onderzoek. Amstelveen: College voor Zorgverzekeringen; 1999.

61. Mullins CD, Ogitvie S. Emerging standardization in phamacoeconomics. Clin Ther 1998:20:1194-202.

62. Detsky AS, Naglie G. A clinician's guide to cost-effectiveness. Ann Intern Med $1990 ; 113: 147-54$. 
63. Smurawska LT, Alexandrow AV, Bladin CF, Norris M. Cost of acute stroke care in Toronto, Canada. Stroke 1994;25:1628-31.

64. Terent A, Marke LA, Asplund K, Norrving B, Jonsson E, Wester PO. Costs of stroke in Sweden. A national perspective. Stroke 1994;25:2363-9.

65. SBU. Chapter 12 Economics. In: Magnusson S, Werkö L, editors. Stroke. Stockholm: The Swedish Council on Technology Assessment in Health Care; 1992.

66. Thorngren $M$, Westling $B$. Utilization of health care resources after stroke. A population-based study of 258 hospitalized cases followed during the first year. Acta Neurol Scand 1991:84:303-10.

67. OECD. OECD statistical compendium. Paris: Data Service Information and the OECD; 1996. 



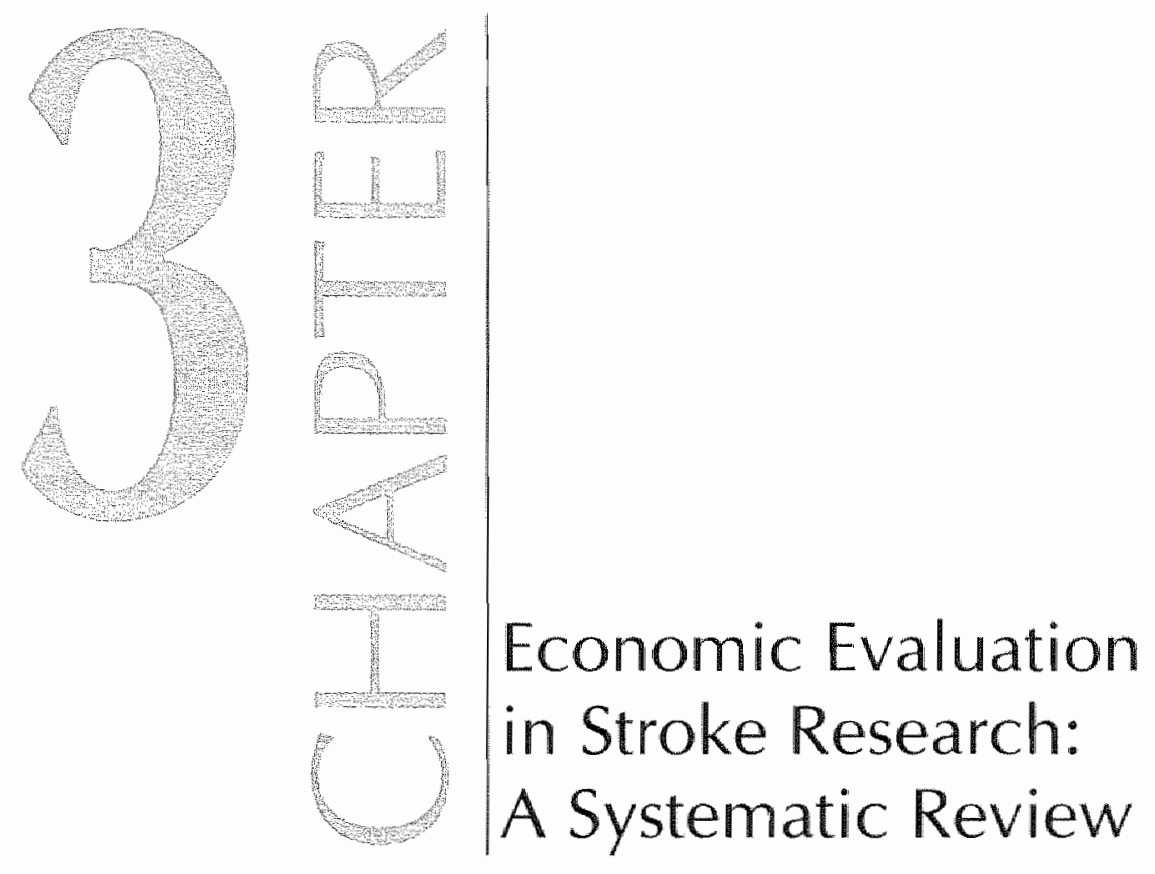





\section{Summary}

The purpose of this review is to provide insight into the quality of economic evaluation in the field of stroke on the basis of a systematic analysis.

A literature search was performed using several sources. Trial-based full economic evaluation studies, were included in this review. The quality of the studies was independently assessed by two reviewers using a checklist.

Twenty-three articles were found to comply with our inclusion and exclusion criteria. Only a few studies mentioned the perspective of the study, and in these cases, it was always the societal perspective. The majority of the studies were cost-minimization and cost-effectiveness analyses based on cohort studies. All studies included health care costs and in some instances, patient and family costs were considered. Costs were usually measured by tariffs. Clinical endpoints and mortality were used to measure effects. Cost and effect measurements were based on hospital records.

Only a few full economic evaluations have been undertaken in the domain of stroke. In most of the studies, the technical execution and methodology were limited.

\subsection{Introduction}

Since Feigensons' editorial', the rising cost of stroke has become an issue of paramount importance. However, one can question whether this increased interest signals a corresponding improvement in quality of the studies. The present study scrutinises economic evaluation studies in the field of stroke, applying methodological criteria. For this analysis a previously developed and applied checklist ${ }^{2,3}$ was used.

No complete systematic review of the quality of trial-based economic evaluation studies in the field of stroke has been performed in the literature, although some efforts have been made to illustrate the state of economic evaluation in the field of stroke. We would like to draw some attention to the review of Holloway ${ }^{4}$ regarding cost-effectiveness studies of stroke. The current systematic review differs from this study on a number of issues. Holloway and his colleagues selected only studies in which the health effects were measured in quality-adjusted-life-years, and left out studies regarding preventive strategies. Finally, the studies in the Holloway review used overall modeling $196 \%$ ) as the principle research method ${ }^{4.5}$. In contrast to Holloway, the 
objectives of this study were (1) 10 systematically obtain and review all published trial-based full economic evaluation studies in the field of stroke and (2) to gain insight into the methodological quality of both the epidemiological as well as the economical study design. This review focuses on trial-based studies, rather than on studies based on modeling, for two reasons. First, a model is a simplified version of reality that is used to describe the essential elements of a real situation. One of the major limitations of modeling is the interdependence of the validity of the input data. That is why trial-based data generally provide the most unbiased and precise data on outcomes. The second, more practical reason, is that the checklist used in this review is not suitable for scoring the quality of economic evaluation studies based on modeling. Because of these selection criteria there is no overlap with the Holloway study.

The purpose of this chapter is to provide insight into the status and the quality of economic evaluation studies performed from 1966 through 1998 in the field of stroke. To start with, a brief outline of the basic designs of economic evaluation studies will be given. After that, the methods of this review will be explained. The first result section discusses the main results of the studies involved. The subsequent sections outline the epidemiological quality of the studies and, finally, the quality of the economic evaluation designs will be discussed.

\subsection{Economic evaluation designs}

This systematic review concentrates on full economic evaluation studies. A full economic evaluation study must compare two or more program alternatives, examining both the costs and the consequences 6 . Broadly there are four types of full economic evaluation, which differ in the way that the consequences are measured, e.g. cost-mimimization analysis (CMA), cost-effectiveness analysis (CEA), cost-benefit analysis (CBA) and cost-utility analysis (CUA). A costminimization analysis examines alternative health care programs, which are equally effective, so that only the costs need to be compared further. The evaluation is then essentially a search for the 'least-cost' alternative. In a costefrectiveness analysis the outcome can be assessed in a variety of ways, such as life-years gained, cases prevented, decreased length of hospital stay or painfree days. One of the major limitations of the cost-effectiveness analysis is that the outcomes of the warious studies are measured in different ways, so that 
comparison between the various studies is hampered. A cost-utility analysis, however, does express health improvement in one uniform measure, the quality-adjusted-life-year (QALY). In the cost-utility analysis, the outcome is the number of life years saved adjusted for the quality of these saved life years by using utilities ( 1 corresponds to optimal health and 0 corresponds to death). Finally, a cost-benefit analysis expresses the outcomes of the study in monetary terms. Costs and benefits are then measured in the same unit and one can see immediately whether the benefits outweigh the costs.

\subsection{Methods}

\subsubsection{LITERATURE SELECTION}

An extensive search of the literature from 1966 until 1998 was performed using Medline, Embase, and other databases (Cochrane, OHE-HEED, NHS, overview issue of Health Economics'). Finally, additional information was found by screening relevant journals, citation tracking, and calling for articles via a Mailbase discussion list on health economic evaluation". Published (several articles and one report) trial-based full economic evaluation studies in the field of stroke were included. Exclusion criteria were editorials, letters, non-English articles and reviews. In order to guarantee a certain level of scientific quality, the intention of this review was to select only economic evaluation studies, using these very strict criteria.

\subsubsection{METHODOLOGICAL QUALITY OF THE STUDY}

The selected studies were evaluated using a checklist applied in other studies $^{2.3}$. The checklist consists of three parts: a general part, an epidemiological part, and an economic part. For details regarding the checklist we refer to a report which includes the checklist and explains the definition and criteria used ${ }^{\text {s. }}$. The quality of the studies was independently assessed by two reviewers using this checklist. Disagreement between the reviewers was resolved in a consensus meeting. 


\subsection{Results}

\subsubsection{STUDY SELECTION}

Initially 137 articles were regarded as possibly relevant for this review. A large number of these studies had to be excluded due to the fact that they were based on modeling, lack of a control group, or the absence of a cost anallysis. After screening the abstract, or if necessary the whole article, only 23 articles were found to comply with the study criteria.

\subsubsection{GENERAL CHARACTERISTICS}

Most of the studies included were Anglo-American 17 USA, 3 UK and were published during the last decade (70\%). Considering the importance of the perspective of an evaluation study ${ }^{10}$, it was remarkable that only two studies explicitly mentioned the perspective used ${ }^{11,12}$. Both studies were performed from the societal perspective, i.e. all costs and effects were included regardless of who incurred the costs and who obtained the effects.

In the absence of a statement regarding the perspective, it was likely that the external source financing the study might give some indication of this. Ten studies were financed by external grants - the majority (6) by public funding ${ }^{12-17}$; two studies received funds from pharmaceutical companies ${ }^{1 B_{1} 19}$, and another two from hospital-related funding organizations ${ }^{20221}$.

\subsubsection{MAIN RESULTS OF THE STUDIES}

The studies reviewed evaluated a wide range of interventions. Unfortunately, in most cases, no comprehensive description was given of the interventions in the control group. Therefore, we could not judge whether the control intervention was the most relevant for the policy questions being addressed. Two studies compared three interventions ${ }^{16,22 ;}$; another study compared four ${ }^{18}$ and another ${ }^{20}$ compared six interventions. To provide an overview of these studies, we grouped the interventions into six categories: diagnosis, therapy, rehabilitation, management teams, protocol, and location of care. 
Table 1. Main conclusions of various types of stroke interventions.

\begin{tabular}{|c|c|c|c|c|}
\hline Author & Intervention & Refierence treatment & Author's main results & Statistios \\
\hline \multicolumn{5}{|l|}{ DIAGNOSIS } \\
\hline Dahr $r^{23}$ & CT-Sican & $\begin{array}{l}\text { Na CT control versus } \mathrm{CT} \\
\text { (after introduction and } 1 \\
\text { year after) }\end{array}$ & $\begin{array}{l}\text { Decreased hospital costs } \\
\text { (ns), } \\
\text { decreased irvasive } \\
\text { procedure (s) }\end{array}$ & $\begin{array}{l}\text { Both } \\
\text { nested }\end{array}$ \\
\hline Britton ${ }^{20}$ & $\mathrm{Cr}$-scan & $\begin{array}{l}\text { Bedside examination, } \\
\text { routine laboratory tests, } \\
\text { bedside examination, } \\
\text { cerebrospinal analysis, } \\
\text { radionuclide brain scan }\end{array}$ & $\begin{array}{l}\text { Most cost-effective strategy } \\
\text { is to perform CT-scan as } \\
\text { sole investigation (nt) }\end{array}$ & $\begin{array}{l}\text { Neither } \\
\text { tested }\end{array}$ \\
\hline Larson $^{165}$ & $C \pi-s c a n$ & NaCT control & $\begin{array}{l}\text { Ancreased specific } \\
\text { diagnosis (s). } \\
\text { decreased lumbar } \\
\text { punctions (s). } \\
\text { decreased radionuclide } \\
\text { brain scan (s) }\end{array}$ & $\begin{array}{l}\text { Both } \\
\text { tested }\end{array}$ \\
\hline 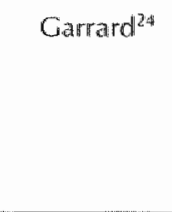 & Non-routine angio & Routine angio & $\begin{array}{l}\text { No increased operative } \\
\text { risk (nt), } \\
\text { no increased length of stay } \\
\text { (nt). } \\
\text { decreased costs (s) }\end{array}$ & $\begin{array}{l}\text { Costs } \\
\text { tested }\end{array}$ \\
\hline \multicolumn{5}{|l|}{ TREATMENT } \\
\hline Glick $^{1 \mathrm{~B}, 3 \mathrm{~S}}$ & $\begin{array}{l}\text { Tirilazad mesylate } \\
\text { in } 3 \text { different doses }\end{array}$ & Placebo control & $\begin{array}{l}\text { Increased survival of }(\mathrm{s}) \\
\text { increased costs } \sigma^{*}(\mathrm{~s}) \\
\text { no effects for }\end{array}$ & $\begin{array}{l}\text { Both } \\
\text { tested }\end{array}$ \\
\hline Jordan" & $\begin{array}{l}\text { Embolisation with } \\
\text { surgery }\end{array}$ & Surgery alone & $\begin{array}{l}\text { Decreased costs (nt), } \\
\text { decreased mobidity (nt), } \\
\text { decreased cost per QALY } \\
\text { (nt) }\end{array}$ & $\begin{array}{l}\text { Neither } \\
\text { tested }\end{array}$ \\
\hline Kelley $y^{15}$ & $\begin{array}{l}\text { Kinetic therapy } \\
\text { with a rotational } \\
\text { hospital bed }\end{array}$ & Routine hospital bed & $\begin{array}{l}\text { Kinetic therapy is cost- } \\
\text { effective inst }\end{array}$ & $\begin{array}{l}\text { Both } \\
\text { Tested }\end{array}$ \\
\hline Lanzieris: & $\begin{array}{l}\text { Emergency } \\
\text { thrombolysis } \\
\text { (intraterterial } \\
\text { urokinase }\end{array}$ & Standard medical care & $\begin{array}{l}\text { Improvement in clinica! } \\
\text { status (s) without } \\
\text { additional costs }\end{array}$ & $\begin{array}{l}\text { Both } \\
\text { tested }\end{array}$ \\
\hline Murphy ${ }^{12}$ & Piracetam & Placebo & $\begin{array}{l}\text { No difference in outcome } \\
\text { (ns), decreased costs } \\
\text { (unclear) }\end{array}$ & $\begin{array}{l}\text { Both } \\
\text { tested }\end{array}$ \\
\hline
\end{tabular}


(Table 1 continued)

\begin{tabular}{|c|c|c|c|c|}
\hline Author & Intervention & Reference treatment & Author's main results & Standeterts \\
\hline \multicolumn{5}{|c|}{ REHABILTATION } \\
\hline Byford ${ }^{2 x, 3 y, n 0}$ & $\begin{array}{l}\text { Shorterm } \\
\text { Intersive } \\
\text { Community } \\
\text { support }\end{array}$ & Usuall rehabititation & $\begin{array}{l}\text { Increased outcome (nt) } \\
\text { decreased costs int) }\end{array}$ & $\begin{array}{l}\text { Neither } \\
\text { tested }\end{array}$ \\
\hline Gladmon ${ }^{14 \text { at }}$ & $\begin{array}{l}\text { Domiciliary } \\
\text { mentolitation }\end{array}$ & $\begin{array}{l}\text { Hospilal-based } \\
\text { rehabilitation }\end{array}$ & $\begin{array}{l}\text { No difference (ns) in effect } \\
\text { but increased costs (s) due } \\
\text { Ho domiciliary services }\end{array}$ & $\begin{array}{l}\text { Both } \\
\text { hested }\end{array}$ \\
\hline Keith & $\begin{array}{l}\text { Subacute } \\
\text { rehabilitarion lless } \\
\text { intense) }\end{array}$ & $\begin{array}{l}\text { Acute rehabilitation } \\
\text { Ccomprehensive inpatient }\end{array}$ & $\begin{array}{l}\text { Decreased costs (s), } \\
\text { decreased length of stay (s) } \\
\text { decreased functional } \\
\text { outcome (ns) }\end{array}$ & $\begin{array}{l}\text { Both } \\
\text { tested }\end{array}$ \\
\hline Young & $\begin{array}{l}\text { Horne } \\
\text { physiotherapy }\end{array}$ & Day hospital & $\begin{array}{l}\text { Decreased costs }(s), \\
\text { no significant difference in } \\
\text { outcome }\end{array}$ & $\begin{array}{l}\text { Both } \\
\text { tested }\end{array}$ \\
\hline
\end{tabular}

\section{TEAMS}

\begin{tabular}{|c|c|c|c|c|}
\hline Falconer & $\begin{array}{l}\text { Coordinalled } \\
\text { comprehensive } \\
\text { team care }\end{array}$ & Usual team care & $\begin{array}{l}\text { No significant difference in } \\
\text { cousts and outcomes }\end{array}$ & $\begin{array}{l}\text { Both } \\
\text { tested }\end{array}$ \\
\hline Webl:" & $\begin{array}{l}\text { Mullidisciplinary } \\
\text { stroke ream }\end{array}$ & Usuall care & $\begin{array}{l}\text { Decreased length of stay } \\
\text { (s), } \\
\text { decreased urinary tract } \\
\text { infections (5) }\end{array}$ & $\begin{array}{l}\text { Effects } \\
\text { tested }\end{array}$ \\
\hline
\end{tabular}

\section{PROTOCOL}

Back ${ }^{31}$

Critical, selective Usual care

clinical pathway

Decreased $\cos t 5(s)$;

Bcth

no difference in mortality tested

and complications (nst

\begin{tabular}{|c|c|c|c|c|}
\hline Bowen ${ }^{5.2}$ & $\begin{array}{l}\text { Sitroke protocol } \\
\text { icritical care path }\end{array}$ & $\begin{array}{l}\text { Usual care thistoric } \\
\text { control grotp and } \\
\text { concutrent control group) }\end{array}$ & $\begin{array}{l}\text { Derceased costs }(s) \\
\text { no difference in outcomes } \\
\text { (ns) }\end{array}$ & $\begin{array}{l}\text { Both } \\
\text { tested }\end{array}$ \\
\hline Calligarot & $\begin{array}{l}\text { Stroke protocol } \\
\text { (same day } \\
\text { admission, early } \\
\text { discharge) }\end{array}$ & Wsual care & $\begin{array}{l}\text { Decreased costs int } \\
\text { decreased length of stay } \\
\text { (s), } \\
\text { no difference in outcome } \\
\text { (ns) }\end{array}$ & $\begin{array}{l}\text { Etects } \\
\text { rested }\end{array}$ \\
\hline Kraiss & 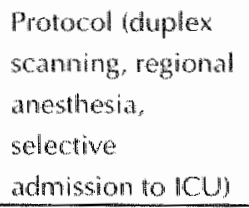 & $\begin{array}{l}\text { Conwentional carotid } \\
\text { endarterectomy }\end{array}$ & $\begin{array}{l}\text { Decreased costs (s) without } \\
\text { differences in outcome }\end{array}$ & $\begin{array}{l}\text { Both } \\
\text { tested }\end{array}$ \\
\hline
\end{tabular}


(Table 1 continued)

\begin{tabular}{|c|c|c|c|c|}
\hline Author & Intervention & Reference treatment & Author's main results & Statistics \\
\hline \multicolumn{5}{|c|}{ LOCATION OF CARE } \\
\hline Bryant ${ }^{33}$ & Home care & No home care & $\begin{array}{l}\text { Decreased costs, } \\
\text { decreased length of stay, } \\
\text { decreased re-admissions, } \\
\text { continuity of care, patient, } \\
\text { more self-sufficient (nt) }\end{array}$ & $\begin{array}{l}\text { Neither } \\
\text { tested }\end{array}$ \\
\hline Feigenson? & $\begin{array}{l}\text { Community } \\
\text { hospital }\end{array}$ & Academic hospital & $\begin{array}{l}\text { No difference in outcome } \\
\text { (ns), } \\
\text { decreased cost (s) }\end{array}$ & $\begin{array}{l}\text { Both } \\
\text { tested }\end{array}$ \\
\hline Green $^{32}$ & $\begin{array}{l}\text { Community } \\
\text { hospital }\end{array}$ & Academic hospital & $\begin{array}{l}\text { No difference in outcome } \\
\text { (ns), } \\
\text { decreased cost (s) }\end{array}$ & $\begin{array}{l}\text { Both } \\
\text { tested }\end{array}$ \\
\hline Hui ${ }^{2 n}, 34$ & Day hospital & Usual care & $\begin{array}{l}\text { Increased functional } \\
\text { outcome (s) reduced } \\
\text { outpatient visits (s) } \\
\text { no difference in costs (ns) }\end{array}$ & $\begin{array}{l}\text { Both } \\
\text { lested }\end{array}$ \\
\hline
\end{tabular}

Statistical analysis

both tested $=$ both costs and effects are rested statistically

neither tested $=$ neither costs nor effects are tested statistically
Resulults

$s=s i g n i f \operatorname{cant}$

ins = not significaint

$n t=$ not lested

Diagnosis: Stroke diagnoses form the basis for rational management. Three relatively old studies ${ }^{16,20,23}$ evaluated the cost-effectiveness of the CT-scan versus other neurodiaginostic armamentaria (such as bedside examinations, cerebrospinal fluid analysis, radionuclide brain scans). Although not always statistically tested, these studies overall came out in favor of CT-scanning. Angiography prior to carotid endarterectomy was studied by Garrard ${ }^{24}$, who showed that non-routine use of angiography does not increase the operative risk or length of slay, but significantly lowers costs.

Therapy: In recent years the nihilistic view of the treatment of stroke, which was mainly due to the belief that brain death was irreversible, has changed into a more active management of stroke, especially in the acute phase. Nevertheless, only five studies ${ }^{11,12,15,1425}$ in our review try to prove the costeffectiveness of stroke treatment. The study by Jordan compared endovascular therapy (embolisation) in combination with surgery versus surgical excision in patients with an arteriovenous malformation". Surprisingly, the study concluded that endovascular therapy in combination with surgery in patients with an arteriovenous malformation resulted in significant economic benefits, 
although these results were not statistically tested". Another study examined emegency thrombolysis (intra-arterial urokinase) as a treatment strategy in patients with thromboembolic intracerebral events as compared with standard care. This small study revealed no significant cost difference between the two groups, with a statistically significant positive change in the National Institutes of Health Score in the experimental groups of at least five points ${ }^{25}$. Kelley evaluated prospectively the costs of kinetic therapy, i.e. a bed that provides continuous slow rotation over $124^{\circ}$ in the horizontal plane, versus standard medical care (routine hospital bed). Kinetic therapy aims at a reduced incidence of infection, which improves the pulmonary toillet, and the prevention of urinary stasis. No significant difference was found in any of the outcome measures. Nevertheless, the authors conclude that the results suggest that kinetic therapy can be cost effective.

Finally, two studies looked at drug treatment. Glick examined tirlazed mesylate therapy in malle patients with subarachnoid hemorrhage and showed a significant increase in survival, with corresponding increase in the cost of care in men, but no difference in survival for wornen ${ }^{18}$. In the study by Murphy ${ }^{i 2}$, the economic impact of neuroprotective treatment (piracetam vs. placebo) of acute ischaemic stroke was investigated. No significant differences in the effects were found, but the study in fact showed a slight difference in costs in favor of piracelam ${ }^{12}$.

Rehabilitation: Rehabilitation of a victim of stroke was mostly designed to help the individual overcome disability resulting from brain damage and to enable the patient to function despite the disability that remains after the spontaneous recovery from brain damage has ceased. Six studies ${ }^{14,17,26.29}$ looked at rehabilitation, sometimes in combination with another care location. In general, the studies illustrated that rehabilitation was more efficient compared with other interventions.

Management teams: To accomplish continuity of care and accessibility, some institutions implement stroke management teams. These teams usually consist of a number of professionals who work together in accordance with a coordinated plan. The study by Webb' showed that such a stroke management team may reduce the length of stay and morbidity in hospitalised stroke patients. Team care on admission to a large, academic, inpatient rehabilitation hospital was studied by Falconer ${ }^{3}$. Adults who had had a recent stroke were randomly assigned to receive rehabilitation services from a team trained in the Clinical Path Method Coordinated, comprehensive team care provided by persons who integrate their observations, expertise, and decisions) 
or from usual care. Results showed that the Clinical Path Method did not contain costs or improve outcomes of inpatient stroke rehabilitation.

Protocol: Based on experience and scientific findings it may be optimal to develop protocols for the sthort-term and long-term care of stroke patients. A pillot study by Kraiss ${ }^{30}$ looked at patients who had carotid endarterectomy performed according to an alternative protocol (duplex scanning only, operation under regional or 'awake' anesthesia, and admission to the ICU only in cases of a proven need for services unique to the ICU) versus patients undergoing conventional carotid endarterectomy (anteriography, general anesthesia, routine ICU admission) during the same period. The study suggested that carotid endarterectomy can be safely performed according 10 the alternative protocol with a significant reduction of hospital charges. Patients with carotid endarterectomy were also the subject of a study ${ }^{31}$ which investigated a critical and selective treatment that included the avoidance of cerebral arteriography, preferential use of regional anesthesia, selective use of the $\mathrm{KCU}$, and early hospital discharge. The rates of mortality and complications did not vary between the two groups, but the implementation of this pathway resulted in a significant reduction in the hospital costs ${ }^{31}$. A project by Calligaro 21 , also studied a clinical pathway with same-day admission and early hospital discharge for patients undergoing major vascular surgery which resulted in costs savings with no increase in morbidity or mortality rates 21 . In another study ${ }^{22}$ there were significant savings in hospitalisation costs for patients with acute stroke after the introduction of an alternative treatment protocol. These savings were almost entirely related to decreased length of stay. There were no differences in outcome measures such as death or discharge disposition. Medical complications were similar in both groups.

Location of care: In recent years there has been a tendency to provide more patient-oriented care, inducing a trend from specialised care to general care, from inpatient to outpatient care and from outpatient care to homecare. Creen compared the results and costs of carotid endarterectomy performed by a single surgeon over a 1 -year period working at both a university hospital and a community hospital. There were no differences in the complication rates and mortality while the costs in the university hospital were significantly higher ${ }^{32}$. In an older study, comparing stroke patients with and without homecare, Bryant $^{3.3}$ showed that during their 9 month follow-up period, stroke patients receiving homecare had in total a shorter hospitall stay, fewer re-admissions, and fewer deaths, while overall costs were greatly reduced. Results were not statistically tested ${ }^{33}$. 


\subsubsection{EPIDEMIOLOGICAL QUALITY OF THE STUDIES}

In this review it was assumed that epidemiological aspects are as important as economic aspects, since only economic evaluation studies with a good epidemiological design can isolate the observed effect of an intervention. About a quarter $(26 \%)$ of the studies $2 \%, 17.2 \%$ used randomization to allocate the treatments 10 different groups: in one study randomization was combined with pre-stratification 14.

The remaining studies could be regarded as cohort studies, in which $26 \%$ used a pre-post design ${ }^{16,21,23,2 \%, 21}$, others a prospective (future) cohort $(13 \%)^{15,24,30}$ or retrospective (historic) cohort $(4 \%)^{2 \%}$ to compare the interventions. Furthermore, in some instances cases were matched with controls $(22 \%)^{112 \%, 2 \% 323}$. Finally, the study by Webb ${ }^{19}$ combined pre-post comparison with a prospective cohort, and in the study by Britton ${ }^{20}$ the diagnostic validity was assessed step by step. Table 2 lists the other epidemiological criteria that were studied for this review.

The number of patients included varied from $34^{25}$ to $2009^{19}$. None of the studies performed a power calculation specifically for the economic evaluation part of the study. In stroke research, the study period has to be long enough to see whether the effect of an intervention is longstanding. The study period in the articles varied from eight weeks to one year. The majority of the studies $(61 \%)$ considered the costs and consequences of interventions during the hospital stay. Of the articles reviewed, $70 \%$ defined inclusion and exclusion criteria. Even with a good study design, the results can be affected by noncompletion. Protocol deviation, such as withdrawals ${ }^{12.15}$, dropouts ${ }^{13.15,18}$ contamination $^{14}$ and non-compliance ${ }^{16}$, was reported by about one-fith of the studies $(22 \%)$. However, it should be remarked that protocol deviation is most likely to occur in randomised controlled studies and prospective cohort studies. The general consensus is that several actors (i.e. patients, observers, clinicians, investigators) in the clinical trial should be blinded', i.e. kept ignorant of which treament the stroke patients had undergone. In our review, three studies ${ }^{\text {2. }}$, used blinding. 


\subsection{Economic quality of the studies}

\subsubsection{ECONOMIC EVALUATION STUDY DESIGN}

Table 2 shows that overall the studies included in our review refer to a costminimization analysis $(48 \%)^{14,15,19,21-24,27,30-32}$ or a cost-effectiveness analysis $(48 \%)^{12,13,16-18,20,25,26,29.33,34}$. The large amount of cost-minimization analysis might be due to the fact that in most instances the researcher did not expect to find any differences in the consequences between the altermatives: instead the study was performed primarily to look for the least costly effect. Furthemore, waluing effects in utilities (cost-utillty analysis) or in pecuniaries (cost-benefit analysis) is more complex, in comparison with for instance, functional outcome measurement (cost-minimization analysis or cost-elfectiveness analysis); therefore cost-mimimization analysis and cost-effectiveness analysis might be used more frequently. Finally, only one study in our review could be classified as a cost-utility analysis", and in none of the studies were consequences translated into monetary terms using a cost-benefit analysis.

\subsubsection{OUTCOME MEASUREMENT}

In the studies examined, a variety of outcome measures was used. Almost half of the studies $(48 \%)$ include mortality as an outcome measure ${ }^{14,15,18,19,21,24,31-13}$; functional outcome and medical complications were also frequently applied. Functional outcomes were measured by $43 \%$ of the studies ${ }^{12 \cdot 14,17,16,25-27,29,34}$ using general and disease specific instruments such as the Barthell Index $12,1,1,2,20,28$, the Glasgow Outcome Scale" the Functional Independence Measure $^{1327}$, the National Institute of Health Neurological Scale ${ }^{1625}$, and the Nottingham Health Profile ${ }^{14,17}$. The number of medical complications was measured in $30 \%$ of the studies ${ }^{10,2322,24,312}$. Our review includes only one cost-utility analysis" so a QALY measure was used rarely in trial-based economic evaluation studies concerning stroke. More than half of the studies $(65 \%)$ use hospital records to measure outcomes, or in other instances questionnaires or interviews. 


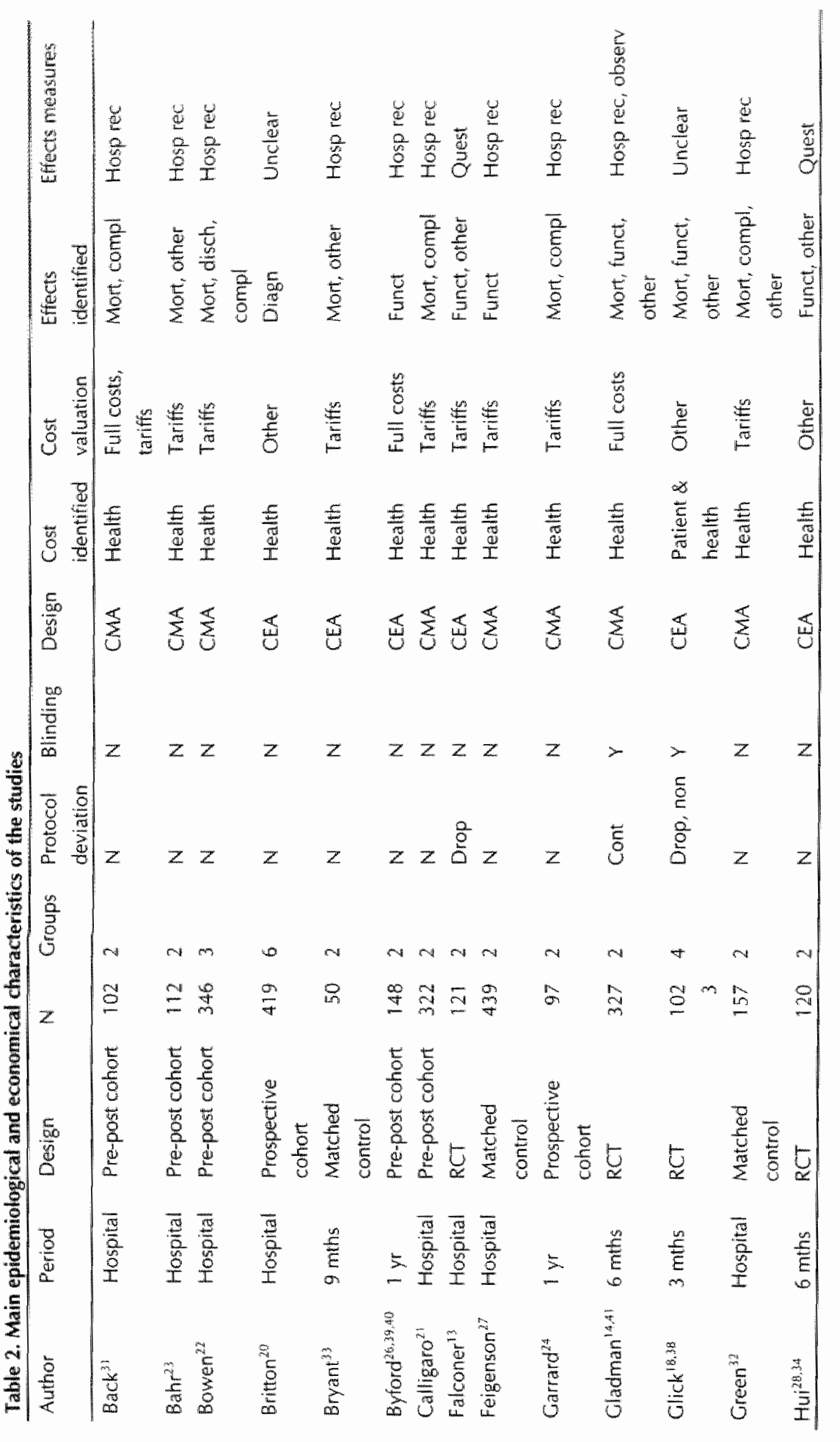




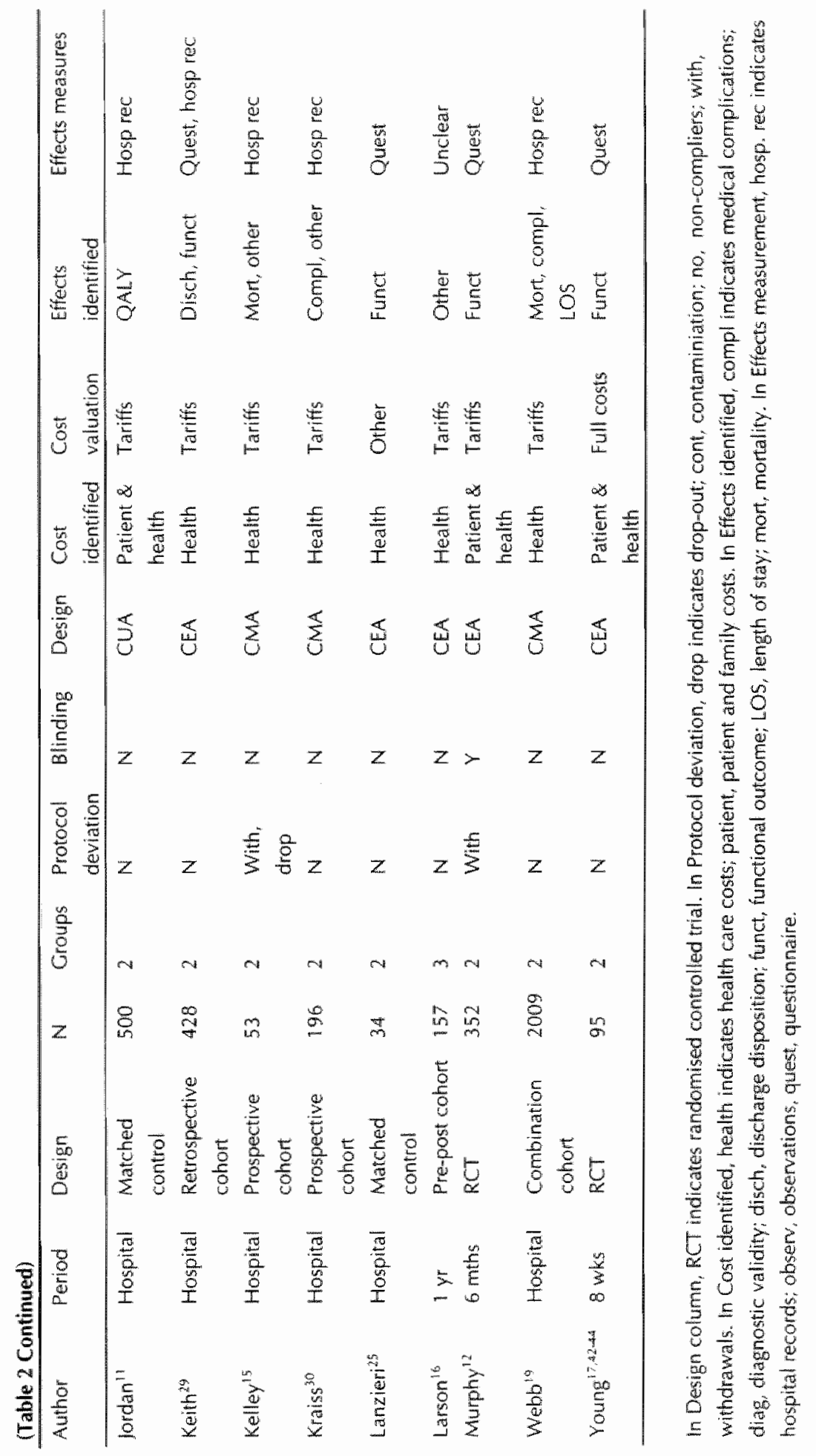




\subsubsection{COST MEASUREMENT}

All of the studies include health care costs. Only a few studies incorporate aspects regarding patient and family costs ${ }^{12,37}$, e.g. Young et al. ${ }^{17}$ looked at the carers stress and showed a significant decrease in leisure activities and an increase in domestic chores. These aspects were not valued in financial terms, but Murphy ${ }^{2}$ did include the cost of home assistance.

To measure costs, $87 \%$ of the studies used hospital records, but other methods were also applied, including diaries ${ }^{14}$, measurement of resource utilisation ${ }^{\text {s: }}$ experts estimating the costs $5^{12}$, and estimations from ather studies ${ }^{25}$. Only three studies ${ }^{4,1 \%}, 3$ calculated the actual economic cost price of the intervention examined. Although tariffs generally were not considered to be a good estimate of cost valuation, the remaining studies $(70 \%)$ used tariffs to assess costs. In order to calculate the full costs of a program, overhead costs have to be estimated, i.e. those resources that serve many different departments and programs, such as general hospital administration, central laundry, medical records, cleaning, porters, power, etc. Five sludies ${ }^{1,14,17,26,31}$ calculated these overhead costs and in most instances a division method was used in which the full costs of an intervention were determined by dividing the total cost by the total production. One of the studies which included productivity losses due to mortality was that by Jordan", in which a human capital approach was used, i.e. calculation of the average life time earnings until the age of 65 years. Furthermore, Glick assessed the daily employment value for those working full-time, part-time or at home ${ }^{\text {is }}$.

\subsubsection{ADIUSTMENTS AND STATISTICAL ANALYSIS}

Costs and benefits of stroke interventions will accrue over time and should. therefore, be discounted. Discounting was not relevant for all studies included in the review as the study period in each case was less han one year. Nevertheless, in our review three studies ${ }^{11.16}$ indexed the results to a centain year using discount rates varying between $4.5 \%{ }^{11}$ and $7 \%{ }^{25}$. The latter was due to the fact that these studies collected data over a number of years. Finally, in four studies, a sensitivity analysis $11,12,4,14$ was pertormed to check the influence of the assumptions made and the robustness of the conclusions. In an economic evaluation study, the best evidence can be gathered if the statistical evidence (see Table 1) of both the effectiveness data and of the cost data are tested. Close to $70 \%$ of the studies included in our review tested the 
differences in both costs and effects statistically. In two studies ${ }^{\text {g.xn, the }}$ statistical analysis was restricted to only the effects; in one study only costs were tested ${ }^{24}$ and in four studies ${ }^{11,20,26,3}$ neither effects nor costs were tested statistically. Furthermore, it was striking that in some studies, although no statistical significance was found, the authors concluded that the intervention was cost-effective".

\subsubsection{INCREMENTAL ANALYSIS AND RATIOS}

For a meaningful comparison, it was necessary to examine the additional costs that one service or program imposes over another, compared with the additional effects, benefits, or utilities it delivers. Four studies in our review explicitly performed an incremental analysis ${ }^{13,25,27}$. Glick ${ }^{13}$, for instance. expressed the incremental costs in a ratio as the difference in cost between the two groups compared divided by the difference in the probability of death in these two groups. This study was also one of the wo' which calculated a ratio. The other was by Jordan' et al. who expressed the 'costs per life year saved' as a ratio.

\subsection{Conclusions}

Despite the increased interest in economic evaluation, this review shows that only few full economic evaluations have been undertaken in the domain of stroke. Our search may not have been exhaustive, but we tried to find as many studies as possible combining several methods. Furthermore, it has long been accepted that researchers are more likely to report effects instead of no-effects (reporting bias) and that statistically significant results are more likely to be published (publication bias). These biases might influence the result of our analysis as the review is limited to published studies.

This study focuses on studies considering patients with stroke. Because of this, some preventive interventions (reduction of blood pressure, smoke cessation programs, thrombosis prevention which focus on more general health aspects (including stroke) may not be included. Of course, recent developments, yet not published, have not been included.

Another limiting factor was the fact that only trial-based full economic evaluation studies were included in our rewiew. Studies based on modeling were excluded. However, the authors agree that modeling ${ }^{3 r_{3}}$ can be used in 
some instances as an addition to or substitute for trial-based economic evaluation studies.

Only two studies included in our review were explicitly performed from a societal perspective. Regarding the epidemiological design, randomised controlled trials are generally regarded as the most scientifically rigorous method to test a hypothesis. However, randomization may not always be realistic. In our review, a quarter of the studies was based on randomised controlled trials. All studies included in the review were "piggybacked" i.e. appendixed, and no separate power analysis was performed for the economic evaluation study. Furthermore, not all studies included a statisticall analysis of both costs and effects.

Almost all of the studies used clinical outcome measures to evaluate the consequences of the interventions. One study used quality-adjusted-life-years, atthough QALYs are reganded as the most holistic way of measuring effects. Especially in stroke, where intangible costs such as psychosocial consequences play an important role, QALYs should be used to quantify effects. Resource use, such as length of stay, was generally incorporated in the cost side of economic evaluation studies. It was remarkable that some studies ${ }^{27}$, so use length of stay both as a cost measure and as an effect measure. Because of the principle of not double-counting, which required that aspects included in the cost should not be included in the effect (and vice versa), we suggest that future studies awoid these duplications in order to achieve consistency. Regarding the cost measurement, only a few studies explicitly measured overhead costs and production losses. A large number of studies used charges as a proxy for costs.

The inferior quality of the studies was not unique to stroke. Previous research in other fields has also shown that sound economic evaluation generally receives litte attention in current evaluation studies, in contrast to medical outcome research ${ }^{2,4}, 36$.

Only a few of the articles reviewed were, in our opinion, good examples of economic evaluation. Although it was difficult to judge, we have the impression that the increasing concern for economic evaluation in stroke does not support an improvement in the quality of the economic evaluation studies performed. The quality, however, could be improved simply by using the basic principles described by experts in the field of economic evaluation ${ }^{6,37}$.

In conclusion, this review shows a significant need to improve the application of economic evaluation in the area of stroke. The initial intention of our study 
was to perform a meta-analysis illuminating which interventions were the most cost-effective regarding stroke.

The interventions for stroke have been classified into diagnosis, treatment, rehabilitation, management teams, protocol and location of care. Data-pooling was unattainable and therefore it was impossible to draw definite conclusions on the cost-effectiveness of each category. This was due to the heterogeneity of the interventions, the large differences in and low quality of costing methodology and the large difference in the stroke population, which limited the comparison between the estimates in the studies received. Therefore, the purpose of our study was altered into assessing the quality of economic evaluation in the field of stroke based on systematic analysis. Thus, the conclusions of this review should be read, bearing in mind the previously mentioned shortcomings, that a decision on the cost effectiveness of therapies for stroke is not yet possible at the moment.

\section{Acknowledgements}

The authors thank Tom Groot (Department of Accounting, the Vrije Universiteit Amsterdam) and Hans Maarse (Department of Health Organization Policy and Economics, Maastricht University) for reviewing earliter wersions of this chapter.

\section{References}

1. Feigenson IS. Stroke rehabilitation: effectiveness, benefits, and cost. Some practical considerations. Stroke 1979;10:1-4.

2. Evers SMAA, van Wijk AS, Ament AHA. Economic evaluation of mental health care interventions: a review. Health Econ 1997;6:161-77.

3. Goossens ME $\mathrm{B}$, Evers SMAA. Economic evaluation of hack pain interventions. Journal of Occupational Rehabillitation 1997;7:15-32.

4. Holloway RG, Benesch CG, Rahilly CR, Courtright CE. A Systematic Review of Cost Effectiveness Research of Stroke Evaluation and Treatment. Stroke 1999; 30:1340-9.

5. Ebrahim S, Holloway RG, Benesch CG. A Systematic Review of Cost-Effectivenes Research of Stroke Evaluation and Treatment (Letter to the editor). Stroke $1999 ; 30: 2759-60$. 
6. Drummond MF, OrBrien B, Stoddart GL, Torrance GW. Methods for economic evaluation of health care programmes. Oxford: Oxford University Press; 1997.

7. Backhouse ME, Backhouse RI, Edey SA. Economic Evaluation Bibliography. Health Exon 1992; Supplement (1).

8. Hollingsworth B. Health economics E-mall discussion lists. Health Economics $7997 ; 6: 95-97$.

9. Evers SMAA, van Wijk AS, Ament AJHA. Economic evaluation of mental health care interwentions: a review. Maastricht: Department of Health Economics; 1994.

10. Evers SMAA, Goossens MEJB. Ament AJHA. Economic evaluation in stroke research: an introduction. Cerebrovascular Diseases; 2001;11:82-91.

11. Jordan JE, Marks MP, Lane B, Steinberg GK. Cost-effectiveness of endovascular therapy in the surgical management of cerebral anteriovenous malformations. AINR 1996;17:247\%54.

12. Murphy N, Kazek MP, Van Vleymen B, Melac M, Souetre E. Economic evaluation of Nootropil in the treatment of acute stroke in France. Pharmacol Res $1997 ; 36: 373-80$

13. Falconer $\mid A$, Roth EI, Sutin JA, Strasser DC, Chang RW. The critical path method in stroke rehabilitation: lessons from an experiment in cost containment and outcome improvement. QRB Qual Rev Bull 1993;19:8-16.

14. Gladman J, Whynes D, Lincolm N. Cost-comparison of domiciliary and hospitalbased stroke rehabilitation. Age Ageing 1994;23:241-5.

15. Kelley RE, Bell LK, Mason RL. Cost analysis of kinetic therapy in the prevention of complications of stroke. South Med $) 1990 ; 83: 433-4$.

16. Larson EB, Omenn GS, Loop WW. Computed tomography in patients with cerebrovascular disease: impact of a new technology on patient care. AIR Am I Roentgenol 1978;131:35-40.

17. Young 1, forster A. Day hospital and home physiotherapy for stroke patients: a comparative cost-effectiveness study. I R Coll Physicians Lond 1993;27:252-8.

18. Glick H, Wilke R, Polsky D, Lliana T, Alves WM, Kassell N, Schulman, K. Economic analysis of tirilazad mesylate for aneurysmal subarachnoid hemorhage: Economic evaluation of a phase III clinical trial in Europe and Australia. Int I Technol Assess Health Care 1998;14:145-60.

19. Webb D), Fayad PB, Wilbur C. Thomas A, Brass LM. Effect of a specialized team on stroke care. Stroke 1995;26:1353-7.

20. Britton $M$, Jonsson E, Marké L-A. Diagnosing suspected stroke; a cost-effectiveness analysis. Int I Technol Assess Health Care 1985;1:147-58. 
21. Calligaro KD, Dougherty MI, Raviola CA, Musser DI, DeLaurentis DA. Impact of clinical pathways on hospital costs and early outcome after major vascular surgery. I Vasc Surg 1995:22:649-60.

22. Bowen 1, Vaste C. Effect of a stroke protocol on hospital costs of stroke patients. Neurology 1994:44:1961:4.

23. Bahr AL, Hodges Fd. Efficacy of computed tomography of the thead in changing patient care and health costs: a retrospective study. AJR Am $\|$ Roentgenol $1978 ; 131: 45-9$.

24. Garrard $\mathrm{CL}$, Manord JD, Ballinger BA, Katewa JE, Sternbergh WC, Bowen JC, Money, SR. Cost savings associated with the nonroutine use of carotid angiography. Am I Surg 1997;14:650-4.

25. Lanzieri CF, Tarr RW, Landis D, Selman WR, Lewin IS, Adler LP, Silvers, JB. Costeffectiveness of emergency intraarterial intracerebral thrombolysis: a pilot study. AINR Am IN Neuroradiol 1995;16:1987-93.

26. Byford $S$, Geddes JML, Bonsall M. Stroke rehabilitation: A cost-effectiveness analysis of a placement scheme. York: University of York, Centre for Health Economics; 1995.

27. Feigenson IS, Feigenson WD, Gitlow HS, McCarthy ML, Greenberg SD. Outcome and cost for stroke patients in academic and community hospitals. Comparison of two groups referred to a regional rehabilitation center. JAMA 1978;240:1878-80.

28. Hui E, Lum CM, Woo I, Or KH, Kay RL. Outcomes of elderly stroke patients. Day hospital versus conventional medical management. Stroke 1995;26:1616-9.

29. Keith RA, Wilson DB, Gutierrez P. Acute and subacute rehabilitation for stroke: a comparison. Arch Phys Med Rehabil 1995;76:495-500.

30. Kraiss LW, Kilberg L. Critch S, Johansen KJ. Short-stay carotid endarterectomy is safe and cost-effective. Am I Surg 1995;169:512-5.

31. Back MR, Harward TRS, Huber TS, Carlton LM. Flynn TC, Seeger IM. Improving the cost-effectiveness of carotid endarterectomy. I Vasc Surg 1997;26:456-64.

32. Green RM, MCNamara 1. Optimal resources for carotid endarterectomy. Surgery 1987:102:743-8.

33. Bryant NH. Candland $\mathbb{L}$, Loewenstein $R$. Comparison of care and cost outcomes for stroke patients with and without home care. Stroke 1974,5:54-9.

34. Hui $\mathrm{E}$, Woo I, Or KH, Chu LW, Wong KH. A geriatric day hospital in Hong Kong: an analysis of activities and costs. Disabil Rehabil 1995;17:418-23.

35. Baltussen RMPM. Real world designs in economic evaluation; bridging the gap between clinical research and policy making. Maastricht: Maastricht Universily; 1998 [Thesis]. 
36. Coossens MEJB, Evers SMAA. Chapter 10 Cost-effectiveness of treatment of neck and low back pain. In: Nachemson A, Ionsson E. Neck and Back Pain. The scientific evidence of causes, diagnosis and treatment. Stockholm/Philadelphia: SBU/Lippincott; 2000.

37. Gold MR, Siegel JE, Russell LB, Weinstein MC. Cost-effectiveness in health and medicine. New York/Oxford: Oxford University Press; 1996.

38. Kassell NF, Haley EC, Apperson-Hansen C, Alves WM. Randomized, double blind, vehicle-controlled trial of tirilazad mesylate in patient with aneurysmal subarachnoid hemorrhage: a cooperative study in Europe, Australia, and New Zealand. I Neurosurgery $1996 ; 84: 221-8$.

39. Geddes JML, Claiden AD, Chamberlain MA, Bonsall M. The Leeds Family Placement Scheme: an evaluation of its use as a rehabilitation resource. Clin Rehabil 1989:3:189-97.

40. Geddes IML, Chamberlain MA, Bonsall M. The Leeds Family Placement Scheme: principles, participants and postscript. Clin Rehabil 1991;5:53-64.

41. Gladman IRF, Lincoln NB, Barer DH. A randomised controlled trial of domiciliary and hospital-based rehabilitation for stroke patient after discharge from hospital. I Neurol Neurosurg Psychiatry 1992;56:960-6.

42. Young JB, Forster A. The Bradford community stroke trial: eight week results. Clin Rehabil 1991;5:283-92.

43. Young 1, Forster A. Cost analysis of geriatric day hospital care. Clin Gerontol $1991,13: 247-62$.

44. Young $1 \mathrm{~B}$, Forster $\mathrm{A}$. The Bradford community stroke trial: results at six months. BMI 1992;304:1085-9. 

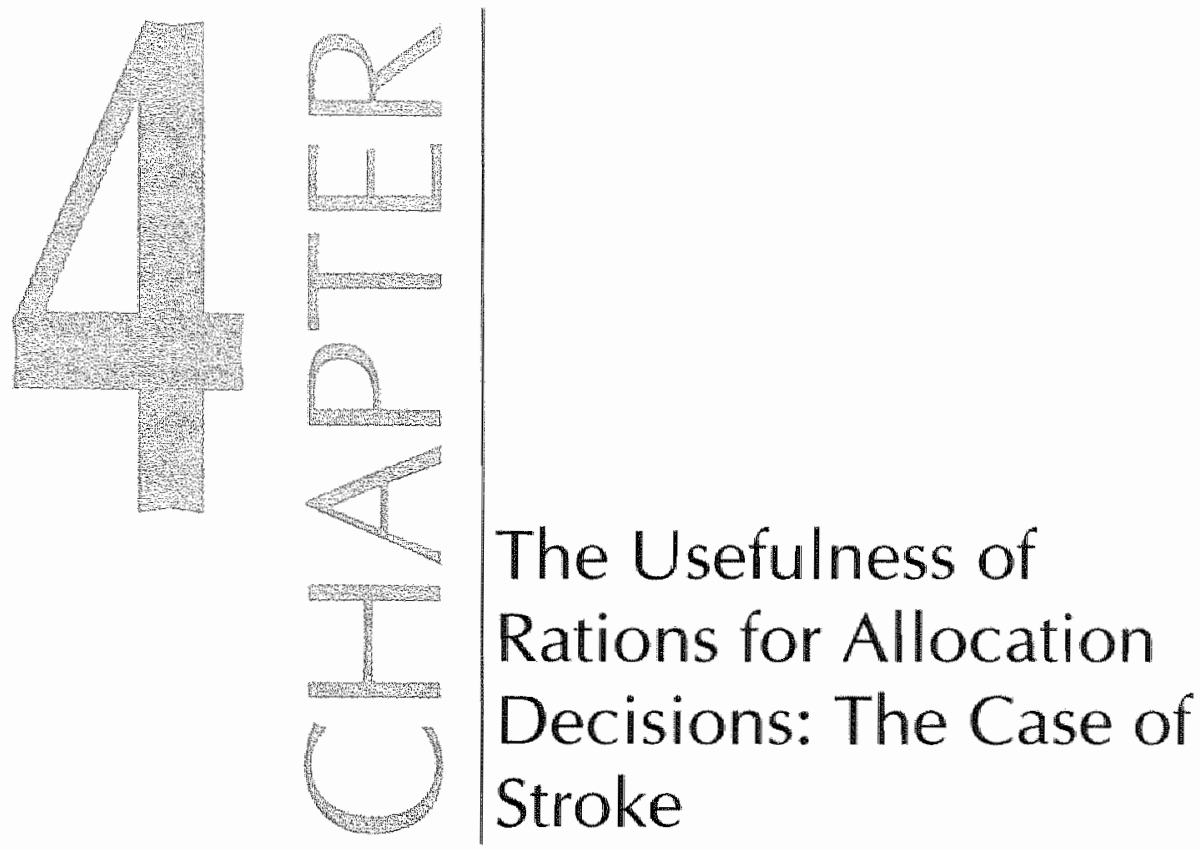


\section{Summary}

Economic evaluation is becoming increasingly important in the field of stroke. The results of economic evaluation can be expressed in cost per QALY gained, which enables policy makers to compare the relative efficiency of different interventions regarding different diseases. Although using the concept of QALY is preferable from a theoretical point of view, in medical practice more often cost-effectiveness analysis (CEA), and not cost-utility analysis (CUA), is applied for practical reasons. One of the main limitations of CEA is that the results may be compared only with results of other CEAs which use the same effect parameter. In many cases the calculation of cost-effectiveness ratios (CERs) is misleading for resource allocation. Effects should be expressed in interval or ratio scales in order to calculate CERs, and this is rarely the case. The calculation of a cost-effectiveness ratio in a CEA should be performed if, and only if, the investigator is convinced that there is a constant relation between the specific effect parameter and the ultimate gain in health.

\subsection{Introduction}

In recent years, more and more attention has been paid to the costs and effects of new (and existing) technologies'. It has been recognised that interventions can only lead to improvement in patients' health situations if the effectiveness of the technologies has been proven; this has led to a plea for evidence-based medicine. Moreover, the economic impact of new technologies has been growing within the health care sector, leading to an increased demand for economic evaluation studies and medical technology assessment (MTA). There is a corresponding recognition that societal resources are limited and therefore insight in costs and effects of different interventions is needed. Economic evaluation studies as part of MTA covers a range of techniques that can be used to investigate the costs and effects of different procedures and programmes. Ideally, the results of an economic evaluation study can be used at the societal level for resource allocation. If studies are used for this purpose this implicitly means that these economic evaluation studies should be performed from the perspective of society ${ }^{\prime 2}$. From a societal point of view, all relevant costs and effects should be included in the analyses, while narrower perspectives (e.g. the perspective of the health insurance fund or hospital) may include only different components. 
In the field of stroke as well, economic evaluation is becoming increasingly important. Economic evaluation is often considered as an instrument to guide decisions on the macro level. It may be that economic evaluation does not seem to be important in daily practice, where physicians are making numerous medical decisions regarding individual patients, but it is clear that the restricted resources at the macro level do influence the decisions at the individual level. Doctors are confronted in a rather indirect way with the economic problem. For example, should clinicians check the blood pressure of each adult who walks into their office, or should a new, expensive, drug be listed on the formulary? Economic evalluations could provide answers to such questions, which are not only important for govermment or insurance companies, but also have implications for clinicians in daily practice.

Today, economic evaluation is often performed routinely in western industrialised countries alongside the clinical trial, and governments and sponsors may even demand that an economic evaluation be executed alongside the clinical trial ${ }^{2,3}$. Clinical investigators have become increasingly familiar with the methods of economic evaluation studies and use this approach to express the results of their clinical studies. Incremental costs per gained effect, essential in economic evaluation studies, are derived by determining the difference in costs and outcome and dividing the difference in casts by the difference in outcome ${ }^{1,2}$.

The aim of this chapter is to show how outcome measurement should be done in economic evaluation studies. We investigate which outcome measures can be used in economic evaluation studies. In order to fully understand the ideas developed in this chapter, some insight regarding the principles of health measurement in economic evaluation studies is provided. For methodological background about the decision rules of economic evaluation studies, see for examplet?

A short overview of the relevant aspects of economic evaluation studies is provided in the next section. Next, some important aspects of measurement theory are briefly discussed and are placed within the framework of economic evaluation studies. In the following section examples are presented, some of them taken from recent literature in the field of stroke, to show the relevance of this discussion. Each example is described and analysed from this theoretical point of view, followed by a short conclusion. It concludes with a more general discussion of the usefulness of incremental cost effectiveness ratios for resource allocation. 


\subsection{CEA or CUA}

Cost Utility Analysis (CUA) and.Cost Effectiveness Analysis (CEA) are both frequently used methods in economic evaluation research. In a CEA, costs are measured in monetary terms and consequences are measured in natural units (e.g. reduction of blood pressure, life-years saved). in a CUA the costs are also measured in monetary terms, but the consequences are measured in Quality Adjusted Life Years (QALY), by which both the quantity (stroke survival) and the quality of life in utilities are considered8. A utility is a preference for a specific level of health status expressed in a cardinal number between 0 (worst health status) and 1 (full health status). The results of a CUA can be expressed in cost per QALY gained. The QALY as effect parameter permits comparison across different domains of health and enables resource allocation across different areas.10. Resource allocation, that is the distribution of scarce (health carel resources, can be considered the core business of economic evaluation research. CUA is the 'golden standard' for ecomomic evaluation research, enabling the creation of a health care system that produces maximum health, in terms of QALYs, for available societal resource allocation. However, actual practice shows that the results of clinical research are often based on CEAs and not on CUAs. One reason for this is that the difference in expected outcome between two possible interventions is often very small and can only be detected with very sensitive disease-specific instruments and not by a more general QALY-instrument ${ }^{10}$. In other cases, it is to be expected that utility measurement cannot be applied within the specific patient group, because the use of a QALY-instrument is highly complex ${ }^{11}$. One of the main limitations of CEA is that the results may be compared only with results of other CEAs, using the same effect parameter ${ }^{3}$. The use of different effect parameters in separate clinical trials makes it impossible to compare the CER of these interventions with each other.

\subsection{Measuring Effects}

In this chapter, the focus is on health outcomes. Scales of measurement can be divided according to their level of measurement in Nominal, Ordinal, Interval or Ratio (memory aid NOIR) scales. The results of a CEA and CUA are often expressed in a ratio, in which the difference in costs of two interventions are divided by the difference in outcome, e.g. either health outcome or utilities. It 
is widely believed that nominal and ordinal scales are not suitable for CostEffectiveness Ratios (CER) or Cost-Utility Ratios (CUR).

For a nominal scale (e.g. male, remale) this is obvious. The reason that an ordinal scale is less useful is that such a scale determines only the rank order of events in a subjective way. The labels of an ordinal categorisation might be good, better, best, which are used as an answering category in numerous questionnaires. In such cases there is no uniform unit of improvement. As there is no absolute number attached to the outcomes, ordinal scales are less suitable for applying the fundamental operations of algebra and therefore it is often not possible to calculate the cost per unit of improvement in a correct way.

For resource allocation decisions, interval or ratio-scales are necessary. In both the interval and the ratio scale, the difference between two points is quantifiable and interpretable. In addition, it is assumed that the difference between two points has the same meaning throughout the wholle range of the measurement scale. Because of these properties both scales are called 'cardinal scales'. The difference between these two scales is that the ratio scale has an unambiguous point that indicates that there is absolutely none of the phenomenon being measured'. However, this difference does not play an important role in this chapter, so in the remainder of the chapter the distinction between 'ordinal' and 'cardinal' scalles (both interval and ratio) is used. Although the superiority of cardinal scales for resource allocation is widely recognised in economic evaluation research, in clinical trials ordinal scales are often used for assessing the effects of interventions.

Another important division, which is often discussed in the literature, is the difference between intermediate and final outcome measures. For clinical reasons, biological markers (such as blood cholesterol) are often used as an intermediate outcome measure in economic evaluation studies. In addition, utilities and QALYs are often used as a final outcome measure for resource allocation. The problem discussed in this chapter, which is related to the above division, is that some studies are limited to the use of intermediate outcome measures, which have clinical meaning but which are not helpful from an economic point of view. Nevertheless, these intermediate outcome markers are still used as final outcome measures in some economic evaluation studies. The use of health outcomes in this chapter relates to their use as final outcome measures. The issue of this chapter is that for final outcome measures, cardinal scales such as QALYs (or utilities) should be used. 
In economic evaluation studies, several cardinal scales are used to measure utilities, such as the Time Trade Off and the Standard Gamble. In both methods the patient has to choose between a certain and an uncertain outcome. As an example, in the Time Trade Off the interviewee is given two alternatives to choose between. The first alternative is a certain event - for instance, that the level of functioning due to stroke will continue for a specific period (e.g. 10 years). The alternative consists of undergoing a treatment that will result in perfect health but will shorten the lifespan. The worse the current health status is valued, the more years of life one is willing to give up, and the lower the utility of the current health status.

\subsection{Illustrations}

In the following section, three examples are discussed in which outcome measures are used in a way that is not suitable for resource allocation. In all these examples, effects are measured in a quantitative way, suggesting cardinality.

\subsection{1 (DISGUISED) INTERVAL SCALE}

In economic evaluation research in the field of stroke disease, disease-specific instruments are frequently applied to express the effects of interventions. As an example, the article of Lanzieri et al. ${ }^{15}$ is discussed.

The authors use the 15 item, 42-point National Institute of Health Stroke Scale (NIHSS) to determine the effects of emergency thrombolysis as treatment sitrategy for thromboembolic intracerebral events. Each item has a 3 to 4-point response16. In their research Lanzieri et al. ${ }^{15}$ find a difference in (mean) costs of $\$ 1724$ between the intervention and control groups. Furthermore, the difference in score is 5.125 points on the NHHSS, which results in a ratio of $\$ 307$ per point on the NHHSS. The interpretation of this ratio is that performing such an intervention would cost $\$ 307$ to produce an average improvement of 1 point on the above scale. The conclusion of the authors is literally: ... "there is a remarkable cost effectiveness to the present method of intra-arterial urokinase (the intervention). We would like to suggest that the costeffectiveness of other strategies for the treatment of acute stroke be determined by this or a similar determination of ratio ${ }^{\prime \prime 15}$. 
The authors do seem to believe that the scale used is a cardinal scale, in which each improvement of 1 point on the NIHSS has the same intrinsic value. A closer look at the above scale and at the dimensions of the scale used reveals that this is not the case. See for example the sub-scale' level of consciousness', in which the patient is asked to name 'the month' and 'his or her age'. Scoring 0 equals both correctly, 1 equals one correctly, 2 equals both incorrectly. With respect to this specific dimension there are two possible transitions of health status: a) from answering both questions correctly to answering one question correctly, b) from this last situation to answering both incorrectly. Both transitions are associated with loss in health. In the numerical scheme of the NIH-Stroke Scale they are validated equally, because both transitions get a penalty of one. However, is the health loss of both transitions equal in reality? Not remembering one common datum might be a major impairment, whereas not remembering the second datum adds rather little to the already existing impairment. This would imply that the health loss in terms of QALYs is different in both transitions. The same conclusion can be drawn concerning many other items of the NIIH Stroke Scale, making clear that the scale is an ordinal scale. This renders the calculation of ratios less useful, and it might easily be misleading. The above conclusion applies to all such 'numerical' effect scales. This class is overloaded with many frequently used scales, such as the Karnowski scale, ADL, Rankin and Barthel index, the last two extremely popular among physicians. The common approach within these scales is to rather arbitrarily assign points to the varying health status of patients. After performing such scoring systems the investigator has a 'number' and might be inclined to think that this score is a cardinal outcome measurement. Indeed, some investigators go one step further in calculating "cost per gained point on such scale", believing that this is useful for economic evaluation research.

We conclude that all scales, using scoring systems like the above stroke scales, are hardly cardinal scales and therefore are less suitable for resource allocation decisions, even for resource allocation decisions within the specific domain of the scale. Calculation of CER based on a simple scoring system could be misleading for resource allocation decisions, and should therefore be avoided.

\subsubsection{DETECTION AS EFFECT}

Calculation of the 'incremental cost per extra detected case' of two different diagnostic or screening methods is often used to determine the optimal procedure. However, there can be serious problems with the comparability of 
ratios in which the number of detected: cases is the effect parameter. This has to do with the problem that different detection methods might select cases with different characteristics and therefore might lead to differences in potential health improvement per patient. As an example, the article of Britton et al. ${ }^{17}$ is disculssed.

This anticle investigates the sensitivity, or diagnostic yield, of a battery of tests. The sensitivity is the number of persons correctly diagnosed with the disease within a given group. In this study, the additional number of persons detected by different diagnostic procedures is calculated. Patients suspected of having a stroke were diagnosed using combinations of tests: bedside examination, routine laboratory tests, CSF analyses, RN and CT. Two disease categories were considered relevant for detection: haemorrhage, and differential diagnosis. The main results of the analysis are presented in an incremental way, meaning that the extra costs and the extra number of detected patients are given in each step (last column of Table 1).

Table 1. Diagnostic yield of different test strategies.

\begin{tabular}{|c|c|c|c|c|}
\hline Tests & $\begin{array}{l}\text { Sensitivity for } \\
\text { Haemorrhage }\end{array}$ & $\begin{array}{l}\text { Sensitivity for } \\
\text { Differential } \\
\text { Diagnoses }\end{array}$ & $\begin{array}{l}\text { Correct } \\
\text { Diagnoses } \\
\text { Total }\end{array}$ & $\begin{array}{l}\text { Cost per } \\
\text { additional } \\
\text { diagnostic } \\
\text { discovery } \\
\text { (USD) }\end{array}$ \\
\hline Bedside method & 39 & 0 & 79 & - \\
\hline Bedside + Clinical Investigation (C) & 39 & 67 & 81 & - \\
\hline Bedside + Cl + CSF & 72 & 71 & 90 & 356 \\
\hline Bedside + Cl + RN & 67 & 78 & 96 & 653 \\
\hline Bedside +CI+CSF $\& \mathrm{CT}$ & 67 & 100 & 99 & 1350 \\
\hline Bedside $+\mathrm{Cl}+\mathrm{RN}+\mathrm{CT}$ & 91 & 100 & 99 & 983 \\
\hline
\end{tabular}

$\mathrm{Cl}=$ Clinical investigation; $\mathrm{CSF}=$ cerebrospinal fluid analysis; $\mathrm{RN}=$ Radionuclide brain scan

The problem with this CEA is the interpretation of the last column, especially the interpretation of the entity "discovery'. Because there is more than one disease, it is no longer unequivocal. A 'discovery' could mean a patient with haemorrhage, but could also mean a patient with differential diagnosis (which is a mix in itself!) or it could be a statistical combination of both types of patients. This mix, however, is not constant in each additional diagnostic step, but changes as a consequence of differential sensitivity for different diseases, so there is no longer a unity of measurement. Adding $\mathrm{Cl}$ to the Bedside method discovers only cases of 'differential diagnoses', whereas adding CSF after the 
Bedside method and Cl discovers relatively many cases of haemorrhage" and only a few cases of 'differential diagnoses'. The consequence of this must be that the denominator discovery (see last column) changes in every additional diagnostic step. Therefore, this specific ratio is not informative and certainly cannot be used for optimal resource allocation.

Detecting patients is the most important goal of diagnostic and screening tests; therefore the number (or percentage) of detected patients is often used as the effect parameter for calculating the costs per detected case in a CER. In comparing different tests with each other, the characteristics of the patients detected may differ per test. If so, the interpretation of a unit of effect is no longer straightforward. In such cases one is inclined to think that the measurement of effects is performed in a cardinal way, but a closer look may reveal that the ultimate health gain of the diagnostic or screening procedure is not linear in relation to this 'number of patient' effect parameter.

\subsubsection{RISK AS INTERMEDIATE EFFECT}

From a clinical point of view, the use of biomedical parameters is attractive: they are often sensitive measurements and can be assessed within a limited time horizon. However, from an economic evaluation viewpoint, these parameters might be less attractive. In the next example we will focus on blood pressure as an important risk factor for stroke.

Suppose there are several alternative interwentions aimed at lowering blood pressure. Some interventions are aimed at lowering blood pressure levels that are only slightly elevated; other interventions are aimed at lowering moderate or higher risks. Table 2 presents the results of three possible interventions.

\section{Table 2. Incremental costs and benefits of 3 hypothetical interwentions aimed at lowering} diastollic blood pressure

\begin{tabular}{|c|c|c|c|}
\hline $\begin{array}{l}\text { Intervention: aimed at reducing } \\
\text { risk: }\end{array}$ & $\begin{array}{l}\text { Incremental } \\
\text { eftect } \\
(\text { in mmulg) }\end{array}$ & $\begin{array}{l}\text { Incremental costs } \\
\text { (4) }\end{array}$ & $\begin{array}{l}\text { Incremental cost per } \\
\text { incremental effect }\end{array}$ \\
\hline Low risk: $80 \mathrm{~mm}$ Hg & 10 & 1000 & 100 \\
\hline Moderatle risk: $100 \mathrm{~mm} \mathrm{Hg}$ & 10 & 1500 & 150 \\
\hline High risk: 120 mm $\mathrm{Hg}$ & 110 & 2000 & 200 \\
\hline
\end{tabular}

Looking at the ratio in the last column, one gets the impression that the intervention for the low risk group is the most attractive (lowest cost per 
$\mathrm{mmHg}$. Depending on the available budget, interventions for moderate and high risks might be considered, but in this sequence of priority.

For our hypothetical example, the following additional relative risk data are assumed. In epidemiological terms, the relative risk (RR) increases if the risk level itself increases. There is substantial empirical evidence for the existence of such a RR concerning hypertension ia . A meta-analysis reported a 10 to 12 fold increase in the risk of stroke for people in the highest category of diastolic blood pressure (a mean of $105 \mathrm{~mm} \mathrm{Hg}$ ), as compared with the lowest (a mean of $76 \mathrm{~mm} \mathrm{Hg})^{19}$. We took the above mentioned RR to illustrate the influence on resource allocation decisions. Lowering blood pressure in people with diastolic blood pressure of $80 \mathrm{~mm} \mathrm{Hg}$ leads to an improvement of 1 unit of health; lowering the diastolic blood pressure in people with $100 \mathrm{~mm} \mathrm{Hg} \mathrm{leads}$ to an improvement of 3 units of health, whereas lowering blood pressure in people with $120 \mathrm{~mm} \mathrm{Hg}$ produces 10 units of health.

Table 3. Incremental costs and benefits of 3 hypothetical interventions aimed at lowering blood pressure

\begin{tabular}{lllll}
\hline $\begin{array}{l}\text { Intervention aimed at } \\
\text { reducing risk: }\end{array}$ & $\begin{array}{l}\text { Incremental cost incremental } \\
(\$)\end{array}$ & $\begin{array}{l}\text { Incremental } \\
\text { effect (in } \\
\text { mmHg) }\end{array}$ & $\begin{array}{l}\text { increment in QALY cost } \\
\text { (see text above) }\end{array}$ & $\begin{array}{l}\text { per incremental } \\
\text { QALY }\end{array}$ \\
\hline Low risk: $80 \mathrm{~mm} \mathrm{Hg}$ & 1000 & 10 & 1 & 1000 \\
Moderate risk: $100 \mathrm{~mm} \mathrm{Hg}$ & 1500 & 10 & 3 & 500 \\
High risk: $120 \mathrm{~mm} \mathrm{Hg}$ & 2000 & 10 & 10 & 200 \\
\hline
\end{tabular}

For a macro policy the last column of Table 3 contains the relevant information. The application of the cost-effectiveness ratio in terms of QALYs leads to just the opposite sequence of priorities, in comparison with the case of the intermediate effect (Table 2).

Consequently, the calculation of CERs based solely on intermediate effects is misleading. In such cases the intermediate outcome measurement might look like a cardinal measurement scale, but often it is not a cardinal measurement of the health improvement in terms such as QALYs.

in clinical trials, effects are often expressed in so-called intermediate effects. For clinical investigators, such effects are relevant because they often represent the primary objectives of the study. Moreover, the use of such effect parameters has the advantage that they are rather sensitive and can be measured easily. However, the above analysis shows that intermediate effects can be used for resource allocation decisions only if there is a constant relation between the intermediate effect parameter and the resulting health 
improvement. In practice this will almost never be the case. The often stated opinion that such CERs can be used for allocating scarce resources within the specific domain has no theoretical foundation, and may even lead to inefficiency in resource allocation.

\subsection{Conclusion}

In recent years, the urge for economic evaluation research has led to an increase in the number of CEAs and CUAs. For various reasons, the number of CUAs performed is much less than the number of CEAs, although from an economic evaluation viewpoint CUAs are to be preferred. The examples discussed earlier show that cost-effectiveness ratios are often misleading and cannot be used for resource allocation decisions.

This conclusion holds for all effects that are not measured in cardinal scales. Sometimes the scalles used seem to be cardinal scales, but a closer look reveals that this is not always the case. In which categories of health measurement instruments can researchers be confronted with this measurement problem? Certainly for disease specific scores, such as the $\mathrm{NIH}$-score. The problem also occurs with the effect parameter 'number of patients detected', often used in diagnostic procedures or screening techniques. In this chapter it has also been shown to occur with intermediate effects. We believe that it occurs in other categories of effect parameters as well, such as generic-, domain- and specific measurement scales. This would lead us to the fundamental conclusion that only health effects, in QALYs, are measured in a cardinal way.

Should we conclude from this that economic evaluation studies which produce results that are not expressed in cost per QALY are of no value at all, and should be eliminated from the repertoire of investigators within the field of economic evaluation research? Before introducing new technologies into the health care system it is important to assess the extra benefits (even in ordinal scales) and the differences in costs. From an economic evaluation viewpoint, assessing the benefits in terms of QALYs is the first choice ${ }^{20,21}$, but this is not always a realistic option. For resource allocation at a societal level, only incremental cost per QALY figures will help us to understand whether the new technology is cost-effective in comparison with other technologies, as only outcome measures such as QALYs are comparable from study to study.

Some of the confusion in this area is introduced by health economists themselves ${ }^{22,23}$. Although the problems described above are well known ${ }^{6,24}$, the 
consequences for resource allocation are less well understood. Often one finds the statement that the difference between CUA and CEA is merely that the last is more restrictive concerning the domain of application. The truth, however is that CEA can hardly be used for resource allocation decisions at all if effects are not measured in a cardinal way, and that calculating CER is easily misleading. Concerning decision making implications, the differences between CEA and CUA are much greater than often suggested. Many authors use the term CEA as the broader category, in which the CUA is considered only as a subcategory ${ }^{2}$. We think that there are good arguments for considering CEA and CUA as two separate categories with their own features. Calculating incremental cost per effect within CUA is extremely informative, whereas calculating incremental cost per effect within CEA is almost always misleading. Finally, this chapter only highlights the correct use of ratios in economic evaluation studies. Other aspects which are relevant for utility measurement are brushed aside. For instance, it is presumed that the interviewee derives utilities only from his or her own health care status. Interpersonal utility interdependence, i.e. the fact that one person's utility also depends on the utility of another person, is not included in the analyses.

\section{References}

1. Drummond MF, O'Brien B, Stoddart GL, Torrance GW. Methods for the economic evaluation of health care programs. Oxford: Oxford University Press; 1997.

2. Gold $M$, Siegel J, Russel, L, Weinstein $M$. Cost-effectiveness in thealth and medicine. New York: Oxford University Press; 1996.

3. Banta HD, Luce BR. Health Care Techmology and its Assessment: An international perspective. Oxford: Oxford University Press; 1993.

4. Phelps CE, Mushlin All. On the (near) equivallence of cost-effectiveness and cost benefit analyses. Int J of Technol Assess Health Care 1991;7:12-21.

5. Birch 5 , Gafni A. Cost effectiveness/utility analyses: do current decision rules lead us to where we want to be? J Health Econ 1992;11:279-96.

6. Johannesson $M$, Weinstein $M$. On the decision rulles of cost-effectiveness analysis. J Health Econ 1993;12:459-67.

7. Ament A, Baltussen R. The interpretation of results of economic evaluation: Explicating the value of health. Health Econ 1997:6:625-35. 
8. Torrance GW, Feeney DH. Utilities and quality-adjusted life years. Int I Technol Assess Health Care 1989;5:559-79.

9. Haddix AC, Teutsch SM, Shaffer PA, Dunet DO. Prevention effectiveness: A guide to decision analysis and economic evaluation. Oxford: Oxford University Press; 1996.

10. Spilker B. Quality of life assessments in clinical trials. New York: Raven Press: 1990.

11. Patrick DL, Erickson P. Health Status and Health Policy; Allocating resources to health care. New York: Oxford University Press; 1993.

12. Kamlet MS. The Comparative Benefits Modelling Project: A framework for costw utility analysis of government health care programs. Washington: U.S. Department of Health and Human Services; 1992.

13. Karlsson $G$, Johannesson $M$ : The decision rules of cost-effectiveness analysis. Pharm Econ 1996:9:113-20.

14. Froberg DG, Kane RL. Methodology for measuring health-state preferences. I Clim Epidemiol 1989;42:459-71.

15. Lanzieri CF, Tarr RW. Cost-effectiveness of emergency intraarterial intracerebral thrombolysis: A pilot study. Am I Neuroradiol 1995;16:1987-93.

16. Bowling A. Measuring Disease, a review of disease specific quality of life measurement scales. Buckingham: Open University Press; 1995.

17. Britton $M_{8}$ fonsson $E$. Diagnosing suspected stroke: a cost-effectiveness analysis. Int J Technol Assess Health Care 1985;1:147-58.

18. Bronner LL, Kanter DS, Manson JE. Primary prevention of stroke. N Engl J Med $1995 ; 333: 1392-400$.

19. McMahon S, Peto R, Curler JA. Blood pressure, stroke, and coronary heart disease: Prolonged differences in blood pressure: prospective observational studies corrected for the regression dilution bias. Lancet 1990;335:765-74.

20. Weinstein MC, Fineberg HV. Clinical Decision Analysis. Philadelphia: W.B. Saunders $C_{0} ; 1980$.

21. Torrance GW, Feeney D. Utilities and quality-adjusted life years. Int J. Technol Assess Health Care 1989:5:559-75.

22. Garber AM, Phelps CE. Economic Foundations of Cost-effectiveness Analysis. Stanford: National Bureau of Economic Research; 1993.

23. Culyer, A. The normative economics of health care finance and provision. Oxf Rev Econ Policy 1989;5:34-58.

24. Johannesson M, Meltzer D. Some reflections on cost-effectiveness analysis. Health Econ 1998:7:1-7. 


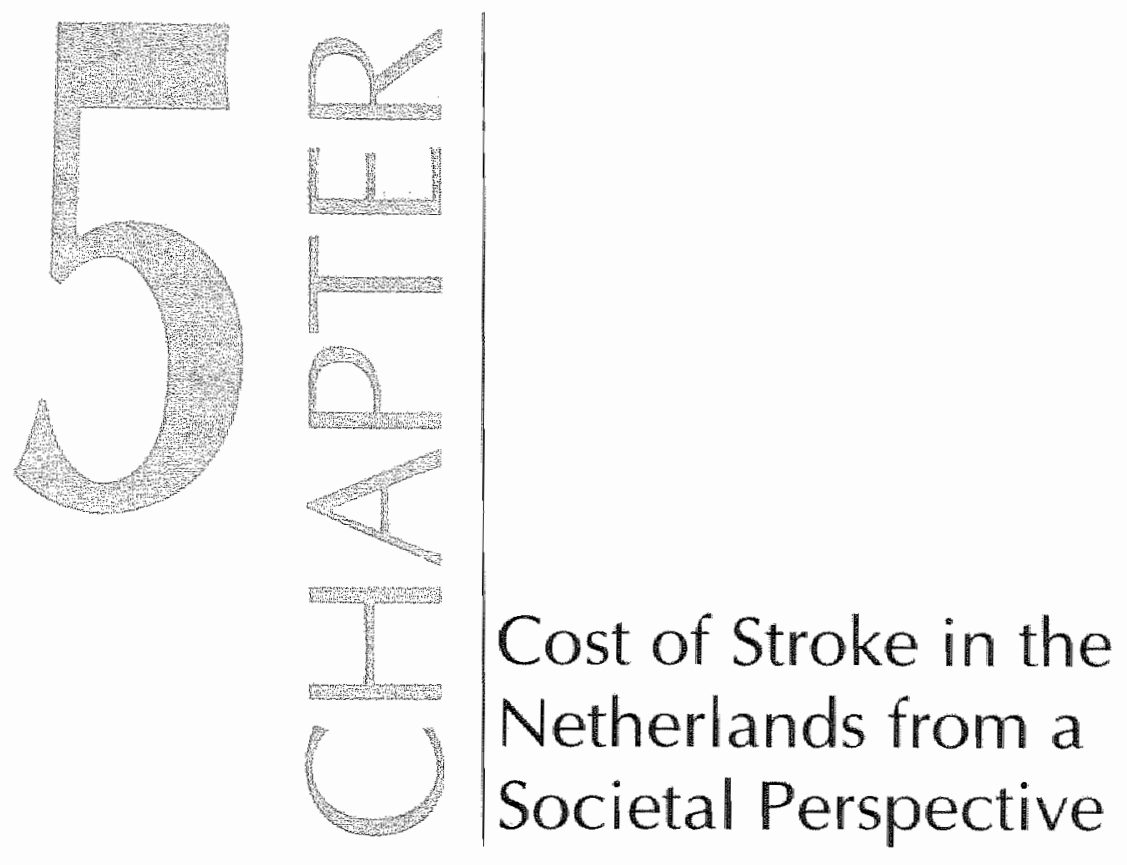





\section{Summary}

Cerebrovascular disorders are associated with a high level of morbidity and mortality and call for considerable resources. The objective of this study was to determine from a societal perspective the medical consumption (direct costs) and productivity losses (indirect costs) caused by cerebrovascular disorders in the Netherlands.

This study can be characterised as a cost-of-illness study based on prevalence data. All data gathered refer to 1993. Cerebrovascular disorders are defined according to the International Classification of Diseases, 9th Revision, (ICD-9) classification. Data from medical registrations and national statistics have been analysed. For both direct and indirect costs, volume and cost components are presented. To test the likelihood of the assumptions, a sensitivity analysis was performed.

The cost of cerebrovascular disorders in the Netherlands in 1993 amounted to E 1.1 billion, of which 0.9 billion were spent on medical consumption. It was found that direct costs are generated mainly by the long-term care of inpatients (in nursing homes and hospitals). The productivity losses were relatively low in comparison with other diseases, probably due to the fact that most patients with cerebrovascular disorders are elderly.

Over $3 \%$ of the Dutch annual health care budget is spent on patients suffering from cerebrovascular disorders. Costs in the future may be influenced by, among other things, demographic changes, new therapies and cost reduction programs introduced by the government.

\subsection{Introduction}

Stroke has a significant social and economic impact on patients, their families, and society as a whole. This is illustrated in the international literature both by cost-of-illness studies and by case-reports. In cost-of-illness studies, a distinction is madie between direct and indirect costs. Direct costs are directly associated with health care interventions, i.e., medical consumption. Indirect costs are broadly defined as the value of productivity losses caused by absenteeism, disability, or (premature) death'.

The organization of services involved in stroke management is multidisciplinary, and can include care provided by general practitioners, hospitals, rehabilitation centres, nursing homes and community services. In the 
Wetherlands, no top-down cost-of-illness study has been performed, although some efforts have been made to quantify the economic consequences of stroke for Dutch society ${ }^{2-4}$. The purpose of this study is to identify and estimate the costs of stroke in the Netherlands, both direct (medical consumption) and indirect (production loss). The study can be typified as a cost-of-illness study based on prevalence data, focused on the year 1993.

The means and methods of the study are described in 'Methods'. In the following sections, the data, analysis, and results by cost category are described for both direct and indirect costs. Finally, in the section on overall results, a comparison is made with other cost-of-illness studies performed in the Netherlands, and the sensitivity of the data found is discussed.

\subsection{Methods}

Figure 1. Method of the study

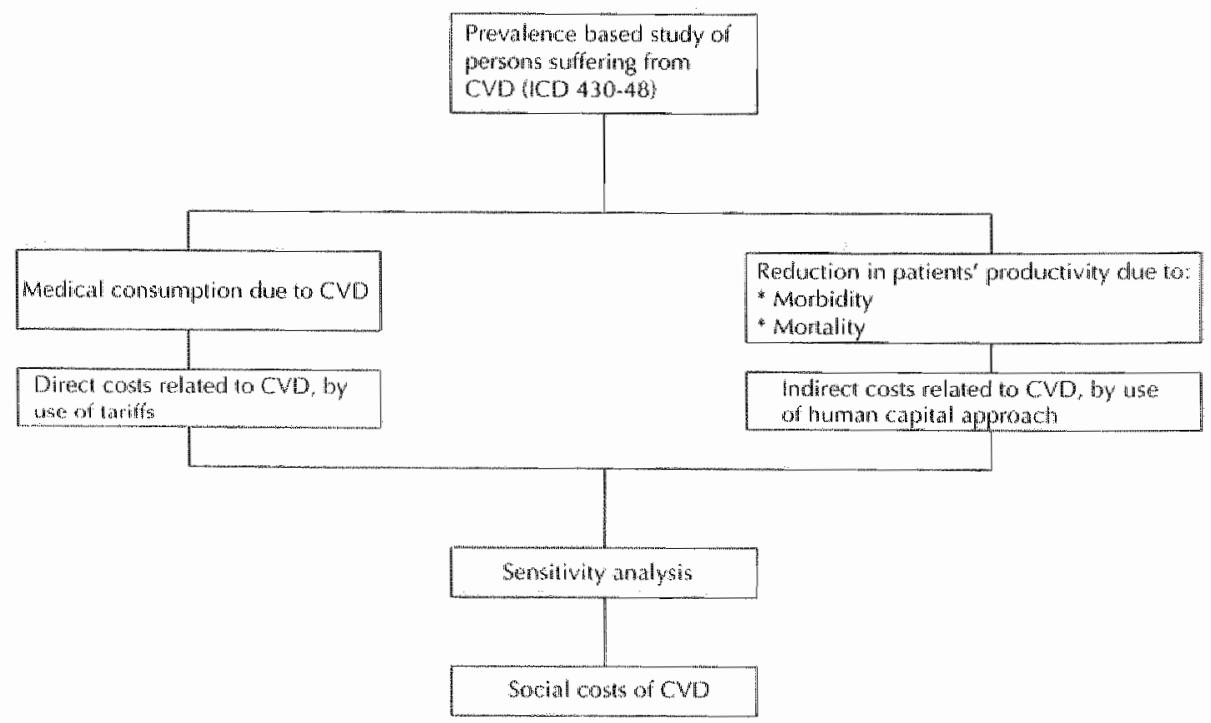

As Figure 1 shows, the first step in a cost-of-illness study is to define the disease. All data in the present study refer to persons suffering from cerebrovascular disorder (ICD 430-438) or who died because of it. The method applied here has been used in other prevalence-based cost-of-illness studies ${ }^{73}$. The underlying rationale is that direct costs and productivity losses 
are assigned to the year in which they occur lin this case, 19931. Expected future incomes lost as a result of premature mortality are assigned to the year of death ${ }^{3}$.

In general, the direct costs are based on figures provided by the Financial Statement of Care ${ }^{10}$. The Financial Statement of Care is a govemment publication that is presented to the Dutch Parliament together with the budget. It gives an integrated overview of financial developments in the health care sector during recent years, in addition to predictions for the subsequent year. Figures from the National Hospital Institute are used to calculate the costs of hospital care ${ }^{1-13}$. The costs of drugs are calculated using information from the Health Insurance Executive Board ${ }^{14.15}$. To quantify the indirect costs, the human capital approach is used. This approach attempts to estimate the value of lost production, which results from temporary or permanent absence from work, disability, or premature death. Production losses are estimated using the average salary per employee. Finally, to test the likelihood of the assumptions made when measuring and evaluating the direct and indirect costs, a sensitivity analysis was performed.

\subsection{Data, anallysis and results by cost category}

\subsubsection{DIRECT COSTS ATTRIBUTABLE TO STROKE}

This cost-of-illness study reflects the course that patients with stroke follow when they become ill. Patients with stroke generally contact the general practitioner or the emergency department of the hospital. Most of those who visit the generall practitioner are referred to more specialised care ${ }^{\| f_{i} t 7}$. After discharge from the hospital, patients visit various types of care providers, such as rehabillitation centres and nursing homes. Furthermore, some patients will be cared for home by professionals or by their own families.

General practitioner: Table 1 shows that there are several studies that have assessed morbidity of stroke as found in general practice ${ }^{16-22}$.

One can also see that the prevalence rate found for stroke in these studies varies between $7^{21}$ and $10^{19}$ per 1,000. These figures differ slightily because the studies vary regarding population, study period, and methodology. In the remainder of this research, the average figure from these studies is used as a basic assumption, e.g., 8.3 per 1,000. The total costs of general practitioner 
practices in 1993 was $€ 999$ million ${ }^{10}$. This would result in a total of about $e 8$ million for generel practitioner consultations due to stroke.

Table 1. Prevalence of strokes seen by general practitioners:

\begin{tabular}{llc}
\hline Study & Period & Annual prevalence per 1,000 \\
\hline Van den Hoogen & $1978-1982$ & 7.2 \\
Van de Lisdonk $^{14}$ & $1971-1988$ & 10.0 \\
Van der Velder $^{20}$ & $1987-1988$ & 8.0 \\
Lamberts $^{21}$ & $1985-1989$ & 7.0 \\
University of Limburg. $^{23}$ & $01-03-1993$ & 9.1 \\
\hline
\end{tabular}

Acute phase inpatient stay in hospitals: After an attack, most stroke patients are admitted to hospitals ${ }^{16,23}$. The National Medical Registration registers $99 \%$ of the admissions to general hospitals, university hospitals or specialised hospitals (i.e., rehabilitation centres) using the ICD-924.25. In this study, the costs of stroke for the hospitals are calculated on the basis of both number of discharged patients and number of days spent in the hospital. In 1993, 28,664 patients with stroke (diagnosis at discharge) were discharged from a hospital, after a total length of stay of 683,270 days. Discharge includes hospital mortality. The diagnosis refers to the primary diagnosis, i.e., the diagnosis that was the main reason for admission to the hospital. On the basis of these figures approximately $1.82 \%$ of the admitted patients account for $4.35 \%$ of the inpatient days.

To get an impression of the costs incurred by hospitals, we added the costs of care in general hospitals, university hospitals and rehabilitation centres (specialised hospitals). The resulting total in 1993 was $€ 7,365$ (including speciallists' salaries) $)^{1-13}$. Taking the overall costs for all hospitals, the costs due to stroke would be $€ 134$ million based on admission figures, and $€ 320$ based on inpatient days.

We assume that the former calculation is an underestimation, since the average length of stay for patients with stroke is relatively long (e.g., 24 days for stroke compared to 10 days for all diagnoses). On the other hand, the first days in the hospital are the most expensive; and therefore, we assume that the figure based on number of days in hospital is an overestimation. Consequently, an average of $e 227$ was reached.

Postacute phase: Stroke patients in the post-acute (hospital) phase fall into three main care categories: (1) those who require continuing rehabilitation; (2) those who require continuing supportive care, i.e. nursing home care; and (3) those whose condition and social situation permit various kinds of outpatient 
care, such as home nursing care, outpatient physiotherapy and exercise therapy, outpatient speech therapy, and outpatient drug therapy.

Rehabilitation: Rehabilitation after stroke aims to improve the disturbed function, and in the case of permanent handicaps, to optimise skills and behaviour ${ }^{26}$. Regarding inpatient care, $35 \%$ of the admissions were due to stroke ${ }^{27}$. We assume that the population in 1994 did not differ from that in 1993. The cost of rehabilitation centre services in 1993 was $e 157$ million". Regarding the inpatient stay of persons with stroke, the cost for this group in 1993 would be about 655 million' 11 . In this cost-of-illness study, the costs of rehabilitation centre services are included in the calculation of hospital costs.

Nursing homes: Almost all patients who are admitted to a nursing home are registered by the Nursing Home Information System ${ }^{2.5}$. According to these national statistics, on September $30,1993,17.6 \%$ of the inpatients were diagnosed primarily as having (late sequelae) stroke $e^{25}$. Of these, $33.8 \%$ were inpatients in the somatic department and $2.3 \%$ were inpatients in the psychogeriatric department. For day care, the figures are more or less similar. On the basis of inpatient figures, the costs of nursing home services were calculated. In 1993, the total cost for nursing homes was $€ 2,384$ million $^{10}$. On the assumption that the costs for somatic and psychogeriatric departments are more or less the same, this results in an amount of e 420 million for nursing homes services that can be assigned to stroke.

Oulpatient home nursing care: for patients with stroke, home nursing care encompasses nursing care, hygiene, bathing, reactivation, and rehabilitation. The National Organization of Home Nursing Care does not, however, keep a central register of diseases ${ }^{29}$. The Home Nursing Care Organization in the southern part of the Netherlands (Groene Kruis Heuvelland) provided prevalence rates of stroke. The area covered by this organization includes 209,657 inhabitants, about $1.4 \%$ of the Dutch population ${ }^{30}$. On Decembar 1. 1995, $12 \%$ of the patients of this Home Nursing Care Organization had cerebrovascular disorder ${ }^{3}$. In 1993, $\in 1,562$ million was spent on home care and nursing ${ }^{10}$, therefore, about $e 187$ million was spent on home care and nursing related to stroke.

Outpatient physiotherapy and exercise therapy: After a stroke, patients are often partially paralysed and may have problems with walking, speech, etc. About $3 \%$ of the patients with a stroke are referred to a physiotherapist. The Netherlands Institute of Primary Health Care (NIVEL) published an inquiry on the use of physiotherapy, in which a distinction was made between paralysis after stroke and other consequences after stroke $e^{2,33}$. The other consequences 
of stroke accounted for $0.5 \%$ of the referrals, the paralysis for even fewer referrals. The total outpatient costs of physiotherapy for the Netherlands in 1993 was $e 557$ million ${ }^{10}$. Hence, the expenditure of $e 3$ million in 1993 might be due to stroke.

In addition to physiotherapy, exercise therapy is well known in the Netherlands ${ }^{34}$. This therapy aims to rehabilitate by improving the posture and basic motor skills by means of an active, individual motor learning process. According to the NIVEL, patients with stroke are not referred to these exercise therapies very often ${ }^{35}$.

Outpatient speech therapy: In 1993, the NIVEL studied 1,761 patients referred to a speech therapist ${ }^{3 / 2}$. Of those whose referral diagnosis is known, $11.2 \%$ were referred because of stroke. Total outpatient costs of speech therapy in 1993 were $E 32$ million ${ }^{10}$. Hence, the total costs for speech therapy in 1993 for stroke were about $E 4$ million.

Table 2. Costs of Outpatient Drug Treatment for Stroke

\begin{tabular}{|c|c|c|c|c|}
\hline $\begin{array}{l}\text { ATC. } \\
\text { code }\end{array}$ & Main drug categories & $\begin{array}{l}\text { Outpatient consumption } \\
\text { of drugs in per cent } \\
\text { (prescriptions) } \\
\text { ( I per cent) }\end{array}$ & $\begin{array}{l}1993 \text { sales at retail } \\
\text { price lewel } \\
\text { (million e) }\end{array}$ & $\begin{array}{l}\text { Total costs of } \\
\text { consumption of } \\
\text { drugs (million } e \text { ) }\end{array}$ \\
\hline$B 1$ & Anti-lhrombotic & 24.3 & 24.2 & 5.9 \\
\hline $\mathrm{Cl}$ & Cardiac & 1.4 & 59.6 & 0.8 \\
\hline $\mathrm{C} 2$ & Anti-hypertensive & 4.2 & 111.9 & 4.7 \\
\hline $\mathrm{C} 3$ & Diurelic & 1.5 & 63.5 & 1,0 \\
\hline $\mathrm{CA}$ & Vasodilation & 8.1 & 5.1 & 0.4 \\
\hline $\mathrm{C7}$ & Beta blocker & 1.2 & 97.9 & 1.2 \\
\hline $\mathrm{CB}$ & Galcium-antagonist & 1.4 & 109.4 & 1.5 \\
\hline $\mathrm{C9}$ & Accentagonist & 2.5 & $111.9^{\circ}$ & 2.8 \\
\hline 17 & Vaccines & 2.9 & 18.8 & 0.5 \\
\hline$M 3$ & Muscle relaxants & 1.1 & 4.4 & 0.0 \\
\hline $\mathrm{N2}$ & Analgetio & 4.5 & 50.3 & 2.3 \\
\hline $\mathrm{N3}$ & Anti-epileptic & 2.5 & 23.1 & 0.6 \\
\hline$N 6$ & Psychoanalleptic & 18.0 & 112.8 & 20.3 \\
\hline$\$ 1$ & Ophthatmologic & 1.7 & 49.8 & 0.9 \\
\hline \multirow[t]{2}{*}{ V } & Nutuition & 6.5 & - & - \\
\hline & Total & & & 42.9 \\
\hline
\end{tabular}

ATC indicates Anatomical Therapeutic Chemical; ACE, angiotensin-converting enzyme. Source: $15 ., 73$

ATC code of the wolume component 3 and the cost component differ slightly ${ }^{15}$; C9 ACEantagonists, therefore, fall into the category anti-hypertensive 
Outpatient drug therapy: For various reasons, patients with stroke may receive medication, frequent examples being anti-thrombotic, anti-hypertensive and anti-psychoanaleptic drugs. Extensive information about drug administration is registered by the Institute for Medical Statistics (MS $)^{37}$. Certain drugs are administered for the treatment of stroke; in this, comorbidity may play an important role. According to the IMS, drugs are usually prescribed by the general practitioner ${ }^{37}$. Table 2 presents an overview of the costs of drug treatment for stroke. The costs are based on a databank that includes the outpatient use of drugs in a sample of 3.2 million patients covered by the insurance $\mathrm{act}^{15}$. Extrapolated for the Dutch population as a whole, it is estimated that outpatient drug costs for stroke were about $€ 43$ million.

\subsubsection{INDIRECT COSTS ATTRIBUTABLE TO STROKE}

Absenteeism: Patients with stroke are often absent from work or incapacitated, which leads to productivity losses for society. This study includes only the production loss for paid work, because little information is available regarding unpaid work. During absences, individuals receive a pension that is regarded as a transfer payment. This refers to workmen's compensation payments, which are a cost to the paying party and a gain to the one receiving the pension, and neither a cost nor a gain to society. However, to gain an insight into the total amount of production loss we used these absenteeism registers. In the Netherlands, the ill employee is entitled to an absenteeism benefit for the first year of being registered as sick. A problem arises when the medical reason for being on the sick-list is examined, especially for short-term absenteeism (up to 7 days); e.g., in $9 \%$ of the cases the absentee was not seen by an insurance doctor. This number decreases to $5.7 \%$ for long-term absenteeism ( $>182$ days). Regarding the duration of the illness, we assume that it is likely that patients with stroke are diagnosed by an (insurance) physician. In 1993, there were 259,081 days of absence under the Sickness Insurance Act due to stroke, which is about $0.2 \%$ of the total days of absenteeism * About $56 \%$ of the work force is registered under the Sickness Insurance Act by occupational associations ${ }^{39}$. The number of days, therefore, is multiplied by 1.79 , resulting in a total number of 462,645 days of absence. The average gross annual income in 1993 for active participants of the work force aged between 18 and 64 years was about $€ 25,366^{40}$. To obtain the average salary per employee per day, this figure should be divided by 365 (the sick-listing is based on all days, including holidays and weekends). The result is an average 
daily income of 69 results. Based on this figure, the total amount of indirect costs due to absenteeism is about 32 million.

Disability: In the Netherlands, after the 1-year period of absence described above, an employee who fulfils certain conditions may be entitled to a disability allowance because he or she is unable to work. All persons who are entitled to a disability benefit, either according to the Disability Insurance or the General Disability Act are registered. In 1993, 1,791,596 converted benefit days $(0.9 \%)$ were due to stroke $e^{4 !}$. Converted benefit days are the number of benefit days corrected for the percentage of disability and the duration of the disability, e.g. one person who is disabled full-time for the whole year incurs 261 converted benefit days (excluding holidays and weekends) ${ }^{2}$.

The average gross yearly income (including special payments and transfers), in 1993 for persons aged between 18 and 64 years was about $e 25,366^{40}$. To obtain the average salary per employee per (converted) day, this figure should be divided by 261, giving an average daily income of $€ 97$. Thus, the mentioned $1,791,596$ days correspond to $e 174$ million.

Premature death: Despite a reduction in stroke mortality in the last 30 years, stroke is the third leading cause of death in the Netherlands. Mortality registration by diagnosis in the Netherlands is obligatory, i.e., the cause of death has to be registered before the deceased is buried or cremated ${ }^{25}$. According to these registrations, 12,907 patients died in 1993 because of stroke, 1,130 of whom were 64 years old or younger ${ }^{43}$. The number of years of life lost before the age of 65 years from stroke (ICD-9 430-438) in 1993 was 12,595 years $^{44}$. One might assume that the years preceding the age of 65 are the productive years. With the prevalence approach, calculation of mortality costs considers salaries over a lifetime rather than a single year. The rationale for this approach is that if an individual had not died in a given year, that person would have continued to be productive until retirement (65 years); therefore, the present value of future losses is used as an appropriate estimate. However, if these patients had not died, their participation in the working population would not be $100 \%$ until retirement ( 65 years). In the Netherlands, in $1993,62 \%$ of the population had a paying job; this percentage varied with age: $80 \%$ in the 25-34 year and $26 \%$ in the age category $55-64$ years ${ }^{45}$. In this study, the production loss due to mortality was corrected for this participation in employment, resulting in a loss of 5,493 production years because of stroke in 1993.

The economic value of an individual is measured according to salaries. As mentioned above, the average gross yearly income lincluding special 
payments and transfers) in 1993 for employed persons aged between 18 and 64 years was about $e 25,366^{40}$. To value the future production losses due to premature death, these costs need to be discounted. The process of discounting converts a stream of earnings into its present value. With a moderate discount rate of $5 \%$ the costs of mortality due to stroke would be $€$ 51 million.

\subsection{Results}

Table 3 shows that the total cost of stroke for Dutch society in the year 1993 was about $€ 1,149$ million. The total direct costs amounted to $€ 892$ million, which is about $3 \%$ of the health care budget of $€ 26,220$ million spent in 1993.

\subsubsection{COMPARISON WITH THE RESULTS OF OTHER STUDIES}

The results are comparable with previous studies ${ }^{2-6}$. Bergman et al. ${ }^{2}$ calculated the health care costs of patients which were incident in 1991, and came up with an amount of $4 \%$ of the total costs. Koopmanschap et al. ${ }^{5}$ estimated costs of stroke in a top-down cost-of-illness study. In this approach, the costs of several types of care are divided by the main disease categories. The total costs for stroke were estimated to be $2.9 \%$ of the total costs of diseases in 1988 .

\subsubsection{SENSITINITY ANALYSIS}

A sensitivity analysis usually tests relevant factors to highlight sensitive components of the calculation. In the present study a sensitivity analysis was considered for those estimates for which no reliable data were available, and informed guesses were made, and furthermore for data for which different value judgements were found. If the results of such manipulations are minor, one can have greater confidence in the results. If the sensitivity analysis produces large changes in the results, then greater caution is necessary when interpreting the data. 
Table 3. Estimates (in e) of the direct and indirect costs of stroke in 1993

\begin{tabular}{|c|c|c|c|c|}
\hline Category of expenditures or losses & $\begin{array}{r}\text { Effect due to } \\
\text { stroke (rate } \\
\text { used) }\end{array}$ & $\begin{array}{l}\text { Estimate to the } \\
\text { nearest million }\end{array}$ & $\begin{array}{r}\% \text { Of tofal } \\
\text { costs }\end{array}$ & $\begin{array}{r}\text { Sensitivity } \\
\text { analysis }\end{array}$ \\
\hline \multicolumn{5}{|l|}{ Direct costs } \\
\hline Ceneral practitioner & $0.8 \%$ & 8 & 0.7 & $7-10$ \\
\hline \multicolumn{5}{|l|}{ Hospitals } \\
\hline (including rehabilitation centres) & $1.8 \%$ & & & \\
\hline $\begin{array}{l}\text { - inpatient discharges } \\
\text { - inpatient hospital days }\end{array}$ & $4.4 \%$ & $227^{1}$ & 19.8 & $134-320$ \\
\hline \multicolumn{5}{|l|}{ Rehabilitation (see hospitals) } \\
\hline - inpatient admission & $35 \%$ & $-^{2}$ & - & - \\
\hline - day care & $14 \%$ & & & \\
\hline Outpatient use of drugs & $=$ & 43 & 3.8 & - \\
\hline Nursing homes & $17.6 \%$ & 420 & 36.5 & - \\
\hline Home nursing services & $12 \%$ & 187 & 16.3 & $109-265$ \\
\hline Physiotherapy & $0.5 \%$ & 3 & 0.2 & - \\
\hline Speech therapy & $11.2 \%$ & 4 & 0.3 & - \\
\hline Subtotal direct costs & & 892 & 77.6 & \\
\hline \multicolumn{5}{|l|}{ Indirect costs } \\
\hline Absenteeism & $0.2 \%$ & 32 & 2.8 & - \\
\hline Disability & $0.9 \%$ & 174 & 15.1 & - \\
\hline Subtotal morbidity costs & & 206 & 17.9 & \\
\hline \multicolumn{5}{|l|}{ Mortality costs } \\
\hline $\begin{array}{l}\text { Lite years lost betore the age of } 65 \\
\text { years }\end{array}$ & 5,493 & 51 & 4.4 & 32.93 \\
\hline TOTAL COSTS & & 1,149 & 100.0 & \\
\hline
\end{tabular}

* Minimum-maximum

1 Average costs of inpatient admission and inpatient care, including rehabilitation (see note 2 ).

2 The total costs for rehabiliation centres were aboul e 55 million.

Table 3 also displays the costs of each particular service discussed above as a fraction of the total (direct and indirect) costs. The fractions give an indication of the sensitivity values of the various items. Regarding the direct costs, the conclusion will be most responsive to variation in nursing homes, hospitals and nursing home care. For some of these health care facilities (general practices and hospitals) several assumptions were indeed made. With regard to hospital stay, it makes a difference if one calculates the cost on the basis of number of days in hospital rather than the number of discharged patients e.g., the costs would vary between $\in 134$ and $\in 320$ million. The costs of home 
nursing care were based on the information provided by one Home Nursing Organization, and differ from the results reported by Koopmanschap et al. ${ }^{5}$. A range of $\pm 5 \%$ is chosen to test the likelihood of these figures. Based on this range, the total costs for home nursing care would vary from 6109 million to 265 million. Finally, if the prevallence of general practitioner consultation ranged from 7 per 1,000 ( $\mathrm{min} .121$ to 10 per 1,000 (max.)19, the corresponding general practitioner costs would vary from $€ 7$ to $€ 10$ million. The cumulative effect of these changes in medical consumption on the total costs, using the minimal and maximal plausible values, would give rise to a $\pm 15 \%$ change.

\subsubsection{INDIRECT COSTS}

Table 3 also shows that the results of this study are very sensitive to changes in the indirect costs. This study includes only production loss by patients. However, family members and other caregivers sometimes also have to quit their jobs or reduce their working hours. The indirect costs in our study are based on the human capital approach, which regards persons as human resources, and their production loss is valued by salaries. However, this method has several disadvantages. When using this approach the value of unpaid work (including that of the retired) is not included and the value of life over and above economic productivity is completely ignored. This may induce an underestimation because the total number of hours of unpaid work is 1 to 1.5 times higher than the total number of hours of paid work ${ }^{\text {th }}$. Second, it is assumed that the production of the worker is roughly the same as the salary. Third, the assumptions of the human capital approach are that there is full use of labour (i.e. no unemployment) and that therefore sick or deceased people are not replaced. However, in the case of long-term absence, the employee concerned is likely to be replaced by another worker as most industrialised countries are faced with unemployment and consequently a labour reserve is available. Recently, a new method, the friction cost method, has been developed that takes the limitations of the human capital approach into account ${ }^{7.48}$. The basic principle of this method is that the amount of production lost because of disease depends on the time-span organizations needed to restore the initial production level. For the friction cost method, considerable additional information is required that is difficult to obtain $(\mathrm{e} . \mathrm{g}$. one has to measure the real production loss in different jobs and locations over the period needed to find a replacement for a lost worker). 
Another issue is that the human capital appraach assumes that persons are fully employed. However, only $75 \%$ of employees work more than 35 hours per week*4. Besides these shortcomings, the costs of absenteeism and disablement were computed rather than estimated, and are, therefore, not subject to uncertainty. However, in calculating the cost of mortality, a moderate discount rate of $5 \%$ was chosen with regard to the present lifetime earnings. For the sensitivity analysis, the costs of mortality are assessed using $2 \%$ and $8 \%$ discount rates (e.g., the corresponding mortality costs would vary from $e 32$ to 93 million.

\subsection{Conclusion}

The purpose of the present study is to assess the burden that stroke places on Dutch society. Uts scope is restricted to the year 1993, and both direct costs (medical consumption) and indirect costs (production losses) are included. The total cost of stroke is about $\in 1,1$ billion, of which $\in 0,9$ billion are for medical consumption. In accordance with other siudies, we found that the costs of medical consumption are mostly generated by inpatient costs, (e.g., nursing homes and hospital stay). The inpatient costs in hospitals may be high because of waiting lists before discharge to a rehabilitation centre or nursing home. In the Netherlands, the government and providers of health care are striving to improve organizational aspects to ameliorate the routing of stroke patients through the health care system and to improve the effectiveness and efficacy of care (e.g, stroke units).

In health care as a whole the indirect costs exceed the direct costs. Following Hartunian et al." this study shows that the indirect costs for stroke do not exceed the direct costs. This is because patients with stroke are older and therefore lose relatively fewer productive years". Thils study estimates the total cost to society of patients suffering from stroke in the Netherlands. Some items, although they might be important, have been difficult to value in monetary terms. Psycho-social aspects, such as pain, grief, and suffering, therefore have not been taken into account here. For the analysis we used the primary diagnosis. It is assumed that all costs can be assigned to stroke; therefore, comorbidity is not taken into account separately, possibly leading to some overestimation.

Traditionally, cost-of-illness studies such as this are based on secondary data sources. The estimation of costs of stroke on a national scale is greatly 
dependent on the quality and precision of the data used. In this study, in addition to national statistics (e.g., hospitals, nursing homes, absenteeism, work disability, and mortality) and national surveys (e.g., outpatient drug therapy, physiotherapy, exercise therapy, and speech therapy), several other sources have been used to collect data on cost, such as records available through health service suppliers (e.g., nursing homes), case records, and continuous morbidity registers (e.g., general practitioner). For these other sources, all results have been extrapolated to a national level, i.e., we assume that if a certain percentage is found in a specific patient population, the same percentage of care and costs will apply to the national population. These assumptions may have induced some bias; we therefore performed a sensitivity analysis. As shown in the section on sensitivity analysis, the results of this study may to some extent be subject to uncertainty. The cumulative effect of modifications in direct costs results in a $15 \%$ change. In addition, in the Netherlands, no data are available for certain aspects, such as prevention, mental health care, and family burden: these have not been included in the analysis. Because of these deficiencies, and because of the outcome of the sensitivity analysis, the results of this study should be treated with some caution.

A number of possible insights can be gained from cost-of-illness studies such as this one. The most important is that cost-of-illness studies are another way of highlighting the importance of a particular disease, over and above the more epidemiological estimates of morbidity and mortality " "It is often the case that ranking disease in terms of economic burden merely mirrors the ranking one would obtain by other methods. In this way, cost-of-illness calculations can help to determine medical research priorities. However, a word of caution is warranted: cost-of-illness studies, without other information, do not tell us whether or not more resources should be devoted to treating the diseases concerned. When deciding on allocation of scarce resources, one must allso take into account treatment options available, their cost, and their effectiveness ${ }^{49}$.

This study describes the situation in 1993. It would certainly be of interest to forecast the development of costs of stroke in the future. Factors that may influence future costs include demographic changes, new therapies, and costreduction programs introduced by the Dutch government. The data of this study could be used, together with prognoses of the trends in stroke, as the basis for forecasting future costs of healthcare and social services. Such forecasts would be of particular interest for policy pllanning. 


\section{Acknowledgments}

The authors thank Professor Beuls, Professor Groot, Professor Troost, Dr. Blaauw, Dr. Boiten, Dr. Franke, Dr. Hupperts, 1r. MSc. Leffers, Dr. Lodder, Antonette Bok and Marielle Goossens for reviewing earlier versions of the chapter. Furthermore, we would like to thank the staff of the Medical and Social information Center of Maastricht University for their help in gathering data, and Mr. Berger (Instituut voor Medische Statistiek), Mr. Habets (Groene Kruis Heuvelland), Mr. Meurs (College van Toezicht Sociale Verzekeringen), Mr. Nool (College van Toezicht Sociale Verzekeringen) and Mr. Piepenbrink (Ziekenfondsraad) for access to information.

\section{References}

1. Luce B, Elixhauser A. Estimating costs in the economic evaluation of medical technollogies. Int I Technol Assess Health Care 1990;6:57-75.

2. Bergman L, van der Meulen $J \mathrm{H}$, Limburg $M$, Habbema $\backslash \mathrm{D}$. Costs of medical care after first-ever stroke in The Netherlands. Stroke 1995;26:1830-6.

3. van den Bosch $\mathrm{HH}$, Kardaun JWPF. Ziekten van het zenuwstelsel in Nederland: een verkenning wan de omvang en de gevolgen. Den Haag: Staatsdrukkerij/ Uitgeverij: 1993.

4. van den Bosch $I H$, Kardaun JWPF. Ziektelast door aandoeningen van het zenuwstelsel in Nederland Ned Tijdschr Geneeskd 1994;138:1219-24.

5. Koopmanschap MA, van Roijen L. Bonneux L. Kosten van ziekten in Nederland. Rotterdam: Instituut Maatschappelijke Gezondheidszorg Instituut voor Medische Technology Assessment Erasmus Universiteit Rotterdam; 1991.

6. Meyboom-de long B, Buis I. Zorg na een beroerte; een publikatie van de Nederlandse Hartstichting over de gevolgen en de daarmee samenhangende zorg: bevindingen, knelpunten en aanbevelingen. Den Haag: Nederlandse Hartstichting: 1995.

7. Ament AIHA, Evers SMAA. Cost of illness studies in health care: a comparison of wo cases. Health Policy 1993;26:29-42.

8. Evers SMAA, Ament AIHA. Costs of schizophrenia in The Netherlands. Schizophr Bull 1995;21:141-53.

9. Hartunian NS, Smart CN, Thompson MS. The incidence and economic costs of cancer, motor vehicle injuries, coronary heart disease, and stroke: a comparative analysis. Am I Public Health 1980;70:1249-60. 
10. Tweede Kamer der Staten-Generaal, vergaderjaar 1995-1996. Financieal Overzicht Zorg (FOZ) 1996. "s-Grawenhage: Staatsdrukkerij/Uitgeverij; 1995.

11. Nationaal Zjekenhuis Instituut (NZi), Financiële statistiek 1993, Categorale ziekenhuizen. Utrecht: Nationaal Ziekenhuis Instituut; 1994.

12. Nationaal Ziekenhuis Instituut (NZi), Financiële statistiek, algemene ziekenhuizen. Utrecht: Nationaal Ziekenhuis Instituut; 1994.

13. Nationaal Ziekenhuis Instituut (NZi), Financiële statistiek 1993. Academische ziekenhuizen. Utrecht: Nationaal Ziekenhuis Instituut; 1994.

14. Piepenbrink IF. Informatie betreffende patiënten die zijn verzekend volgens de ziekentondswet en patiënten die particulier verzekerd zijn. Ziekentondsraad: niet gepubliceerde gegevens; 1996.

15. Ziekenfondsraad. GiPeilingen, kerngetallen farmaceutische hulp 1994. Amstelveen: Geneesmiddelen Informatie Project Ziekenfondsraad; 1995.

16. Rijkuniversiteit Groningen Vakgroep Huisartsgeneeskunde. De patiënt met een cerebrovasculair accident en de huisarts. Groningen: Rijksuniversiteit Groningen, vakgroep huisartsgeneeskunde; 1992.

17. van der Meer K, Smith RJA, Bremer GI. Cerebrowasculaire aandoeningen gepeild, het voorkomen van CVA en TIA in de huisartspraktijk en de lotgevallen wan de getroffien patiënten. Utrecht: Nederlands Instituut voor Onderzoek van de Eerstelijnsgezondheidszorg (NIVEL); 1990.

18. Van den Hoogen $H \| M$, Huygen FIA, Schellekens $W G_{\text {, Strat } M} M$, van der Velden HGM. Morbidity figures from general practice, data from four general practices. Nijmegen: Nijmegen University Department of General Practice; 1985.

19. wan de Lisdonk EH, wan den Bosch WJHM. Huygen FHA, Lagro-Janssen ALM. Ziekten in de huisartspraktijk. Ltrecht: Wetenschappelijke uitgeverij Bunge; 1994.

20. van der Velden ), de Bakker DH, Claessens AAMC, Schellevis FG. Dutch National Survey of General Practices, morbidity in general practices. Utrecht: Netherlands Institute of Primary Health Care; 1992.

21. Lambers $H$. In het huis van de huisarts, verslag van het transitieproject. Lelystad: Meditekst; 1991 .

22. Rijksuniversiteit Limburg, Registratienet Huisarlspraktijken. Gezondheids problemen en diagnosen in de huisartspraktijk. Maastricht: Rijksuniversiteit Limburg; 1993.

23. Franke $\mathrm{CL}$. Intracerebral hemorthage. Heerlen: De Wever Ziekenhuis, Department of neurology: 1991] [Thesis].

24. SIG. Landelijke Medische Registratie. Utrecht: SIG; 1993.

25. Bouter LM, van Dongen MCMM. Epidemiologisch onderzoek, opzet en interpretatie. Houten/Zaventem: Bohn Stafleu Van Loghum; 1991. 
26. Landelijk Coördinatiepunt Niet aangeboren Hersenletsel, Revalidatiezorg voor mensen met niet-aangeboren hersenletsel. Utrecht: Nationaal Ziekenhuis Instituut; 1994.

27. LivRE. Landelijk Informatiesysteem voor Revalidatie, jaarboek 1994. Utrecht: Landelijk Informatiesysteem voor Revalidatie; 1995.

28. SIG, zorginformatie. Jaarboek werpleeghuizen 1993. Utrecht: SIG zorginformatie; 1994.

29. Landelijke Vereniging voor Thuiszorg. Thuiszorg ten gevolge van een beroerte. Landelijke Vereniging voor Thuiszorg: ongepubliceerde gegevens; 1996.

30. Centraal Bureau voor de Statistiek (CBS). Maandbericht Gezondheidsstatistiek. Voorburg/Heerlen: Centraal Bureau voor de Statistiek; 1996.

31. Habets H. Inventarisatie CVA-patiënten in zorg Groene Kruis Heuvelland. Maastricht: niet gepubliceerde gegevens; 1996.

32. van der Valk RWA, Dekker I, Boschman $M$. Basisgegevens extramurale fysiotherapie 1989-1992. Utrecht: Nederlands Instituut voor Onderzoek van de Eerstelijnggezondheidszorg (NIVEL); 1995.

33. Roebroeck ME, Hutten JBF, Kerssens II, Dekker I. De omvang wan fysiotherapeutische behandeling naar verschillende patientcategorieën. Utrecht: Nederlands Instituut voor Onderzoek van de Eerstelijnsgezondheidszorg (NIVEL); 1995.

34. Gisbergen MUWM. Dekker J. Reliability of the diagnosis of impairments and disabilities by exercise therapists. I Rehabil Sci 1992;5:67-73.

35. Zuijderduin, W.M. and 1. Dekker, Oefentherapie-Cesar, en oefentherapieMensendieck in de Nederlandse gezondheidszorg : een beschrijwing en analyse van de beroepsuitoefening. Utrecht: Nederlands Instituut voor Onderzoek van de tersteitnosgezononetdszorg (NIVEL); 1994.

36. Raailmakers MF, Dekker 1. Logopedie in de Nederlandse gezondheidszorg. Utrecht, Netherlands: Nederlands Instituut voor Onderzoek van de Eerstelijnggezondheidszorg (NIVEL); 1995.

37. Instituut voor Medische Statistiek (MS), Medische Index Nederland: niet gepubliceerde gegevens; 1996.

38. Meurs $\mathrm{G}$. Ziekteverzuim ten gevolge wan beroerte. College van Toezicht Sociale Verzekeringen, ongepubliceerde gegevens; 1996.

39. Sociale Verzekeringsraad (SVr). Ziektewet 1993. Zoetermeer: Sociale Verzekeringsraad; 1994.

40. Trimp L. Inkomensverdeling 1993. Soc-econ Mndstat 1994;12:13-5.

41. Nool IW. Arbeidsongeschiktheid ten gevolge van beroente. Zoetermeer: College van Toezicht Sociale Verzekeringen, ongepubliceerde gegevens; 1996. 
42. CTSV, Kroniek van de sociale verzekeringen. Zoetermeer: College van Toezicht Sociale Verzekeringen; 1995.

43. Centraal Bureau voor de Statistiek (CBS). Overledenen naar doodsoorzaak 1993 (A1), Primaire doodsoorzaken. Voorburg/Heerlen: Centraal Bureau voor de Statistiek; 1995.

44. Centraal Bureau voor de Statistiek (CBS), Ministerie van Welzijn, Volksgezondheid en Cultuur. Vademecum gezondheidsstatistiek Nederland 1995. Voorburg/Heeten: Centraal Bureau voor de Statistiek; 1995.

45. Centraal Bureau voor de Statistiek (CBS). Enquête beroepsbevolking 1993. Voorburg/Heerlen: Centraal Bureau voor de Statistiek; 1994.

46. Bruyn-Hundt $M$. The economics of unpaid work. University of Limburg; 1996 [Thesis].

47. Koopmanschap MA, Rutten FFH, van Ineveld BM, van Roijen $L$. The friction cost method for measuring indirect cost of disease. I Health Econ 1995;14:171-89.

48. Koopmanschap $M A$, Ineveld van BM. Towards a new approach for estimating indirect costs of disease. Soc Sci Med 1992;34:1005-10.

49. Drummond MF. Cost-of-lliness Studies A Major Headache? PharmacoEconomics $1992 ; 2: 1-4$ 



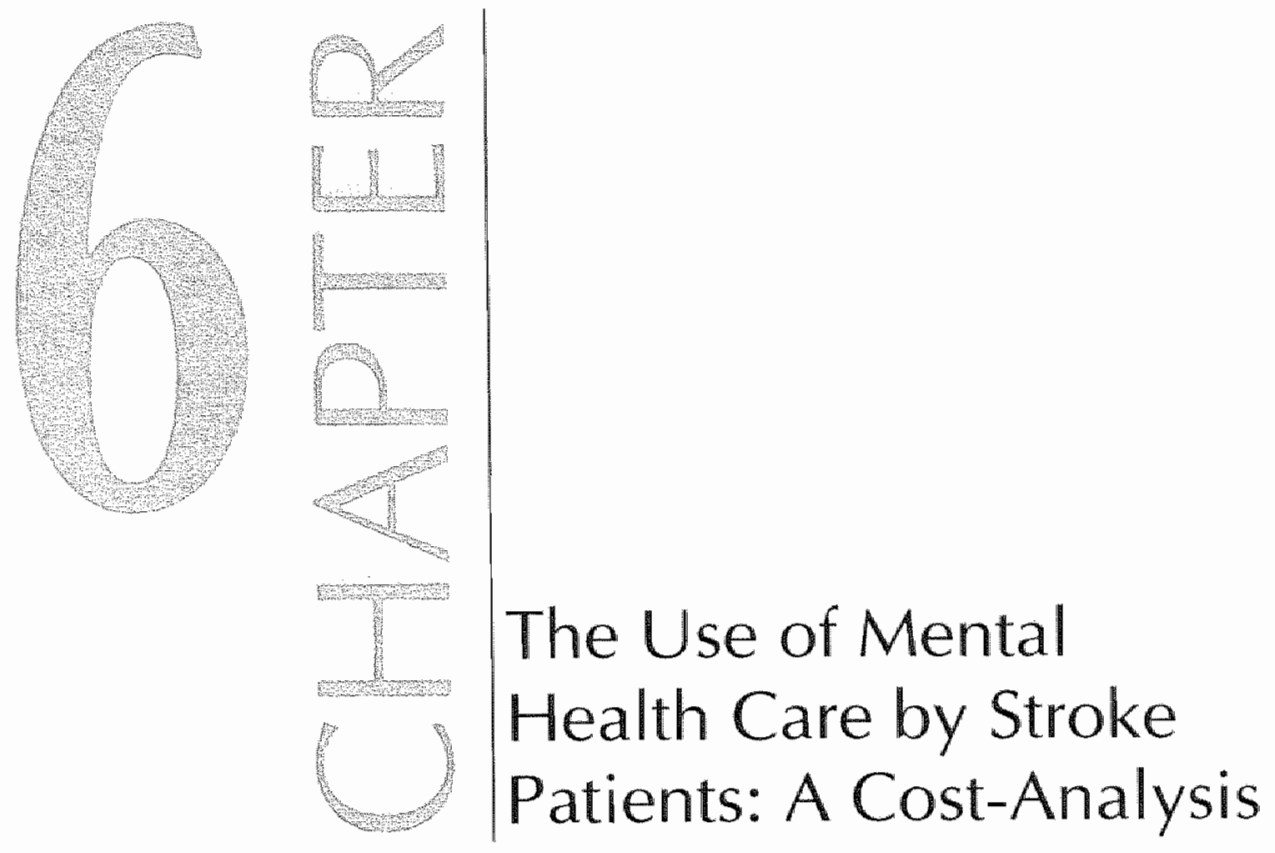





\section{Summary}

Although psychiatric comorbidity is relevant for a number of diseases, it is often ignored in technology assessment. This chapter examines the service use rate in mental health care facilities and related costs for stroke patients discharged from the University Hospital Maastricht between 1987 and 1995. Through anonymous record linkage, the medical registration of the hospital and the registration of the Maastricht Mental Health Case Register were linked. Linkage succeeded for $16 \%$ of the 2,020 stroke patients, indicating that these patients used mental health services during a 10-year period around the stroke ( \pm 5 years). Of the users group, $88 \%$ had a mental health care contact following stroke. Regression analysis shows that age, length of hospital stay, and mental health care contact before stroke are associated with mental health care use after stroke. It is remarkable that there is already an increase in the consumption of mental health care in the prodromal phase just before the stroke occurred. When comparing costs before and after stroke, the outpatient costs increase on average by $€ 43$, semi-institutionalised costs increase on average by $€ 208$, and intramural costs by $€ 1,189$. The total increase in costs is $e 1,440$. For all mental health care facilities, the increase in costs is significant. No study, so far, has revealed the total costs for use of mental health care facilities following stroke. Extrapolating these costs to the Netherlands illustrates that stroke patients have a high psychiatric comorbidity, inducing about $1.3 \%$ of total mental health care costs.

\subsection{Introduction}

When looking at morbidity, mortality, and costs, the impact of stroke on society is relatively high. The World Health Organisation (WHO) defines stroke as sudden signs of focal or global loss of neurological functions, which last longer than 24 hours, or cause death before then, with confirmed or suspected vascular origins'. Stroke has a significant social and economic impact on patients, their families, third-party payers and on society as a whole. In western countries, about $2-4 \%$ of total health care costs are devoted to stroke ${ }^{2}$. No study, so far, has revealed the total costs of psychiatric comorbidity following stroke ${ }^{3}$. The only available information is that about $1 \%$ of the costs of stroke patients during their hospital stay can be assigned to the Department of Psychiatry". 
However, medical outcome studies show that stroke is associated with psychiatric diseases. Mental problems encountered after stroke include affective disorders, dementia, anxiety disorders and personality disorders. This study examines the use of mental health facilities and costs associated with stroke. A more profound analysis of the related stroke prevalence in psychiatric disorders and the patterns of mental health care consumption using the same set of data is published elsewhere ${ }^{5}$. This chapter focuses on the economic aspect of psychiatric morbidity related to stroke. In addition, sociodemographic factors and length of hospital stay determinants for the use of mental health facilities by stroke patients are sought by looking at stroke diagnosis.

\subsection{Psychiatric morbidity related to stroke}

To gain insight into psychiatric morbidity related to stroke, a Medline literature search from 1966 through 1999 was conducted, combining thesaurus 'mental disorders' with 'cerebrovascular disorders'. In the literature, it is suggested that affective disorders, dementia, and anxiety disorders are encountered after stroke $^{6-39}$. Several studies also note a high percentage of coexistence between several psychiatric disorders related to stroke, especially between depression and anxiety disorders ${ }^{6.5 \%}$. It should be remarked, however, that most studies do not compare the results with control subjects. However, in the few studies in which such a comparison is made, a significant difference is found in psychiatric morbidity between the stroke population and the general population ${ }^{10,41}$.

Depression: Despite the fact that the relation between stroke and depression is frequently studied, findings are inconclusive ${ }^{12,13}$. The prevalence of Post Stroke Depression (PSD) found in various studies is widely variable ${ }^{12}$. In the studies reviewed, the percentage varies from $14 \%^{14}$ for major depression to $36 \%$ for all depressions ${ }^{15}$. These differences can be explained by variations in the diagnostic criteria used, in the follow-up period ${ }^{13}$, and in the characteristics of the study population. Furthermore, these figures may differ because neurological signs in stroke patients, such as aphasia and emotional lability, may both mask and mimic depression ${ }^{12,16_{0} 17}$. This means that diagnosing PSD is difficult, especially for non-psychiatrists such as the neurologists and neurosurgeons who in most instances perform the medical checkups ${ }^{18,19}$. For this reason, some investigators have suggested that PSD might be over- 
diagnosed due to changes in appetite, sleep, or sexual interest which are caused by stroke; others have suggested that PSD may be under-diagnosed because neurologists may deny symptoms of depression "In addition, the relation between stroke and depression might be reciprocal, as several studies found that a depressed mood is also associated with increased stroke mobidity and stroke mortality ${ }^{20-23}$.

Other affective disorders: Next to PSD, emotional lability and manic disorders have been studied in relation to stroke. Emotional lability is a common emotional behavioural syndrome following stroke and is probably a separate condition from PSD ${ }^{16,24}$. In a study that tried to determine the frequency of emotional lability following a first stroke, $18 \%$ of the patients had emotional lability ${ }^{16}$. The occurrence of mania following stroke is another recent area of investigation ${ }^{25}$. In comparison with depression, the occurrence of mania after stroke is relatively rare and is therefore illustrated only by case studies ${ }^{26,27}$.

Dementia: In the literafure ${ }^{28-35}$, the frequency of dementia after stroke varies from $6 \%^{32}$ to $32 \%$. As with affective disorders, this variation can be explained by differences in the diagnostic criteria used, in the follow-up period and in the study population. The Pohjasvaara study ${ }^{32}$ was illustrative, showing that the frequency of dementia in one population could vary from $25.5 \%$ using the DSM-III criteria, to $6.0 \%$ using the ICD-10 criteria ${ }^{32}$. Diagnosis is further hampered because some clinical markers for dementia, such as disorientation, are also persistent following stroke ${ }^{36}$. In addition, the occurrence of dementia may be overestimated, as in other psychiatric diagnoses, due to the fact that most studies rely on the diagnosis of dementia after stroke, without measurement of prestroke cognitive function ${ }^{1}$.

Anxiety disorders: Threatening events, such as stroke, are likely to be associated with anxiety, and it is therefore expected that an increased incidence of anxiety disorders follows stroke. Study results ${ }^{6,3,10,37,34}$ report a prevallence of generalised anxiety disorders (GAD) aner stroke ranging from $3 \%$ to $27 \%$. GAD is long lasting, as no significant decrease is seen in studies during a 3 year follow-up ${ }^{37}$. 


\subsection{Methodological aspects}

\subsubsection{RESEARCH QUESTIONS}

In sum, the literature shows that there is a correlation between stroke and mental disorders. To study post-stroke mental health care consumption, we have phrased three research questions:

1 What are the extra costs of mental healih care consumption after stroke, from the health care perspective?

2 To what extent can the difference between stroke patients who use mental health care after stroke and those who don't (AFTER vs. NONAFTER) be explained by such factors as mental health care use before stroke, stroke diagnosis (infarction, haemorrhage, TUA), sociodemographic factors (age, gender, living together), length of hospital stay, and discharge destination? And,

3 To what extent may the difference between low-cost users and high-cost users (LOWAFTER and HIGHAFTER) of these mental health facilities be explained by such factors as mental health care use before stroke, stroke diagnosis (infarction, haemorrhage. TIA), socio-demographic factors (age, gender, liwing together), length of hospital stay, and discharge destination?

\subsubsection{DATA SOURCE}

For this study, the medical registration of the University Hospital Maastricht and the regktation of the Mental Health Case Register were linked. Since 190*, whe Nastrich Mental Health Care Register (MHCR) ${ }^{40}$ has collected data cumblatwely on all mental health contacts the psychiatric hospital, the communty mendatheath centre, the psychiatric department of University Hospitew, community psychiatric outreach team, psycho-geriatric nursing homes, shehered housing, child psychiatric services, services for the mentally mparred, atcohol and drug abuse services etc.) and demographic and diagnostic data in a region with a population of around 200,000 (city of Madstrich: 120,000; surrounding areas: 80,000). For the current study, registered contacts with child psychiatric services, alcohol and drug abuse sevices which are separate from the general psychiatric services in the Netherands) and services for the mentally impaired were excluded. The University Hospital Maastricht is the only hospital in the city of Maastricht and 
the surrounding area with both a regional and a top-referral care function. At University Hospital Maastricht, all patients are registered with an $\| C D-9$ classification on discharge. Patients with an ICD-9 code of 430 to 438 have cerebrovascular diseases ${ }^{41}$. All stroke patients discharged from the University Hospital between 1987 en 1995 are included in this study. If patients were admitted more than once, only the first admission was considered in the analysis.

Initially, 4,913 clinical patients with ICD-9 code $430-438$ were selected for the study from the hospital registration in the period 1987 through 1995. Further inclusion in the study was based on the following criteria: patients coming from the Maastricht region, who did not die during their hospital stay (survivors) and who had a primary stroke diagnosis. This selection was necessary in order to obtain unpolluted data for our study. E.g. insight into post-stroke mental health care consumption is hampered if the patient comes from outside the Maastricht region (16.1\%), dies during the hospital stay $(20.4 \%)$, or if they have only a subsidiary stroke diagnosis $(37.2 \%)$. Because of this, only $41 \%$ of the original hospital registration data set was used for the analysis. In total, 2,020 patients were eligible for the study.

Through anonymous record linkage, this group of 2,020 patients from the registration of the University Hospital Maastricht was linked with the registration of the MHCR. The Medical Ethics Board approved this data linkage. The linkage was based upon the first letter of the family (maiden) name, gender, date of birth, residence and postcode of the general practitioner (identifiers). Experience from the MHCR and other studies showed that these identifiers give the best linkage, in which the chance of mistaken identity is minimal ${ }^{42}$. The group for which the linkage succeeded were regarded as USERS of mental health care facilities; the remaining group were regarded as NONUSERS of mental health care facilities. For the last two research questions, only those users who had a mental health care contact within the 10-year reference period ( 5 years before and after the stroke) were analysed.

\subsubsection{COST ANALYSIS}

In this study, only direct mental health care costs are considered, as no information is available regarding other costs. Direct health care costs include costs in terms of health care utilisation. The quantities in this study derive from the MHCR. Prices used reflect mean costs, which are based on figures provided by the Financial Statement of Care ${ }^{43}$. The Financial Statement of Care 
is a government publication that is presented to the Dutch Parliament together with the budget ${ }^{4}$. It gives an integrated overview of financial developments in the health care sector during recent years in addition to predictions for the coming year.

Table 1. Cost prices for the different mental health care facilities

\begin{tabular}{lll}
\hline Category & Volume & Price \\
\hline Psychiatric Hospital & Day & e 157 \\
Psychiatric Department of a University Hospital & Day & $e 193$ \\
Psychiatric Department of a Nursing Home & Day & $e 126$ \\
Psychiatric Day Care & Contact & $\in 106$ \\
Community Mental Health Centre & Visit & $e 71$ \\
Sell-emplloyed Psychiatrists & Visit & $e 74$ \\
Outpatient Visit Psychiatric and General Hospital & Visit & $e 52$ \\
\hline
\end{tabular}

All cost data used refer to the year 1995. Based on this publication, we calculated mean prices, which were checked by financial experts in several institutions (see acknowledgements). Overall the calculated mean prices matched the cost figures of these institutions; only the costs of the Community Mental Health Centre differed from those reported in the Financial Statement of Care. Table 1 shows all-inclusive costs per unit in Euros, which were used in the study for the relevant mental health care facilities.

\subsubsection{VARIABLES}

Neither of the registrations were especially devised for this study. As a result, only a limited number of variables were available. The following variables are included in the analysis:

\subsubsection{Dependent variable}

Costs were measured using the MHCR registration. If patients contacted an outpatient, semi-institutionalised (e.g. day-care), or inpatient facility, their contact was registered. Using the procedures described in the paragraph on cost analysis, these data were transformed into costs. 


\subsubsection{Independent variables}

Socio-demographic factors: Socio-demographic factors included age, gender, and living arrangements. Age refers to age (in years) at admission. Gender was coded 1 for female and 0 for male. We used the term 'living arrangements' to distinguish between people who were living together (1) and people who were living alone (0).

Previous mental health care: The use of mental health care facilities before the stroke in unit prices was also measured for outpatient, semi-institutionalised and inpatient facilities.

Hospital factors: The diagnosis upon discharge from the hospital was measured using the ICD-9 classification. For further analysis, patients were divided into infarctions, haemorrhages, TIA and other strokes. Length of hospital stay refers to the number of days between admission and discharge, including both the admission day and the discharge day. Discharge status is described using several categories. These include home, homes for the elderly, other hospital, nursing home, rehabilitation centre, psychiatric hospital, other institutions, died with or wilthout autopsy, unknown, and went home against medical advice. As most stroke patient are discharged to a home situation, these variables were dichotomised into discharged to home and discharged not to home. The discharge specialist gives an indication of the discipline that is most closely related to the patient's treatment. In most instances this would be neurology, but this study also took into account whether patients were discharged by a psychiatrist (1) or by any other specialist ( 0 ).

\section{3 .5 DATAANALYSIS}

To explore the difference between the several subgroups, a twest was used for continuous variables, and for binary variables a Mann-Whitney test was employed. For the first research questions, it appeared that the differences in cost before and after the stroke are non-normally and asymmetrically distributed; therefore the non-parametric SICN-test for two-related samples was used. As is also noted in other studies", mental health care costs in this study are heavily skewed to the right due to a minority of stroke patients who account for the majority of the costs. However, applying the square root logtransformation of the costs did not result in a normal distribution of the costs. In order to explain the difference between AFTER users and NONAFTER Users (research question 2), and between HIGHAFTER users and LOWAFTER users 
(research question 3) the cost had to be dichotomised. A logistic regression analysis was used to answer these last two research questions. Categorical and ordinal variables were transformed into dummies. Variables were entered into a logistic regression analysis using backward stepwise selection. A p-value of $s$ 0.05 was considered as statistically significant.

\subsection{Results}

\subsubsection{SUBJECTS AND SELECTION}

A total of 2,020 primary stroke survivors from the Maastricht region are included in the study. Of this patient group, $18.7 \%(n=3.77)$ had contact with the MHCR at any time, e.g. stroke patients for whom the linkage succeeded on the previously mentioned identifiers: the so-called USERS. The remainder of the group were regarded as NON-USERS.

Figure 1. USERS and NONUSERS of mental health care and moment of contact $(n=2,020)$

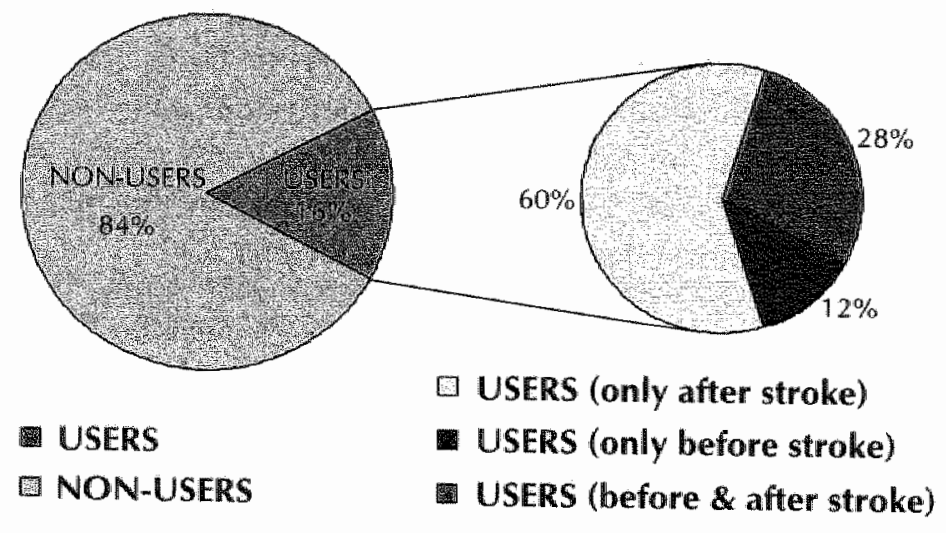

The major part of this USERS group, 317 out of 377 , had contact within a 10year reference period around the stroke ( \pm 5 years). As Figure 1 shows, $60 \%$ of this USERS group had a mental health care contact following stroke, $28 \%$ had contact before and after the stroke, and $12 \%$ had contact with the mental health care facility only before the stroke. 


\subsubsection{MENTAL HEALTH CARE CONSUMPTION}

Figure 2 shows that in comparing the five years before stroke hospital admission with the five years after stroke hospital admission, mental health care costs rise. When comparing the costs before and after stroke, the outpatient costs increase on an average by $€ 43$, the semi-institutionalised costs on an average by $€ 208$, and the intramural costs by $€ 1,189$. The total increase in costs is $€ 1,440$. For all mental health care facilities, the increase in costs is significant for outpatient care (standardised $z$ value is -6.543 , two-sided $P$. value $<.001)$; for semi-institutionalised care $(z=-3.320$ and $P$-value $<.001)$; for inpatient care $(z=-5.700$ and $P$-value $<.001)$; for total care $(z=-8.986$ and $\mathrm{P}$-value $<.001)$. This figure also illustrates that there is a shift towards more intensive care. It is remarkable that there is already an increase in mental health care consumption in the prodromal phase just before the stroke occurred.

Figure 2. Average mental health care costs (EUR) all stroke patients $(n=2,020)$

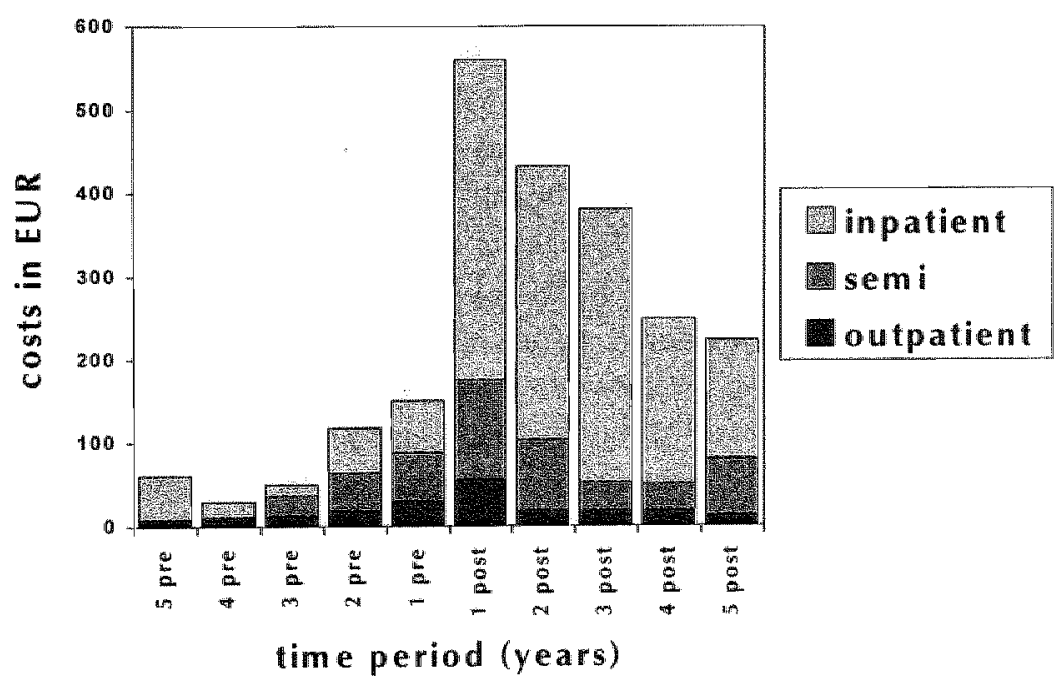

Note: Changes tested by using a non -parametric SIGN-test for two-related samples; outpatient, semi-institutional ised and inpatient costs increased significantly.

In comparison with the $5^{\text {th }}$ year before the attack, the total costs increase twoand-a-half times, to $€ 150$ in the last year before the stroke. In the first year 
following the stroke, the costs increase to $€ 561$, and these costs finally decrease to $€ 223$ in the five year follow-up period.

As a check, the costs of the mental health care episode of stroke patients are compared with the costs of the mental health care episode for non-stroke patients of the same average age. These data are also derived from the MHCR. A mental health care episode is a period in which a patient continuously consumes mental health care (limited by 90 or more days without mental health carel. This comparison indicates that the episode costs of mental health care for stroke patients are significantly higher - $€ 24,768$ - as compared to the mental health care episode costs for non-stroke patients, which on the average are $\mathrm{e} 18,439$.

\subsubsection{AFTER AND NONAFTER USERS}

For further analysis of research question 2, those (before \& after-users and only after users) who used mental health care facilities after stroke (AFTER) are compared with the groups who did not use mental health facilities after stroke (NONAFTER), i.e. the non-users and the only before users.

Table 2 presents means and standard deviations for the characteristics for the several subgroups in our population. The average age of the study population was 71 years, and in general there was an equal distribution over the sexes. The AFTER users have a significantly higher age (2.7 years older) in comparison with the NONAFTER users. The patients included have a mean length of hospital stay of 24.3 days, which is comparable to the national figures for stroke. Of the total study group, $6.3 \%$ of the stroke patients had mental health care contact before their stroke; not surprisingly, this percentage is significantly higher $(32.0 \%)$ in the AFTER users than in the NONAFTER users $(2.2 \%)$. AFTER users had a significantly longer length of hospital stay (37 days) in comparison with NONAFTER users ( 22 days). The majority of patients can be categorised as having had a cerebral infarction. Stroke patients who used mental health care after their attack were more likely to be diagnosed as having a haemorrhage instead of an infarction. For most patients $(55.1 \%)$, the Department of Neurology was responsible for treatment during their hospital stay; only a small percentage of patients were under the responsibility of a psychiatrist. However, if patients were discharged by a psychiatrist, they were more likely to consume mental health care after stroke, indicating that psychiatric comorbidity is already recognised in the hospital. On being discharged, four-fifths of the patients return to a home situation. 
Table 2. Exploratory statistics of the four subgroups of the population

\begin{tabular}{|c|c|c|c|c|c|c|c|}
\hline & $\begin{array}{l}\text { Total group } \\
n=2,020\end{array}$ & $\begin{array}{l}\text { NON } \\
\text { AFTER } \\
n=1,742\end{array}$ & $\begin{array}{l}\text { AFTER } \\
n=278\end{array}$ & $\begin{array}{l}\text { P. } \\
\text { value* }\end{array}$ & $\begin{array}{l}\text { LOW } \\
\text { AFTER } \\
n=139\end{array}$ & $\begin{array}{l}\text { HIGH } \\
\text { AFTER } \\
n=139 \\
\end{array}$ & P-value* \\
\hline Age & $71.1(13.3)$ & $70.7(13.4)$ & $73.4(12.7)$ & $.002^{*}$ & $70.9(14.2)$ & $75.8(10.5)$ & $.001 *$ \\
\hline $\begin{array}{l}\text { Gender } 1 \% \\
\text { male) }\end{array}$ & 50.5 & 51.0 & 47.5 & .279 & 46.8 & 48.2 & .811 \\
\hline $\begin{array}{l}\text { Living together } \\
(\%) \text { ) }\end{array}$ & - & - & - & - & 45.3 & 32.1 & $.028 *$ \\
\hline $\begin{array}{l}\text { Mental health } \\
\text { before }(\%)\end{array}$ & 6.3 & 2.2 & 32.0 & $<.001^{*}$ & 23.0 & 41.0 & .001 \\
\hline $\begin{array}{l}\text { Length of } \\
\text { hospital stay }\end{array}$ & $24.3(29.0)$ & $22.2(23.0)$ & $37,2(51.3)$ & $<.001^{*}$ & $25.1(27.5)$ & $49.4(65.1)$ & $<.001^{*}$ \\
\hline Infarction (\%) & 24.2 & 25.1 & 18.3 & $.015^{*}$ & 18.7 & 18.0 & .877 \\
\hline $\begin{array}{l}\text { Haemorthage } \\
(\%)\end{array}$ & 14.6 & 13.9 & 18.3 & .054 & 18.7 & 18.0 & .877 \\
\hline$T \mid A(\%)$ & 9.7 & 9.6 & 9.7 & .972 & 10.8 & 8.6 & .544 \\
\hline $\begin{array}{l}\text { Other diagnoses } \\
(\%)\end{array}$ & 51.6 & 51.3 & 53.6 & .481 & 51.8 & 55.4 & .548 \\
\hline Neurology $(\%)$ & 55.1 & 56.0 & 49.6 & $.047^{*}$ & 52.5 & 46.8 & .338 \\
\hline Psychiatrist (\%) & 1.0 & 0.5 & 4.3 & $<.001 *$ & 0.0 & 8.6 & $<.001 \%$ \\
\hline $\begin{array}{l}\text { Discharged to } \\
\text { home }(\%)\end{array}$ & 80.5 & 81.0 & 77.7 & .197 & 86.3 & 69.1 & $.001 \%$ \\
\hline
\end{tabular}

Age and Length of hospital stay Independent Samples T-test; other Independent Samples MannWhitney U-test

* A p-value of $s 0.05$ was considered as statistically significant.

In order to answer our second research question, variables were entlered into a logistic regression analysis with AFTER users (1) as the dependent variable, compared to NONAFTER users (0). Logistic regression results of the situdy population are presented in Table 3 . The odds ratios indicate the change in consumption of mental health care after stroke. Odds ratios above 1 enhance a positive relation between the variables and mental health care after stroke. Odds ratios of less than one indicate a negative association; if the odds ratio equalls one there is no association between the variable and mental health care consumption. Not surprisingly, the main factor explaining whether patients have mental health care after stroke is if they already consumed mental health care betore the stroke. Other factors indicating that stroke patients are more likely to consume mental health care after stroke are high age, a long hospital stay and if a psychiatrist discharges them. If a patient has an infarction, as 
opposed to haemorrhage, (s)he is less likely to consume mental health care after her/his stroke.

Table 3. Logistic regression analysis of the AFTER versus the NONAFTER users

\begin{tabular}{lrrrr}
\hline & $\beta$ & S.E. & P-value & Odds ratio \\
\hline Discharged by psychiatrist & .974 & .576 & .091 & 2.649 \\
Age & .015 & .006 & .010 & 1.016 \\
Diagnosis infarction & -.528 & .186 & .005 & 0.590 \\
Length of hospital stay & .009 & .002 & $<.001$ & 1.009 \\
Mental care betore & 2.932 & .216 & $<.001$ & 18.760 \\
Constant & -3.459 & .445 & $<.001$ & \\
\hline
\end{tabular}

\section{Goodness of fit}

Initial log-likelihood function

Final log-likelihood function

Model improvement (Chi-squared)

$\mathrm{R}^{2}$

Correct classification $(\%)$

- Noni-after group 101

- After group (1)

- Overall
1340.987

13.45 .207

$273.324 \quad(\mathrm{P}<.001)$

.230

98.0

32.0

88.9

Regarding research question 2, on the main factors explaining the difference between stroke patients who use mental health care after stroke and those who don't, the explained variance is low $\left(R^{2}=23 \%\right)$. The current model gives a significantly better fit of the data, in which overall $88.9 \%$ of the patients are classified correctly; the correct classification is also relatively low (32\%) for the AFTER group.

\subsubsection{HIGH COST USERS AND LOW COST USERS}

In our final research question, high cost users after stroke (HIGHAFTER) are compared to low cost users after stroke (LOWAFTER). The cut-off-point (2 equal groups, percentile 50) was total mental health care costs of $e 1,300$ after the stroke.

Table 2 also gives the main characteristics of both groups, showing that high costs users are older (by 4.9 years), and more likely to be living alone. As might be expected, the HICHAFTER group were more likely to have consumed mental health care before their stroke. Also, the length of hospital stay is longer than for the LOWAFTER group. Furthermore, high cost users were likely to be discharged by a psychiatrist, and less likely to be discharged to a home situation. 
Table 4. Logistic regression analysis of the HIGHAFTER versus the LOWAFTER users

\begin{tabular}{|c|c|c|c|c|}
\hline & $\beta$ & S.E. & P-value & Odds ratio \\
\hline Discharged to home & .775 & .338 & .022 & 2.171 \\
\hline Discharged by psychiatrist & 6.890 & 10.369 & .506 & 982.397 \\
\hline Age & .029 & .011 & .010 & 1.029 \\
\hline Length of hospital stay & .006 & .004 & .091 & 1.006 \\
\hline Mental care before & .680 & .295 & .021 & 1.975 \\
\hline Constant & -.3 .3235 & .843 & .001 & \\
\hline \multicolumn{5}{|l|}{ Goodness of fit } \\
\hline Initial log-likelihood function & 332.342 & & & \\
\hline Final log-likelihood function & 335.777 & & & \\
\hline Model improvement (Chi-squared) & 49.613 & $(P<.001)$ & & \\
\hline $\mathrm{R}^{2}$ & .218 & & & \\
\hline \multicolumn{5}{|l|}{ Correct classification $(\%)$} \\
\hline - Law costs group (0) & 76.3 & & & \\
\hline - High costs group (1) & 55.4 & & & \\
\hline - Overall & 65.8 & & & \\
\hline
\end{tabular}

Table 4 shows the regression results regarding the difference between the lowcost users and the high-cost users. The explained variance of the model diffierentiating between high and low costs is low, i.e. $22 \%$. The strongest relationships statistically emerge with respect to patients discharged to a home situation (as opposed to being discharged to an institution), high age, a long hospital stay and the use of mental health care before the stroke.

Although the logistic regression analysis showed some improvement, the overall correct classification $(76.3 \%)$ in this model is even lower than in the previous research question.

\subsection{Conclusion and discussion}

This study was initiated as a result of a cost-of-illness study showing that little information was available regarding the use of mental health care facilities following stroke $e^{3}$. In accordance with the literature, this study illustrates that there is a correlation between stroke and mental disorders. The most important result of the present study, however, is that it is the first to give an impression of the additional mental health care costs following stroke. Psychiatric comorbidity is thus a relevant problem in stroke, although it is usually ignored in economic evaluation studies. 
In our study, about $16 \%$ of survivors admitted to hospital with a diagnosis of primary stroke had a mental health care contact within the reference period of 10 years ( \pm 5 years attack). Of this group, about $88 \%$ had a mental health contact following the stroke. Outpatient, semi-institutionalised as well as inpatient mental health care costs increased significantly after the stroke. In the five years following the stroke, compared with the five years before the stroke, the costs increase on an average of $e 1,440$ for all stroke patients in our study. It is striking that there is already an increase in mentall health care consumption in the prodromal phase just before the stroke occurred. This might possibly be explained by the fact that stroke patients may have had a less serious stroke or TIA before being hospitalised. In addition, the average mental health care episode costs for stroke patients are significantly higher as compared with mental health care episode costs for non-stroke patients. This might indicate that stroke patients not only consume more mental health care, but also more intensive mental health care.

Extrapolating this cost figure of $€ 1,440$ to the Dutch situation indicates that mental health after stroke is a relevant problem. In the Netherlands, the annual incidence of stroke is estimated at $174 / 100,000$, of which $83 \%$ are first strokes, i.e. $145 / 100,000^{45}$. In the period from 1987 through 1994, on the average 27,069 stroke patients were discharged (including those who died) from the hospital. For the extrapolation it is assumed that $83 \%$ of these patients had first strokes; this would result in 22,558 first stroke patients per year. On average, $81 \%$ of this group survived the hospital stay, resulting in 18,272 first stroke patients who survived the hospital. If the average costs and the admission rates remain stable, this would result in about $€ 26$ million extra costs related to stroke. In 1995, the total mental health care budget was $\in 1,963$ million. The extra costs per year for stroke, limited to those patients who were hospitalised and survived, would thus amount to $1.3 \%$ of the annual mental health care budget in the Netherlands in 1995.

Based on the variables of the study, it is difficult to explain the variance between patients who use mental health care after stroke and those who do not, and between the high cost and the low cost users. Current data illustrate that older stroke patients who live alone and who had a mental health care history before the stroke are at risk for mental health care consumption after stroke; this last correlation is also illustrated in other studies ${ }^{4}$. The finding that stroke patients with high mental health care costs after the stroke are more likely to have been discharged by a psychiatrist illustrates that the psychiatric comorbidity is already recognised in the hospital. The longer length of hospital 
stay for those who use mental health care after stroke might indicate problems related to blocked beds; i.e. stroke patients may stay relatively long in the general hospital due to non-medical reasons, such as having to wait for place in mental health care facilities. Further research on this subject, but with a more extensive database, is needed, particularly as our data analysis lacks an indication of the psychiatric diagnoses.

The results of this study are based on a probability record linkage of two prospectively collected data sources. Both linkage and data analysis are based on conservative assumptions. However, it should be remarked that this study may suffer from some methodological limitations. The study is based on secondary data analysis. The two data sources used are the medical registration of the University Hospital Maastricht and data of the Mental Health Care Register, which recruit patients from the same limited area. Due to regulations, the data of both registers had to be anonymous. L inkage was based on the first letter of the family (maiden) name, gender, date of birth, residence, and postcode of the general practitioner (identifiers). Although this linkage may be criticised, former research utilising the MHCR showed that these identifiers give the best linkage, in which the chances of misidentification are minimal ${ }^{42}$. Furthermore, the assumption underlying this study is that there is a causal relation between stroke and mental health care problems. One of the main limitations of the current design of this study is that it is impossible to give enough evidence for this relationship. Although the literature suggests a logical chain from stroke to mental health care, this does not rule out the possibility of a common cause for both stroke and mental health care (for instance, advanced age), or even a reciprocal relation, as many patients had a history of mental care close to or even before the stroke. Further research in this field is needed. In addition, due to practical considerations, the calculation of cost per unit is limited to the Financial Statement of Care as a cost source. Also, this study is limited to mental health care costs, leaving out other aspects related to psychiatric comorbidity and stroke. In addition, no attention has been paid to other possible comorbidities in relation to stroke.

Meanwhile, we believe that these limitations do not invalidate the conclusion that can be drawn from the current results, indicating that stroke patients have a high psychiatric comorbidity related to additional costs in the mental health care sector. 


\section{Acknowledgements}

This chapter was presented at the Annual Meeting of the International Society for Technology Assessment in Health Care in The Hague, the Netherlands, June $18-21,2000$. The authors gratefully acknowledge the statistical guidance of Math Candel (Maastricht University, Dept. of Methods and Statistics). We thank Marielle Goossens (Institute for Rehabilitation Research), Jan Lodder (University Hospital Maastricht, Dept. of Neurology), lim van Os (Maastricht University, Dept. of Psychiatry and Neuropsychology), and Frans Verhey (University Hospital Maastricht, Dept. of Psychiatry and Neuropsychology) for support and review. We would like to recognise Math Habets for his help with the data collection; Jack Bibo (University Hospital Maastricht), Mayke Derix (Psychiatric Hospital Vijverdal, Maastricht), and Henk Bayer (Community Mental Health Centre) for checking the cost-price calculations.

\section{References}

1. World Health Organization (WHO). Stroke 1989 Recommendations on Stroke Prevention, Diagnosis and Therapy Report of the WHO task force on stroke and Other Cerebrovascular Disorders. Stroke 1989;20:1 407-31.

2. Evers SMAA, Goossens MEJB, Ament AJHA, Maarse JAM. Economic evaluation in stroke research; an introduction. Cerebrowas Dis 2001;10:283-8.

3. Evers SMAA, Engel GL, Ament AIHA. Cost of stroke in the Netherlands. Stroke $1997 ; 28: 1375-81$.

4. SBU. Chapter 12 Economics. In: Maghusson S, Werkö L, editors. Stroke. Stockholm: The Swedish Council on Technology Assessment in Health Care: 1992.

5. Driessen $G$, Evers $S$, van Os J. Stroke and Mental Health Care: A Record Linkage Study. Soc Psychiatty Psychiatr Epidemiol 2001; submitted for publication.

6. Burvill PW, Johnson GA, Jamrozik KD, Anderson CS, Stewart Wynne EG, Chakera TM. Anxiety disorders after stroke: results from the Perth Community Stroke Study. Bif I Psychiatry 1995:166:328-32.

7. Burvill PW, Johnson $\mathrm{GA}$, Jamrozik $\mathrm{KD}$, Anderson $\mathrm{CS}$, Stewart Wynne $\mathbb{E G}$, Chakera TM. Prevallence of depression after stroke: the Perth Community Stroke Study. Br J Psychiatry 1995;166:320-7.

8. Castillo CS, Starkstein SE, Fedoroff JP, Price TR, Robinson RG. Generalized anxiety disorder after stroke. I Nerv Ment Dis 1993;181:100-6. 
9. Schultz SK, Castillo CS, Kosier IT, Robinson RG. Generalized anxiety and depression. Assessment over 2 years after stroke. Am I Ceriatr Psychiatry $1997 ; 5: 229-37$.

10. House A, Dennis M, Mogridge L, Warlow C, Hawton K, Jones L. Mood disorders in the year after first stroke. Br J Psychiatry 1991;158:83-92.

11. Kase CS, Wolf PA, KellyHayes M, Kannel WB, Beiser A, RB DA. Intellectual decline aiter stroke: The Framingham Study. Stroke 1998;29:805-12.

12. Johnson GA. Research into psychiatric disorder after stroke: the need for further studies. Aust N Z | Psychiatry 1991;25:358-70.

13. Hosking SG, Marsh NV, Friedman PJ. Poststroke depression: prevalence, course, and associated factors. Neuropsychol Rev 1996;6:107-33.

14. Robinson RG, Bolduc PL, Price TR. Two-year longitudinal study of poststroke mood disonders: diagnosis and outcome at one and wo years. Stroke $1987 ; 18: 837-43$.

15. Herrmann $M$, Bartels $C$, Schumacher $M$, Wallesch $C W$. Poststroke depression. Is there a pathoanatomic correlate for depression in the postacute stage of stroke? Stroke 1995;26:850-6.

16. Morris PL, Robinson RG, Raphael B. Emotional lability after stroke. Aust N Z I Psychiatry 1993;27:601-5.

17. Sambunaris A, Hyde TM. Stroke-related aphasias mistaken for psychotic speech: two case reports. I Geriatr Psychiatry Neurol 1994;7:144-7.

18. Godderis I. De psychiatrische verschijnselen bij en na een acuut CVA. Tijdschr $v$ Gerontologie en Geriatrie 1983;14:157-63.

19. Schubert DS, Taylor C, Lee S, Mentari A, Tamaklo W. Detection of diepression in the stroke patient. Psychosomatics 1992;33:290-4.

20. Morris PL, Robinson RG. Andrzejewski P, Samuels 1, Price TR. Association of depression with 10-year poststroke mortality. Am J Psychiatry 1993;1 50:124-9.

21. Schubert DS, Taylor $C$, Lee $S$, Mentari A, Tamaklo W. Physical consequences of depression in the stroke patient. Gen Hosp Psychiatry 1992;14:69-76.

22. Sharpe M, Hawton K, Seagroatt V, Bamford 1, House A, Molyneux A, Sandercock $P$, Warlow $C$. Depressive disorders in long-term survivors of stroke. Associations with demographic and social factors, functional stlatus, and brain lesion volume. Br J Psychiatry 1994;164:380-6.

23. Morris PL, Raphael B, Robinson RG. Clinical depression is associated with impaired recovery from stroke. Med J Aust 1992;157:239-42.

24. House $A$, Dennis $M$, Molyneux $A$, Warlow $C$, Hawton $K$. Emotionalism after stroke. BMI 1989;298:991-4. 
25. Robinson RG, Starkstein SE. Mood disorders following stroke: new findings and fulure directions. I Geriatr Psychiatry 1989:22:1-15.

26. Berthier ML. Post-stroke rapid cycling bipolar affective disorder. Br I Psychiatry $1992 ; 160: 283$.

27. Starkstein SE, Robinson RG. Affectiwe disorders and cerebral vascular disease. $\mathrm{Br}$ ! Psychiatry 1989;154:170-82.

28. Censori $B$, Manara $O$, Agostinis $C$, Camerlingo $M$, Casto $L$, Galavotti $B$, Partziguian T, Servalli MC, Cesana B, Belonni G, Mamoli A. Dementia after first stroke. Stroke 1996,27:1205-10.

29. Desmond DW, Bagiella E, Moroney IT, Stern $Y$. The effect of patient attrition on estimates of the frequency of dementia following stroke. Arch Neurol $1998 ; 55: 390-4$.

30. Kokmen E, Whisnant JP, O'Fallon WM, Chu CP, Beard CM. Dementia after ischemic stroke: A population-based study in Rochester, Minnesota (1960-1984). Neurology 1996;46:154-9.

31. Pohjaswaara T, Erkinjuntti T, Vataja R, Kaste M. Comparison of stroke features and disability in daily life in patients with ischemic stroke aged 55 to 70 and 71 to 85 years. Stroke 1997:28:729-35.

32. Pohjasvaara $T$, Erkinjuntti $T$, Vataja $R$, Kaste M. Dementia three months after stroke. Baseline frequency and effect of different definitions of dementia in the Helsinki Stroke Aging Memory Study (SAM) cohort. Stroke 1997:28:785-92.

33. Pohjaswaara T, Erkinjuntli T, Ylikoski R, Hietanen M, Vataja R, Kaste M. Clinical determinants of poststroke dementia. Stroke 1998;29:75-81.

34. Tatemichi TK, Foulkes MA, Mohr JP, Hewitt JR, Hier DB, Price TR, et al. Dementia in stroke survivors in the Stroke Data Bank cohort. Prevalence, incidence, risk lactors, and computed tomographic findings. Stroke 1990;21:858-66.

35. Tatemichi TK, Desmond DW, Mayeux $R$, Paik $M$, Stern $Y$, Sano $M$, et al. Dementia after stroke: baseline frequency, risks, and clinical features in a hospitalized cohort. Neurology 1992;42:1185-93.

36. Desmond DW, Tatemichi TK, Figueroa M. Groben TI, Stern Y. Disorientation following stroke: frequency, course, and clinical correlates. I Neurol 1994; $241: 585-91$.

37. Astrom M. Generalized anxiety disorder in stroke patients. A 3-year longitudinal study. Stroke 1996:27:270-5.

38. Morris PL. Robinson RG, Raphael B. Prevalence and course of depressive disorders in hospitalized stroke patients. Int I Psychiatry Med 1990;20:349-64. 
39. Starkstein SE, Bohen BS, Fedoroff P, Parikh RM, Price TR, Robinson RG. Relationship between anxiety and depression disorders in patients with cerebrovascular injury. Arch Gen Psychiatry 1990:47:246-51.

40. Hamers $H J F R$, Romme MAJ, De Vries MW. Resistance, privacy and technology: comments on the negotiations of the case register in Mastricht. In: Ten Horn, Giel, Gulbinat, Henderson, editors. Psychiatric Case Registers in Public Health. Maastricht: Elsevier; 1986.

41. Centrum voor informatieverwerking voor de Nederlandse ziekenhuizen (SMR). Classificatie van ziekten 1980; gebasseerd op de International Classification of Diseases, 9 th revision, Clinical Modification (ICD-9-CM). Utrecht: Stichting Medische Registratie; 1981.

42. Sytema S. Patterns of Mental Health Care. Groningen: Drukkerij Van Denderen B.V.; 1994.

43. Tweede Kamer der Staten-Generaal. Financieel Overzicht Zorg (FOZ), 1996. Den Haag: Staatsdrukkerij/ Uitgeverij; 1995.

44. Korkeila JA, Lehtinen V, Tuori T, Helenius H. Frequently hospitalised psychiatric patients: a study of predictive factors. Soc Psychiatry Psychiatr Epidemiol $1998 ; 33: 528-34$.

45. Herman B, Leyten AC, van Luijk JH, Frenken CW, Op de Coul AA, Schulte BP. Epidemiology of stroke in Tilburg, the Netherlands. The population-based stroke incidence register: 2 . Incidence, initial clinical picture and medical care, and three-week case fatality. Stroke 1982;13:629.34. 



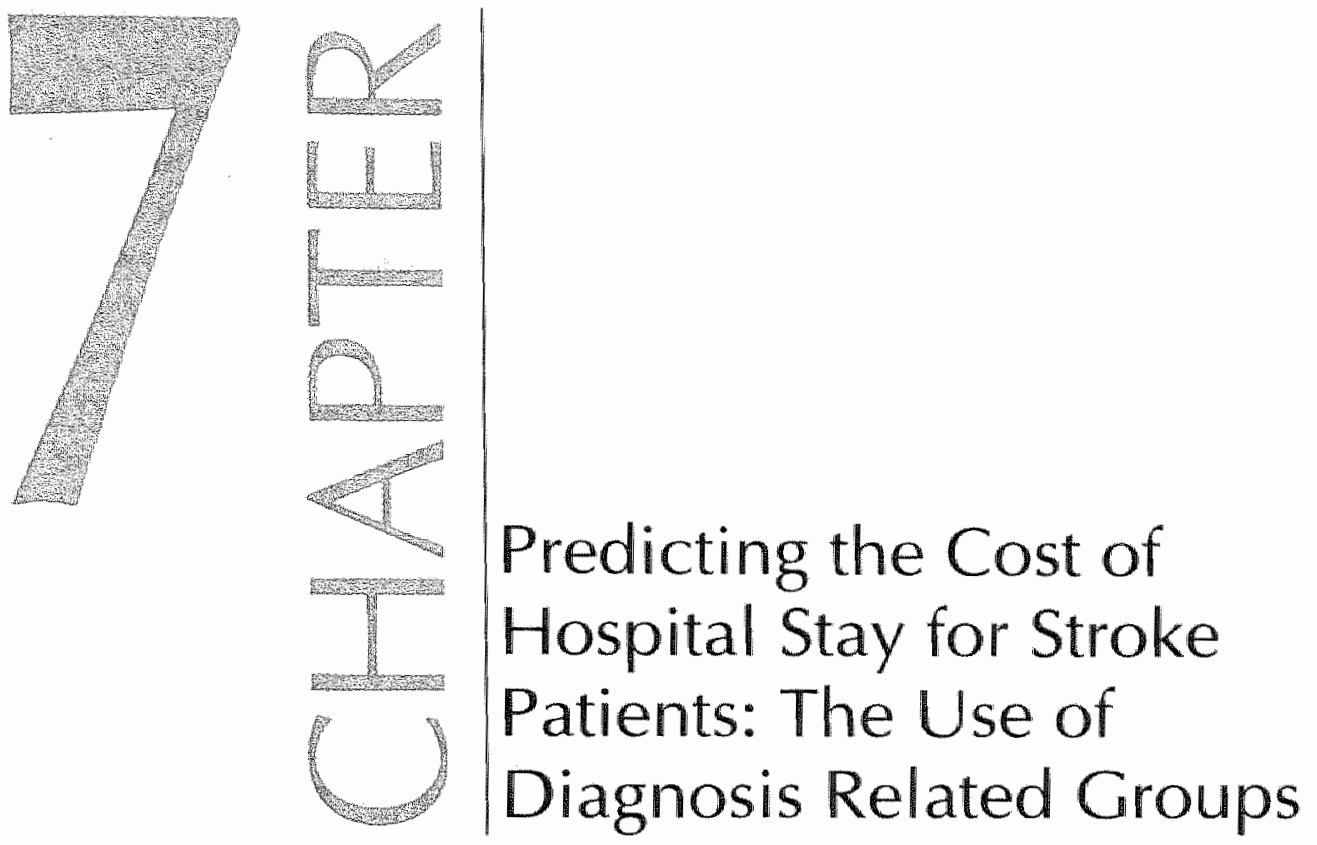





\section{Summary}

In order to provide tailor-made care, governments are considering the implementation of output-pricing based on hospital case-mix measures, such as Diagnosis Related Groups (DRGis). The question is whether the current DRG classification system can provide a satisfactory prediction of the variance of costs in stroke patients and if not, in what way other variables may enhance this prediction. In this chapter, data from 731 stroke patients hospitalised at University Hospital Maastricht during 1996 to 1998 are used in the cost analysis. The DRG classification for this group uses information - in addition to the DRG classification operation or no operation - on the patient's age combined with discharge status. The results of regression analysis show that using DRGs, the variance explained in the total costs amounts to $34 \%$. Adding other variables to the DRGs, the variance explained increases to about $61 \%$. Additional factors highly correlating with impatient costs are the level of functioning after stroke, comorbidity, complications, and 'days of stay for nonmedical reasons'. Costs decreased for stroke patients discharged during the latter part of the years studied, and if stroke patients happened to die during their hospital stay. The results do suggest that future implementation of outputpricing based on the DRG case-mix measures is feasible for stroke patients only if it is enhanced with information on complications and the level of functioning.

\subsection{Introduction}

In the Netherlands, 9 to $10 \%$ of the annual gross national product is spent on health care. Cost containment in the health care sector has been an important political issue since the late $1970 \mathrm{~s}^{1.3}$. As a result, strong emphasis has been put on control on the supply side, e.g. containment of the volume of health care facilities rules supreme'. Consequently, during the last decade, Dutch hospitals have been subject to extensive and frequently changing government regulations on reimbursement. Currently, the Netherlands has a fixed functional budgeting system consisting of three budget components: an availability component (size of the clinical catchment area), a capacity component (number of beds, medical specialists), and a production component (number of hospital admissions, inpatient days, first outpatient visits and day-care visits $)^{3}$. 
The general consequence of changes in the reimbursement system was to increase the financial responsibility of hospitals. This growing responsibility, together with increased inter-hospital competition and negotiations with insurers, places greater demands on cost information systems; e.g. these systems now have to go beyond the regular hospital cost accounting systems that sufficed in the past ${ }^{2}$.

In recent years it has become obvious in the Netherlands that the current fixed functional budgeting system does not meet current needs. The main problems are that the current system is not transparent and that its components leave little room for reimbursement based on aclual activities ${ }^{5}$. Therefore, the Dutch government is now considering the implementation of output-pricing based on hospital case-mix measures, e.g reimbursement based on market prices calculated on a combination of diagnoses and treatments, in the Netherlands, a new patient-classification system called 'Diagnose-BehandelCombinaties (DBCs) ${ }^{\prime}$ is being developed ${ }^{4,5}$. In most other Western countries, similar problems have been encountered, leading to the consideration of a Diagnosis Related Groups (DRG) system for reimbursement purposes ${ }^{6 \%}$. The DRG system ${ }^{10-13}$ is thus a well-known case-mix measure for reimbursement purposes. At University Hospital Maastricht, a DRG-based cost accounting system has already been implemented. Based on the experience of using this DRG-cost accounting system for local in-hospital budgeting, the question arises of how suitable this system is for reimbursement costing. To identify and understand some of the problems associated with a DRG hospital financing system, DRG cost data for a selected group of hospitalised patients will be studied: in this case patients with stroke. Stroke is defined as rapidly developed clinical signs of focal (or global) disturbance of cerebral function, lasting more than 24 hours or leading to death, with no apparent cause other than vascular $\operatorname{origin}^{\mid 4,15}$. The main reason stroke patients have been analysed is that treatment of stroke patients has a major impact on hospital expenditures. In western countries, stroke patients generate about $3-4 \%$ of costs within the health care sector ${ }^{16,17}$. After an attack, most stroke patients are admitted to a hospital ${ }^{18,15}$, and about a quarter of total health care costs for stroke patients are due to hospital admissions ${ }^{17}$. Furthermore, stroke is a common cause of morbidity and mortality.

The aim of the paper is to look at the use of DRGs as an instrument for outputpricing. More specifically, in order to be useful for output-pricing, the DRGs will have to explain substantially the variance in stroke costs. We intend to evaluate whether a DRG classification system predicts a sufficiently large 
amount of the variance of costs in stroke and, if not, whether other variables (i.e. demographic background, region, discharge status, medical history, hevel of functioning, or complications) may give a better prediction.

\subsection{Diagnosis Related Groups}

\subsubsection{DRG CASE-MIX}

The DRG patient classification system was originally developed by Fetter in the USA; since 1983 it has been used in the United States as the basis for Medicare's Prospective Payment System (PPS) 11.20.21. The DRG system is used to describe inpatients admitted to hospitals during a certain period. A number of features have played a prominent role in the development of the DRCs". for instance, each patient category is defined in such a way as to be medically meaningful, and at the same time it is supposed to be cost-homogeneous (large differences in costs between the DRG groups are combined with the low variance within these groups). First, patients are allocated to a Major Diagnosis Category (MDC) based on their principal diagnosis. Surgical and medical categories are distinguished, based on the type of principal diagnosis. Each surgical and medical category is further divided using relevant patient features, such as secondary diagnosils, age, and gender and discharge data, resulting in a well-defined Diagnosis Related Group (DRG). Feasibility studies performed at University Hospital Maastricht have resulted in a local version of the American DRG patient classification system. This locall version will be used in this study ${ }^{22-25}$.

Figure 1 gives an overview of the rules for the local classification of stroke patients. These rules are based on a feasibility study ${ }^{26}$ involving expent opinions (physicians) and statistical analysis (analysis of variance). Results showed that classification according to surgical procedure, age and clischarge destination are both medically and economically meaningful. Similar factors are found in the literature $2 \pi, 26$. The main group of stroke patients are classified in DRG 119 to 122 based on both age (classified as "younger than 50 ' or " 50 and over'), and on whether or not patients are 'referred to another health care institution" after leaving the hospital. In addition, stroke patients may undergo a surgical procedure, and these patients are classified into a surgical DRG. In each DRG classification, patients can be classified as outliers. Outliers are 
defined as patients with a hospital length of stay that is longer or shorter than two standard deviations from the average DRG hospital length of stay.

Figure 1. University Hospital Maastricht DRG-classification of stroke-patients

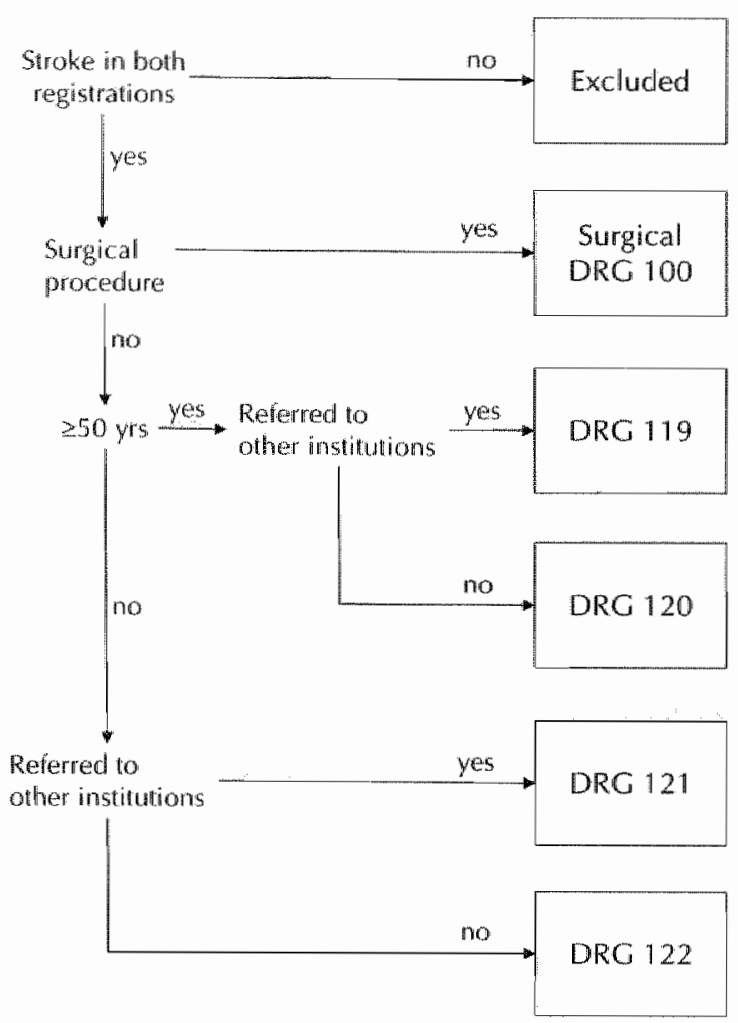

\subsubsection{DRGS-SOME LIMITATIONS}

Although DRGs have been widely used, the introduction of a DRG-system has always been beset with some criticism. One of the major limitations is that the DRG-system may introduce a sort of financial selection if it is applied as a basis for a financing system ${ }^{25}$. In connection with this concern, there may be doubts regarding the medical and economical homogeneity of the DRGclassification. This criticism is mainly based on the lack of recognition of different levels of severity of illness within any given $D R G^{30,31}$. It is thus possible that some hospitals will have some DRGs in which their patients are always more severely ill than in other hospitals ${ }^{32}$. Another implication might be that a patient could receive poorer quality of care to reduce costs or that 
costs might be shifted to outpatient institutions. A further point of criticism is that the DRG-system stands or falls by the reliability and validity of the registration. In addition, it might be tempting to place patients unjustly in expensive DRGs, the so-called DRG creep ${ }^{33}$.

\subsection{Factors predicting utilisation of stroke}

Our study focuses on factors, which can predict hospital utilisation and costs; these factors include the level of functioning and complications accompanying stroke. From the start of this study, it was nof likely that a DRG case-mix as defined above could predict the total variance in hospital utilisation by stroke patients ${ }^{34}$. However, there were indications that a DRG case-mix could predict part of the variance in hospital utilisation and costs in patients with stroke ${ }^{35}$. Furthermore, it has been found that length of stay (LOS) is a strong indicator for hospital utilisation and costs in these patients ${ }^{36}$.

These results immediately pose the question of what factors will shorten or prolong the length of patient stay. A Medline literature search was conducted in order to get an overview of the important factors for hospital utilisation in stroke patients. As applied in other studies ${ }^{37}$, the model of Andersen and Newman ${ }^{3 a}$ was used to distinguish factors typically related to the volume of hospital utilisation. In this model, it is assumed that factors contributing to the wolume of hospital utilisation can be divided into predisposing factors, enabling factors, and need factors. Regarding predisposing factors, it is evident that some individuals have a tendency to use services more than do other individuals, and this tendency towards use is related to individual background characteristics. Such background characteristics may include demographic factors, functional level before stroke and previous periods of illness. Enabling factors are those which make health services resources available to the patient, and refer to the accessibility of certain sources. Enabling factors reflect characteristics of the health care sector, insurance, and social support. Finally, need factors refer to the current level of illness in patients; elements included in these factors are diagnostic characteristics such as type of stroke, clinical complications and comorbidity, and the level of post-stroke functioning. 


\subsubsection{PREDISPOSING FACTORS}

In the literature, the majority of studies have investigated the relationship between patients" age and hospital utilisation or costs ${ }^{3949}$. Predominantly, these sudies found no relation whatsoever between age and hospitalisation in stroke patients. In the three studies that report a statistical relation, the results found are contradictory. One study ${ }^{39}$ reported that older patients had a higher hospital utilisation, probably due to the fact that the functional recovery of older stroke patients is slower, while other studies ${ }^{45,48}$ found that younger stroke patients are more extensive users of hospital services. Lee ${ }^{45}$ has explained the short LOS of patients older than 85 by the clinical custom that these patients might receive a less aggressive approach in treating the disease. The relation between gender and hospital utilisation in stroke patients has been investigated in four studies ${ }^{40,43,47,49}$, only one of which ${ }^{40}$ reported a significant difference between men and women. This study found that men had a longer LOS. In the four studies $44,47,48,50$, that investigated the relationship with marital status, two studies, ${ }^{47}$ reported that 'being single' led to more hospital utilisation.

\subsubsection{ENABLING FACTORS}

Three studies looked at the relation between type of insurance and hospital utilisation. One study ${ }^{46}$ found no relation, while the other studies ${ }^{475}$ found that the LOS is related to the insurance type (participation in a Health Maintenance Organization; Medicare PPS). Several authors ${ }^{40,43,40,50,52}$ studied the relationship between hospital and physician characteristics with hospital utilisation and costs. It was found that less health care utilisation took place in smaller hospitals ${ }^{40}$ within a metropolitan environment ${ }^{40}$ and within hospitals with a high nurse/bed ratio ${ }^{50}$. Regarding physician characteristics, it was found that medical doctors with a general background ${ }^{40,50}$ tend to keep their patients longer in hospital, resulting in more hospital utilisation. The same was found for senior physicians ${ }^{40}$. Waiting lists, blocked access to discharge institutions and an inadequate home situation can also hinder a short hospitalisation. The results of the Hakim study ${ }^{43}$ show that discharge to the patient"s own home situation will reduce costs. Lee ${ }^{45}$ found that the limited number of post-stroke facilities in a region may increase costs, due to the fact that patients have to stay longer before being discharged from the hospital setting. The availablle capacity of after care stroke facilities was also a relevant factor in a Dutch 
study ${ }^{53}$, in which it appeared that $36 \%$ of the lotal hospital length of stay for stroke patients is mainly due to non-medical reasons, such as waiting for placement in a nursing home. The relationship of social support in the home situation with hospital costs was investigated several times, but the studies ${ }^{43,49}$ showed that the availability of social support does not contribute to hospital cost reduction. Social support refers to informal care, that is care provided to patients by relatives and friends who are not paid for their help. In addition, a rapid provision of disability aids and home adaptations (4) $^{4}$ an accelerate discharge to the home situation, and this can be an important factor in reducing hospital costs.

\subsubsection{NEED FACTORS}

In looking at need factors, a more uniform picture of costs arises. In general, stroke patients with a lower level of functioning ${ }^{34,41,42,54.57}$, with complications ${ }^{41,42,45,50}$ and a high level of comorbidity $4,47,56$ generate more hospital utilisation. The same effect is found for patients with a haemorrhage ${ }^{50,56}$ and for patients whose medical conditions require a feeding tube ${ }^{57}$. Patients who die during a hospital stay after a stroke tend generally to have a shorter stay, which leads to lower costs ${ }^{50}$. This might not be true for all types of costs during the whole hospital period, for Lee ${ }^{45}$ found that admission costs are relatively high for patients who die during the acute (admission) phase of the disease.

\subsection{Methods}

\subsubsection{PATIENT POPULATION AND DATA}

The population used in this study consists of inpatients with stroke discharged from University Hospital Maastricht in the years 1996-1998. University Hospital Maastricht is the only hospital in the city of Mastricht and the surrounding area; the hospital has an adherent population of approximately 230,000 people. In addition to regional functions, the hospital has a countrywide top-reference function, in which specialised high-quality care is given to patients from outside the region of adherence.

For this study, discharge abstract data, cost data from the billing administration, and DRG data (DRG, MDC, outliers) were collected. Discharge 
abstract data provide information on age, gender, stroke diagnosis, length of stay, discharge destination, and place of residence. The billing administration registers the type and volume of hospital services to the patient. Subsequently, the results of cost price studies have been used to calculate the actual costs per hospital services, and ultimately the actual costs per hospital admission. In this study, the case-mix accounting methodology follows a general concept in defining and calculating costs of patient categories. The methodology has been reported elsewhere ${ }^{24}$. The resulting data have been matched with data of the Maastricht Stroke Registry (MSR), using the patient-registration number. The MSR is an ongoing prospective registry at University Hospital Maastricht which includes all adult patients referred to the Neurological Department. The MSR collects, among other data, data regarding the functional level before the stroke, the vascular risk profile, disease severity, complications and comorbidity.

\section{4 .2 DEFINITION OF THEPROBLEM}

The literature thus suggests that DRGs can predict in part the variance in hospital costs, and may therefore be suitable as an instrument for outputpricing. The question we pose in this study is: which other factors, apart from the three factors defining the current DRGs (i.e. classified age, discharge destination, and operation/no operation), can be used in order to provide a better explanation of the variance in costs among stroke patients? Regarding the other variables, our study is limited to factors commonly available in the Maastricht Stroke Registry (MSR) or in the discharge abstract data of University Hospital Maastricht. Some factors, such as 'living single', insurance, hospital characteristics, physician characteristics, and the availability of social support are therefore not included in the analysis.

\subsubsection{RESEARCH MODEL}

Figure 2 presents the research model. In this model, the cost of stroke inpatients is the outcome variable. We expected that the main part of the prediction for the inpatient costs would come from the DRG-classification. As noted above, the DRG classification is defined by three factors: having an operation or no operation, age group and discharge status. Therefore, these factors will not be included as variables in the model. In the remaining of this section the outcome variables and main predictors will be described. 
Figure 2. Model to predict costs of stroke patients

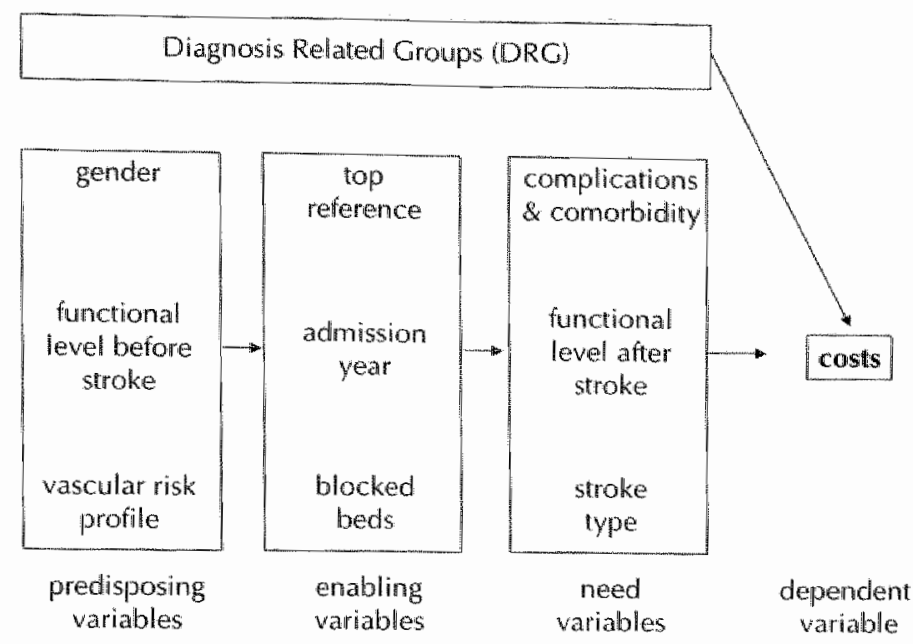

\subsubsection{Outcome variables}

Because in our study the DRG-system is regarded as a lool for reimbursement, only variable costs that are directly related to medical care and that can be influenced by the physicians behaviour have been included. These are costs for lab tests, radiology, physiotherapy, nursing care etc. Fixed costs of hospital overhead, like general administration, are excluded from our definition of the clinical budget because physicians cannot control them. Because data on drug costs are not collected at patient level at our hospital, these have also been excluded from the cost calculation in the analysis.

The inpatient costs are subdivided into three types: costs of nursing care, costs of diagnostic procedures, and costs of therapeutic interventions, In addition to these, total costs are analysed (i.e. the sum of the three types of costs). The Euro was chosen as the currency unit.

\subsubsection{Predictor variables}

The goal of the analysis is to see whether other variables, in addition to the DRG classification, will increase the explained variance in costs. These variables can be subdivided into need, enabling, and predisposing variables. Need variables: A list of 'complications' and 'comorbidities' are included separately, which may occur during hospital stay, such as venous leg 
thrombosis, pulmonary embolism, cardiac sequel, systemic emboli, pneumonia, urinary tract infection, sepsis and seizures. 'Other events' refers to interfering factors such as abdominal factors, anemia, dehydration, depression, and whether patients received a Percutaneous Endoscopic Gastronomy. Overall, the level of functioning during stay is again measured using the Rankin scale (ranging from 0 'no symptoms' to 5 'severe handicap') and the Eye and Motor scale (EM) (ranging from 2 'severely handicapped' to 10 'no symptorns'). The Canadian Neurological Scale (CNS) (ranging from 1.5 'severely handicapped' to 10 'no symptoms') is used to measure the severity of disease.

Enabling variables: The factor 'top reference' is used to distinguish between two types of patients: patients coming from the typical adherence region of University Hospital Maastricht and patients coming from outside this region. 'Admission year' refers to the year of admission to the hospital. The factor 'admission year' is included in the analysis because, as hospitals in the Netherlands have been aiming to work more efficiently, the expectation is that costs will have decreased in more recent years. The factor 'days of stay for non-medical reasons' (or blocked beds), in this chapter, refers to the possibility that some patients have had to wait for referral to other health care institutions, e.g. nursing homes or rehabilitation centers. This factor is registered by the medical administration department and refers to the circumstance when a prolonged stay in the hospital is no longer clinically necessary.

Predisposing variables: Predisposing variables included in our analysis are the level of functioning before stroke, vascular risk profile and gender. Neurologists use the so-called Rankin scale also (ranging from 0 'no symptoms' to 5 'severe handicap') to make estimations of the level of functioning before stroke. In addition, a number of vascular risk factors which are known to increase the risk of stroke are separately included in the analysis; these factors include having had a prior stroke, prior TIA, angina pectoris, myocardial infarction, $C A B G$, hypertension or hypertensive medication, diabetes mellitus, COPD, peripheral artery disease, peripheral artery surgery, carotid surgery, current cigarette smoking, hypercholesterol, vascular family history (1st degree), and alcohol consumption. Finally, the only predisposing demographic factor to be included beforehand is gender. 


\subsubsection{STATISTICS}

Descriptive analyses of the independent variables and inpatient costs are performed in order to obtain a global impression. As could be expected, the outcome variables - inpatient costs - are not normally distributed. All cost figures in our study are negatively skewed to the right due to a minority of stroke patients who account for large costs. However, logarithmic transformation resulted in an approximately normal distribution.

An initial screening of the variables for multiple regression analysis is done by inspecting their correlation with the transformed inpatient costs. The variables are then entered one at a time and stepwise into the regression model to determine which factors - need, enabling and predisposing - are significantly controlling costs for earlier selected variables. To solve the problem of missing observations, only cases with valid values for all variables are included in the analysis (listwise deletion of missing cases). Categorical factors and ordinal variables are transformed into dummy variables. As a first step in the regression analysis, the four dummy DRG categories were entered: the fifth DRG category $(120)$ is then automatically represented by the intercept (constant in the regression equation). The second step consists of finding a basic model in which each risk factor thas a direct statistically significant relationship with the transformed outcome variable. In this step groups of variables are entered starting with 1) need 2) enabling and 3) predisposing variables. Next, all first order interaction variables are entered in the basic model to see if combinations of variables could also explain the variance in costs. All statistics were performed using SPSS-PC, version 9.0 and 10.0558. A p-value of $\leq 0.05$ was considered as statistically significant.

\subsection{Results}

A total of 731 stroke patients from the period of 1996 to 1998 are included in the study. As Table 1 shows, the average age of the study population is 72 years, and there is an equal distribution between females and males. In general, stroke patients had minor handicaps (Rankin mean: 0.8 ) before stroke, and at admission after stroke, patients are on average moderately or severely handicapped (Rankin mean: 3.8). Patients included show a mean length of stay of 26 days. The majority of patients are categorised into the DRG 120 " 50 years and over", and "not referred to another institution'. About $18 \%$ of the 
patients died during hospital stay. After discharge, a large part of the patients $(43.6 \%)$ returned to their own home. Furthermore, 9 out of 10 patients are recruited from the adherence region of the University Hospital. The average direct inpatient costs are about $e 4,021$ in total, of which the majority is spent on nursing care. Only $2.6 \%$ of the patients could be classified as 'outliers'.

Table 1. Patient characteristics

\begin{tabular}{|c|c|c|}
\hline Characteristics $n=731$ & Mean (SD) or \% & $\min . \max$ \\
\hline Age & $72(19)$ & $16-99$ \\
\hline Gender (female) & $49.9 \%$ & \\
\hline Outside hospital adherence region & $10.1 \%$ & \\
\hline Rankin before stroke & $0.8(1.1)$ & $(0-5$ (severe $)$ \\
\hline Rankin at admission & $3.8(1.2)$ & $(0.5$ (severe) $)$ \\
\hline LOS (in days) & $25.8(28.8)$ & $(1-3) 6)$ \\
\hline Intarction & $67.0 \%$ & \\
\hline DRG 120 (= 50 \& home $)$ & $53.4 \%$ & \\
\hline Died during hospital stay & $17.6 \%$ & \\
\hline Referred to own thome & $43.6 \%$ & \\
\hline Nursing care costs (in $\triangleq$ ) & $2,822(3,626)$ & $(99-38,903)$ \\
\hline Diagnostic costs (in e) & $929(1,064)$ & $(13-12,968)$ \\
\hline Therapeutic costs (in el & $269(558)$ & $(0.00-8,230)$ \\
\hline Total costs (in E) & $4,021(4,593)$ & $(214-49,112)$ \\
\hline Outliers & $2.6 \%$ & \\
\hline
\end{tabular}

\subsubsection{COSTS PREDICTED FROM THE CURRENT DRG-CATEGORIES}

In Figure 3 the distribution of the non-transformed totall costs and the number of cases are box-plotted over the several DRGs. The majority of the patients are classified in DRG $120(n=390)$, followed by DRG $119(n=250)$. The DRG with highest costs is the surgical DRG (mean: $€ 10,706 ; \mathrm{SD}: € 10,537$ ), which also shows the largest variation in costs $(\min =€ 1,768$; $\max =$ e 4,912). The next most costly DRGs are the ones in which stroke patients are referred to another institution (DRG 1119 (mean: $€ 5,765 ;$ SD: $€ 4,306$ ) and DRG 121 (mean: $\in 5,596 ; S D: \in 5,992$ ). On the average, stroke patients who are discharged to the own home situation or who die (DRG 120 (mean: $\in 2,285$; SD: $€ 2,278$ ) and DRG 122 (mean: $€ 2,702$; SD: $€ 2,021$ ) have lower hospital costs. 
Figure 3. Total cosis for the DRG categories

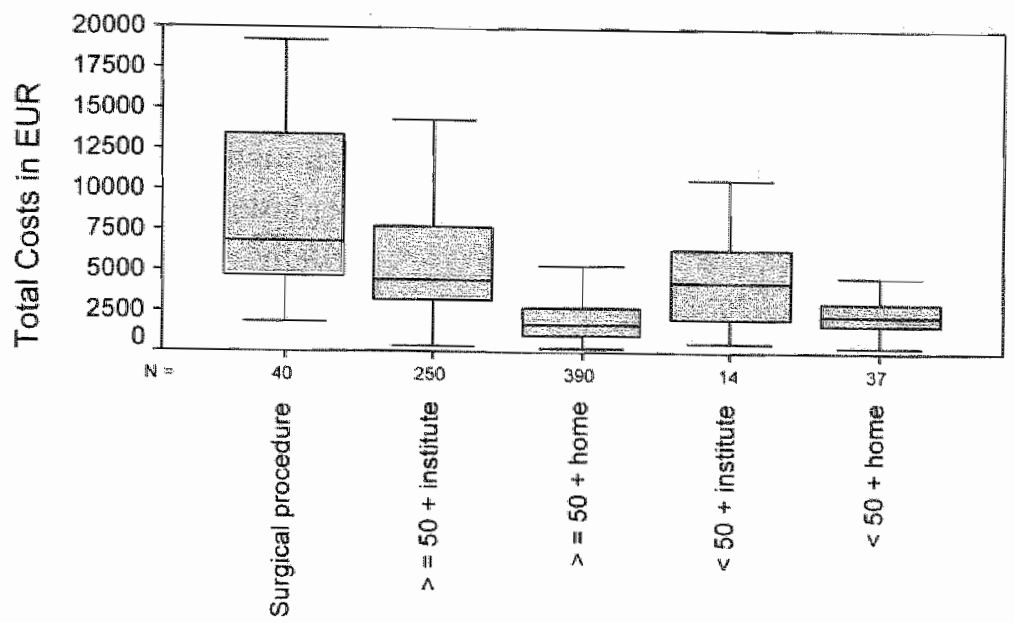

DRG and number of cases

Horizon line is the median, rectangle all observations between the 25th and the 75 th percentile, top/bottom line 1.5 fimes 25 th/75th percentile

\subsubsection{REGRESSION ANALYSIS}

Totall inpatient costs are analysed in the first regression analysis. Subsequently, to get a more detailed insight into costs, the expenditures for diagnostic procedures and therapeutic procedures are analysed separately. No separate analysis was made for nursing care costs, as these turned out to be very highly correlated with the total costs.

\section{5 .3 .1 Total costs}

Multiple regression analysis shows that the explained variance of the lotal costs amounts to $34 \%$ by using DRGs alone, and is increased to $61 \%$ by using other factors in our model, in addition to these DRGs.

Need factors: Table 2 shows which specific variables or factors significantly predict the total costs. Patients with specific complications during hospital stay tend to have higher costs; this is so for patients with cardiac complications, pulmonary embolism, pneumonia, and 'other events' during their stay. 
Normally, deceased patients generate lower costs, but if patients die after an infarction, their costs are higher. The reason for this strange interactive relationship between having an infarction, dying in hospital and total costs resides in the length of stay. Patients who die during their hospital stay generally have lower total costs, and they generate even lower total costs if this happens at the beginning of their stay. Having had an infarction does not have an effect on total costs, but infarct patients who die during their stay do have higher total costs than one would expect of (usually) low-cost, deceased patients. Apparently, deceased infarct patients stand out from patients who die after a short stay (and therefore have low costs), because in a short time they generate extremely high costs, resulting nevertheless in death.

The other interaction factor in the model is that deceased patients with a seizure induce higher costs. Normally, epileptic seizures raise the total costs for a patient, but the results show that deceased patients in this group generate even higher costs. This last interaction appears to be independent of the length of stay, and cannot be explained by other factors in our model.

Enabling factors: If patients were discharged during 1997 and 1998 , they tend to have lower costs in comparison with patients discharged during 1996. This is due to the fact that there is an overall reduction in length of stay in stroke patients from year to year (ANOVA overall $F=4,10 ; p=0.017$ ). The longer the patient has to wait in-hospital for after-care institutions (days of stay for non-medical reasons), the higher his/her costs will be. Furthermore, if patients are admitted from outside the adherence region, they tend to have lower costs. This may be explained by the fact that patients from outside the region stay in the University Hospital for a significantly shorter time (on average, almost 10 days less).

Predisposing factors: No direct effects were found for the predisposing factors. For men with a urinary tract infection, total costs are high. Further analysis showed that the effects of gender and urinary tract infection on high costs can be explained by the fact that male patients with a urinary tract infection have 10 times higher costs than do female patients with a urinary tract infection. Upon inquiry, it appeared to be common practice among the neurological staff to consult an urologist if male patients have problems with the urinary passages. For male stroke patients who score more severely (higher) at admission on the Rankin scale measuring post-stroke level of functioning, the total costs are also relatively higher. 
Table 2. Results of multiple regression analysïs on lotal costs (log-transformed)

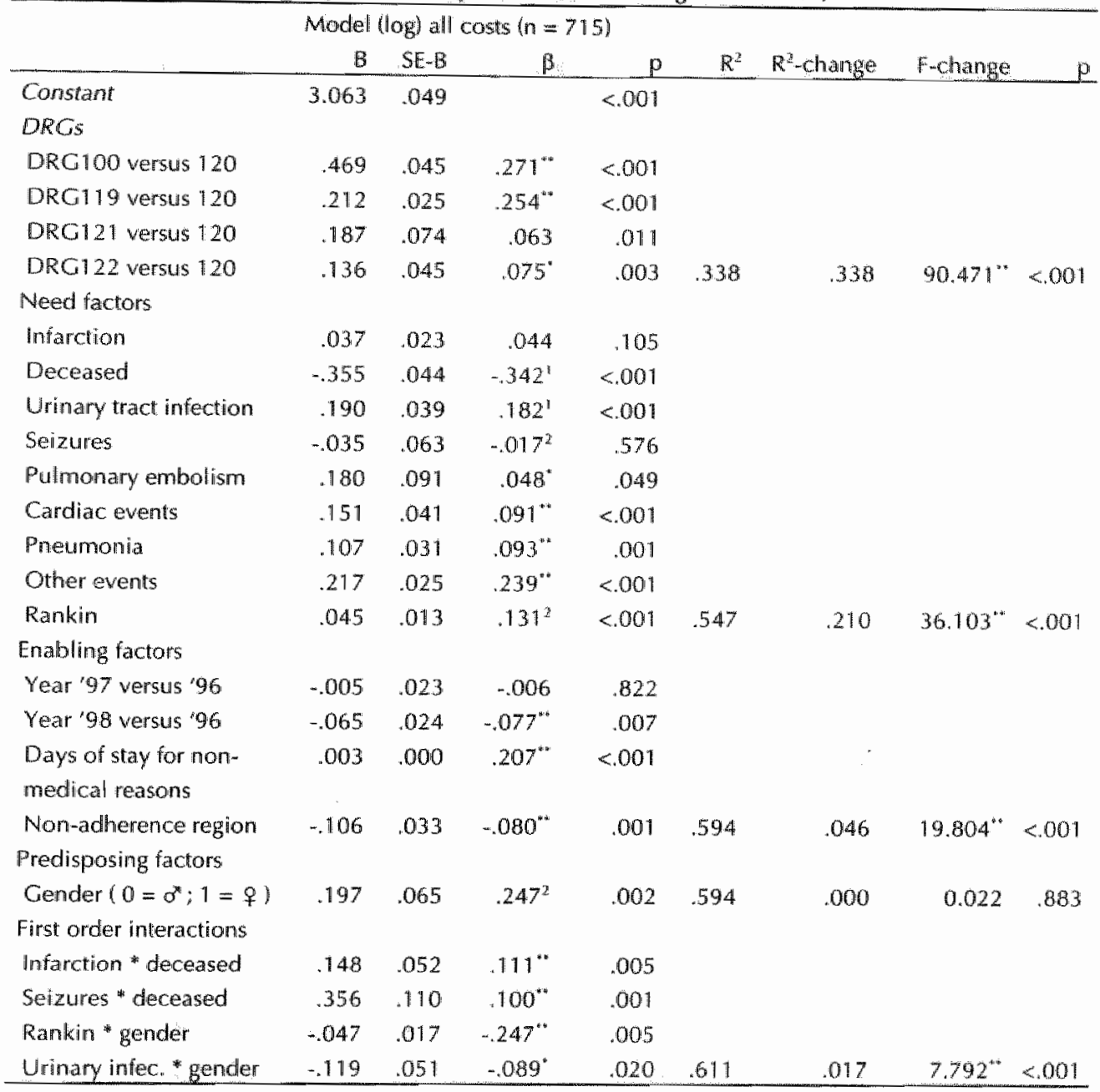

" $p=0.05, " p=0.01$

"Significant, if entered separately in the model, before entering the first onder interactions

${ }^{2}$ Not significant, if entered separately in the model, before entering the first onder interactions

\subsubsection{Diagnostic costs}

Need factors: Not surprisingly, specific complications and comorbidity (such as cardiac events, pneumonia, pulmonary embolism, sepsis, urinary tract infections, venous leg thrombosis and other events) each induce higher diagnostic costs (see Table 3 ). In addition, if patients at discharge are labelled 
with a diagnosis of infarction (as opposed to haemorrhage and TIAs) they will generate higher diagnostic costs. As they do in total costs, deceased stroke patients also generate lower diagnostic costs.

Enabling factors: If patients were admitted during 1997 the diagnostic costs tend to be lower than they were in 1996.

Table 3. Resullts of multiple regression analysïs on diagnostic costs (log-transformed)

\begin{tabular}{|c|c|c|c|c|c|c|c|c|}
\hline & \multicolumn{8}{|c|}{ Model (log) diagnostic costs $(n=710)$} \\
\hline & B & SE-B & $\sqrt{1}$ & $p$ & $\mathrm{R}^{2}$ & $R^{2}$-change & F-change & $p$ \\
\hline Constant & 2.583 & .053 & & $<001$ & & & & \\
\hline \multicolumn{9}{|l|}{ DRGS } \\
\hline DRG 100 versus 120 & .335 & .048 & $.224^{* * *}$ & $<.001$ & & & & \\
\hline DRG119 versus 120 & .008 & .027 & .012 & .746 & & & & \\
\hline DRG121 versus 120 & .231 & .079 & $.090^{* *}$ & .004 & & & & \\
\hline DRGi 122 versus 120 & .352 & .048 & $.225^{* *}$ & $<001$ & .168 & .168 & $35.625^{* *}$ & $<.001$ \\
\hline \multicolumn{9}{|l|}{ Need factors } \\
\hline Infarction & .080 & .022 & $.110^{* *}$ & $<.001$ & & & & \\
\hline Deceased & -.093 & .033 & $-.104^{* 4}$ & .005 & & & & \\
\hline Urinary aract infection & .122 & .029 & $.135^{* *}$ & $<.001$ & & & & \\
\hline Sepsis & .147 & .068 & $.067^{\circ}$ & .031 & & & & \\
\hline Pulmonary embolism & .202 & .097 & $.062^{*}$ & .039 & & & & \\
\hline Cardiac events & .178 & .045 & $.123^{* 4}$ & $<.001$ & & & & \\
\hline Preumonia & .164 & .033 & $.164^{* \prime \prime}$ & $<.001$ & & & & \\
\hline Venous leg thrombosis & .277 & .115 & .074 & .017 & & & & \\
\hline Other events & .156 & .027 & $199^{* *}$ & $<.001$ & & & & \\
\hline Rankiln & .022 & .014 & $.075^{9}$ & .108 & .362 & .194 & $21.073^{\circ *}$ & $<.001$ \\
\hline \multicolumn{9}{|l|}{ Enabling factors } \\
\hline Year 97 versus 96 & -.030 & .025 & -.041 & .230 & & & & \\
\hline Year 99 versus 96 & -.122 & .026 &. $.168^{60}$ & $<.001$ & & & & \\
\hline $\begin{array}{l}\text { Days of stay for non- } \\
\text { medical reasons }\end{array}$ & .001 & .001 & .064 & .063 & .388 & .026 & $9.742^{\circ}$ & $<.001$ \\
\hline \multicolumn{9}{|l|}{ Predisposing factors } \\
\hline Prior diabetes mellitus & .062 & .027 & $.070^{\circ}$ & .020 & & & & \\
\hline Gender $\left(0=0^{*} ; 1=\right.$ 家) & .149 & .069 & $.217^{k}$ & .031 & & & & \\
\hline Smoking (known) & .066 & .024 & $.087^{* *}$ & .007 & & & & \\
\hline Smoking (unknown) & -.039 & .033 & -.037 & .240 & .402 & .015 & $4.235^{* \prime}$ & .002 \\
\hline \multicolumn{9}{|l|}{ First order interaction } \\
\hline Rankin " Bender & -.041 & .018 & $-.247^{\circ}$ & .021 & .407 & .005 & $5.311^{\circ}$ & .021 \\
\hline
\end{tabular}

$" p=0.05, " p=0.01$

'Not significant, if entered separately in the model, before entering the first order interactions 
Predisposing factors: initially, having had a more severe stroke pre-admission (Rankin) does not seem to increase or decrease diagnostic costs at all. However, when corrected for gender, scoring more severely on the Rankin scale becomes statistically significant, as men with a high Rankin generally induce higher costs. Also, patients who have a prior history of diabetes mellitus have higher diagnostic costs during their hospital stay. Finally, tobacco smokers generate more costs.

\subsubsection{Therapeutic costs}

Table 4. Results of multiple regression analysis on therapeutic costs (log-transfiormed)

\begin{tabular}{|c|c|c|c|c|c|c|c|c|}
\hline & \multicolumn{8}{|c|}{ Model $(\log )$ therapeutic costs $(n=715)$} \\
\hline & B & $\mathrm{SE}-\mathrm{B}$ & $\beta$ & p & $\mathrm{R}^{2}$ & $\mathrm{R}^{2}$-change & F-change & $p$ \\
\hline Constant & 1.120 & .101 & & $<.001$ & & & & \\
\hline \multicolumn{9}{|l|}{ DRGS } \\
\hline DRG100 versus 120 & 1.322 & .097 & $.375^{\prime \prime}$ & $<.001$ & & & & \\
\hline DRGi119 versus 120 & .495 & .055 & $.291^{\circ *}$ & $<.001$ & & & & \\
\hline DRG121 versus 120 & .297 & .162 & .049 & .067 & & & & \\
\hline DRG122 versus 120 & -.158 & .1101 & -.043 & .117 & .377 & .377 & $107.514^{* *}$ & $<001$ \\
\hline \multicolumn{9}{|l|}{ Need factors } \\
\hline TIA & -393 & .111 & $.094^{\circ}$ & $<.001$ & & . & & \\
\hline Deceased &.. .515 & .072 & $-.244^{\prime}$ & $<.001$ & & & & \\
\hline Urinary tract infection & .144 & .065 & $.068^{1}$ & .028 & & & & \\
\hline Seizures &. .230 & .139 & $-.053^{2}$ & .099 & & & & \\
\hline Other events & .335 & .054 & $.182^{* *}$ & $<.001$ & & & & \\
\hline Rankin & .133 & .028 & $.190^{\natural}$ & $<.001$ & .483 & .106 & $24.123^{* *}$ & $<.001$ \\
\hline \multicolumn{9}{|l|}{ Enabling factors } \\
\hline $\begin{array}{l}\text { Days of stay for non- } \\
\text { medical reasons }\end{array}$ & .005 & .001 & $.139^{* \#}$ & $<.001$ & & & & \\
\hline Non-adherence region & -.330 & .072 & $-.123^{*+1}$ & $<.001$ & .512 & .028 & $20.306^{\circ}$ & $<.001$ \\
\hline \multicolumn{9}{|l|}{ Predisposing factors } \\
\hline Gender $\left(0=0^{\pi} ; 1=q\right)$ & .434 & .143 & $.268^{2}$ & .002 & .512 & $\ll .001$ & .128 & .721 \\
\hline \multicolumn{9}{|l|}{ First order interactions } \\
\hline Seizures * deceased & .876 & .240 & $.121^{\circ+1}$ & $<., 001$ & & & & \\
\hline Uninary infection * deceased & .422 & .152 & $.086^{\circ}$ & .005 & & & & \\
\hline Rankin* gender & -.119 & .036 & $-305^{*}$ & .001 & .533 & .022 & $10.835^{\circ+}$ & $<.001$ \\
\hline
\end{tabular}

" $p=0.05, " p=0.0 \%$

"Signifficant, if entered separately in the model, before entering the first order interactions

${ }^{2}$ Not significant, if entered separately in the model, before entering the first order interactions 
Need factors: Regarding therapeutic costs (Table 4), patients who have a TIA as final diagnosis (as opposed to haemornage and infarction) have lower therapeutic costs. Next to that, patients with 'other events' during their hospital stay will also induce higher costs. In general deceased stroke patients have lower costs. For deceased stroke patients there are two exceptions: patients who die and who have seizures or urinary tract infection as comorbidity will induce higher therapeutic costs.

Enabling factors: As in the total costs, 'days of stay for non-medical reasons' induce higher therapeutic costs. Finally, patients from outside the hospital's adherent region induce lower therapeutic costs.

Predisposing factors: As with all other costs, if men score more severely (higher) on the Rankin scale, they induce significantly higher costs than do women with the same outcome on the Rankin test.

\subsection{Conclusion}

The regression analysis results (Table $2-4$ ) show that the variance explained in costs can substantially and significantly increase with factors other than those which are used to define the DRG stroke categories. For all of the costs categories analysed, but especially for total costs, need factors are important in order to increase the variance explained in our model. The results of regression analysis for total costs show that, using DRGs, the explained variance of the costs amounts to $34 \%$. When adding onlly need factors to the DRCs, the variance explained increases to about $55 \%$. The additional introduction of enabling factors, predisposing factors, and first order interactions leads to a supplementary increase in variance explained of about $6 \%$, for a total of $61 \%$. Need factors, related to high inpatient costs, are the following factors or variables: severity/type of stroke, complications and comorbidity. Patients with an infarction induce higher diagnostic costs in comparison with patients with hemornage and TIAs, while patients with a TIA induce lower therapeutic costs in comparison with patients with hemorrhage and infarction. For each type of costs, deceased patients induce llower costs.

Regarding the enabling factors, the study shows that patients admitted during recent years induce lower costs, indicating that the hospital might be working more efficiently. One of the major factors leading to increased costs is 'days of stay for mon-medical reasons', because people have to wait to be transferred to a rehabilitation centre or to a nursing home. Currently, using an organised 
inpatient (stroke unit) care model, a solution is being offered for this problem, e.g. by early diagnosis and closer cooperation with referral health care institutions. Systematic reviews in this field have shown that this method will be cost-effective ${ }^{59}$. In general, patients from outside the region induce lower costs, but this can largely be explained by the fact that they have a shorter length of stay. This can be explained by the fact that stroke patients are referred to their own regional hospital after being stabilised at University Hospital Maastricht, or that they stay in the University Hospital only for a short diagnostic consultation period. Regarding the predisposing factors, male stroke patients induce high costs if they have had a more severe stroke or a stroke in combination with a urinary tract infection. Finally, regarding the two-way interactions, one can see that there are a few exceptions to the statement that deceased patients induce lower costs. In some respects, deceased stroke patients are even more expensive, especially if they have been diagnosed with seizure, urinary tract infection, or infarction.

\subsection{Discussion}

Several limitations must be considered when interpreting and implementing the results of this study. The quality of the diagnostic coding system is an important issue in the DRG-system. One has to be alert to this problem, as the diagnostic coding of stroke is often incorrect ${ }^{60,61}$. At the beginning of our study we also encountered some problems with records linkage, due to the fact that discharge abstract data (medical registration) and the Maastricht Stroke Registry are not always comparable on the principal diagnosis of stroke patients - because of these inconsistencies some patients had to be excluded from data analysis.

Furthermore, it was impossible to include all factors found relevant in the literature on costs analysis. Therefore, factors like "living alone', insurance type, hospital characteristics, physician characteristics, and the availability of social support had to be excluded from analysis. In addition, recent insights in neurology indicate that the location of the stroke in the brain is an important indicator for the recuperation of the stroke patient. In this classification stroke infarct patients are categorised into four clinically identifiable subgroups, e.g. Total anterior circulation infarcts, $\mathrm{TACl}_{\text {; }}$ Partial anterior circulation infarcts, PACl; Posterior circulation infarcts, POCl, and Lacunar infarcts, $\mathrm{LACl}$, which give an accurate prediction of the prognosis ${ }^{62}$. It is likely that the inclusion of 
this clinical system in the DRGs may lead to the development of a more sensitive classification system. Another factor not included in this study, that might possibly clarify the unexplained variation in diagnostic and therapeutic costs, is the difference in the level of experience among neurologists. If possible, these factors should be included in future studies of patients' costs. Finally, the current local DRG categories are mainly based on factors which are directly related to the hospitalisation period. In order to provide more tailor-made care and to ensure continuity of care, it would be helpful to get some insight into ractors which determine patterns of care after stroke. Therefore, neuralogists are currently focusing on early detection and on early diagnosis of relevant factors. In the future, these factors should be included to define more valid DRG categories and to achieve better costs predictions.

A further point of criticism is that implementation of the results of this study, e.g. redefining the DRGs for stroke, might be difficult, because much will depend on solid and computerised clinical registration, in which for instance the level of functioning, risk profile and complications are integrated. The usefulness of the DRG system stands or falls on the reliability and validity of this registration. Redefining the DRG system induces additional costs and the problem is whether these efforts are worth the investment. Clearly, for practical reasons, the number of DRGs has to be low, for the clinicians, economists, and policy makers, when they are using them in dailly practice.

In the meantime, these limitations do not invalidate the conclusion that the implementation of an output-pricing DRG system for stroke patients may be possible in hospital settings. However, one should integrate into the DRG systems, in addition to (current DRG) factors like age and discharge status, the factors of complications, risk profile and level of functioning. By including these variables, the variance explained for cost will rise to $60 \%$. Because of this, the current model provides a better prediction of inpatient costs for stroke patients. Although these conclusions seem to be specific for patients in University Hospital Maastricht, they should also be relevant for policy makers in general. As the results are congruent with findings in the literature, it is plausible that the conclusions of our study are applicable to hospitalised stroke patients in general.

As stated in the introduction, a new hospital financing system will be introduced in the Netherlands based on hospital case-mix characteristics, the 'Diagnose-Behandel-Combinaties (DBCs)', which differs from the DRG-system. Although the DRG-system has disadwantages, like the omission of classifying ambulatory care, a low predictive validity in some DRGs or the medical 
heterogeneity in a few DRGs, it is believed that the DRG-system is a useful instrument for hospital financing. The DRG-system is an extensively validated classification system which is widely used internationally. The patient groups are tested on medical and economic meaningfulness, reliability and practicality. On the other hand, as we have seen in this study, adaptations are necessary to improve present shortcomings. Development of a new patient classification system as has been done in the Netherlands does not guarantee that DRG qualifications may be exceeded. It is not yet known if the DBC system will exceed the DRG system, because no literature or cost prediction results are available from the $\mathrm{DBC}$ system. In predicting the hospital costs of CVA patients, we have seen that next to the patient's diagnosis and age, factors like complications, risk profile and level of functioning are also important patient characteristics. It is unlikely that the new DBC-system will include these features. However, further studies will be necessary to explore the differences between these systems.

\section{Acknowledgments}

This paper was presented at the Annual Meeting of the International Society for Technology Assessment in Health Care in The Hague, the Netherlands, June 18-21, 2000. Saskia Meerhoff, who checked the clinical data of the MSR, has done a great deal of the preliminary work. Furthermore, we would like to thank Jos van den Akker, Marion Beckers, Math Habets, Richard Schurgers, and John Vossen for access to relevant data, Bert Panis for helpful assistance on 'blocked beds', and Jack Bibo and Brigitte Essers for information on the local DRG-system. The chapter has benefited from the comments made by Hans Maarse, professor of Policy Sciences at Maastricht University.

\section{References}

1. Groot TLCM, Evers SMAA, Wenemoser RAS. Management accounting praklijk in Nederlandse ziekenhuizen. Tijdschrift voor bedrüfsadministratie 1996;100:18-24.

2. Maarse JAM. Fixed budgets in the inpatient sector: the case of the Netherlands. In: Schwarz. FW, Glennester $H$, Saltman RB, eds. Fixing Health Budgets: experience from Europe and North America. Chichester: Wiley; 1996. 
3. Groot TLCM. Budgettary reforms in the non-profit sector: a comparative analysis of experiences in health care and higher education in the Netherlands. Financial Accountability \& Management 1999:15:353-76.

4. Tweede Kamer der Staten-Generaal vergaderjaar 2000-2001. -Bekostiging ziekenhuiszorg. "s-Gravenhage: Sdu Uitgeverij; 2000.

5. Tweede Kamer der Staten-Generaal vergaderjaar 1999-2000. Positionering algemene ziekenhuizen. 's-Gravenhage: Sdu Uitgeverij; 2000.

6. Cots F, Elvira D, Castells X, Dalmau E. Medicare's DRG-weights in a European environment: the Spanish experience. Health Policy 2000;51:31-47.

7. Jackson T. Using computerised patient-level costing data for setting DRG weights: the Victorian (Australia) cost weight studies. Health Policy 2001;56:149-63.

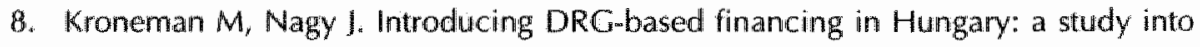
the relationship between supply of hospital beds and use of these beds under changing institutional circumstances. Health Policy 2001;55:19-36.

9. Scholkopf M. The hospital sector in Germany: an overwiew. World Hosp Health Serv $2000 ; 36: 13-8$.

10. 3 M Health Information Systems. All Patient- Diagnosis Related Groups (AP-DRG); Definition manual; 1993.

11. Felter RB, Shin Y, Freeman JL, Averill RF, Thompson JD. Case Mix Definition by Diagnosis-Related Groups. Med Care 1980;18:1-53.

12. Fetter RB. Diagnosis related groups: the product of the hospital. Clin Res $1984 ; 32: 336-40$.

13. Nederstigt PFPM, Voss GBWE. Diagnosis Rellated Groups; klinisch en poliklinisch. Tijdschrift voor Sociale Gezondheidszorg 1985;63:476-83.

14. World Health Organization (WHO). Stroke 1989: Recommendations on stroke prevention, diagnosis and therapy; Report of the WHO task force on stroke and other cerebrovascular disorders. Stroke 1989;20:1407-31.

15. WHO MONICA Project Principal Investigators. The World Health Organization MONICA project (Monitoring trends and detterminants in cardiovascular disease): a major international collaboration. I Clin Epidemiol 1988;41:105 15.

16. Evers SMAA, Goossens MEIB, Ament AIHA, Maarse IAM. Economic evaluation in stroke research: an introduction Cerebrovas Dis 2001;11:82-91.

17. Evers SMAA, Engel GL, Ament AJHA Cost of stroke in the Netherlands from a societal perspective. Stroke 1997:28:1375-81.

18. Rijkuniversiteit Groningen Vakgroep Huisartsgeneeskunde. De patient met een cerebrovasculair accident en de huisarts. Groningen: Rijksuniversiteit Groningen, vakgroep huisartsgeneeskunde; 1992. 
19. Franke CL. Intracerebral hemorrhage. Heerlen: De Wever Ziekenhuis, Department of neurology; 1991 [Thesis].

20. Fetter RB. Thompson D. Inventors of DRCs look at PPS now. Hospitals $1992 ; 66: 136,138$.

21. English IT, Sharfstein SS, Scherl DI, Astrachan B, Muszynski IL. Diagnosis-related groups and general hospital psychiatry. Am I Psychiatry 1986;143:131-9

22. Daemen PJM, Dassen IA, Halffman AMG. Patient-georienteerd management. Tijdschrift Medische Informatica 1990;19:107-11.

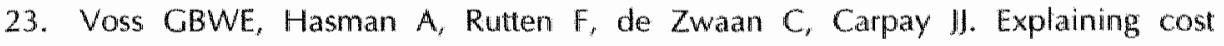
variations in DRGs 'Acute Myocardial Infarction' by severity of illness. Health Policy 1994;28:37-50.

24. Voss GBW, Limpens PGP, Brans-Brabant LJH, wan Ooij A. Cost-variance analysis by DRGs: a technique for clinical budget analysis. Health Policy 1997;39:153-66.

25. Voss GBWE, Silkens RMJ. Patient-gerelateerde kosteninformatie; ontwikkelingen in het Academisch Ziekenhuis Maastricht. Tijdschrift Medische Informatica $1998 ; 17: 61-65$.

26. Voss GBWE, Calpay IJ. DRG-kosteninformatie en ziekenhuismanagement. In: van Beek $\mathrm{CC}$, Jansen FMBH. Sturen met zorgproducten; handboek voor innovatief management in gezondheidszorg en welzijin. Houten/Diegem: Bohn Stafleu Van Loghum; 1996.

27. Scholte op Reimer W. Long-term care after stroke: studies on care utilisation, quality of care and burden of caregiving. Amsterdam: University of Amsterdam; 1999 [Thesis].

28. Van Straten A. Quality of hospital care and health outcomes after stroke. Amsterdam: University of Amsterdam; 2000 [Thesis].

29. Nackel JG, Kis GMJ, Fenaroli PJ. Cost Management for Hospitals. Rockwille: Aspen Publishers, Inc; 1987.

30. Wood TI. Thomas SE. Severity of illness and Diagnosis Related Groups. Med I Aust 1986;7 45:79 918 .

31. Hughes IS, Lichtenstein I, Magno L, Fetter RB. Improving DRGs. Use of procedure codes for assisted respitration to adjust for complexity of illness. Med Care $1989 ; 27: 750-7$.

32. Finkler SA. Flexible budget variance analysis extended to patient acuity and DRGs. Health Care Manage Rev 1985;10:21-34.

33. Voss GBWE, Dijk PH. DRG's Onbekend maakt Onbemind. Medisch Contact 1988;12: 365-68.

34. Segal ME, Whyte 1. Modeling case mix adjustment of stroke rehabilitation outcomes. Am J Phys Med Rehabill 1997;76:154-61. 
35. Davenport RJ, Dennis MS, Warlow CP. Effect of correcting ourcome data for case mix: an example from stroke medicine. BMI 1996;312:1503-5.

36. Seitz $\mathrm{CH}$. Edwardson SR. Nursing care costs for stroke patients in a rehabilitation setting. I Nurs Adm 1987;17:17-22.

37. de Boer AGEM, Wijker W, de Haes JC.M. Predictors of health care utilization in the chronically ill: a review of the literature. Health Policy 1997;42:101-15.

38. Andersen $R$, Newman IF. Societal and individual determinants of medical care utilization in the United States. The Mibank Memorial Fund Quarterly 1973;51:95-124.

39. Brosseau L, Phillippe P, Potvin L, Boulanger VL. Post-stroke inpatient rehabilitation. I. Predicting length of stay. Am / Phys Med Rehabil 1996:75:422 30.

40. Burns L.R, Douglas RW. The effects of patient, hospital, and physician characteristics on length of stay and mortality. Med Care 1991;29:251-71.

41. Feigenson IS, MCCarthy ML, Greenberg SD, Feigenson WD. Factors influencing outcome and length of stay in a stroke rehabilitation unit. Part 2. Comparison of 318 screened and 248 unscreened patients. Stroke 1977;8:657-62.

42. Feigenson IS, McDowell FH, Meese P, MCCarthy ML, Greenberg SD. Factors influencing outcome and length of stay in a stroke rehabilitation unit. Part 1. Analysis of 248 unscreened patientsmmedical and functional prognostic indicators. Stroke 1977;8:651-6.

43. Hakim EA, Bakheit AMO. A study of the factors which influence the length of hospital stay of stroke patients. Clin Rehabil 1998;12:151-6.

44. Herman IM, Culpepper L, Franks P. Patterns of utilization, disposition, and length of stay among stroke patients in a community hospital setting. I Am Geriatr Soc $1984 ; 32: 421-6$.

45. Lee $\mathrm{A}$, Huber $\mathbb{J H}$, Stason WB. Factors contributing to practice variation in poststroke rehabilitation. Health Serv Res 1997;32:197-221.

46. Lagoe RI, Lauko SJ. Stroke hospitalization under prospective payments: analysis of diagnosis related group 14. Arch Phys Med Rehabil 1985;66:773-6.

47. Monane $M_{*}$ Kanter DS, Glynn RJ, Avorn J. Variability in length of hospitalization for stroke. The role of managed care in an elderly population. Arch Neurol ॥ $996,53: 875-80$.

48. Wade DT, Langton Hewer R. Hospital admission for acute stroke: who, for how long, and to what effect? | Epidemiol Community Health 1985;39:347-52.

49. Wade DT, Wood VA, Langton Hewer R. Use of hospital resources by acute stroke patients. R Coll Physicians Lond 1985;19:48-52. 
50. Cristina A, Allevi A. Taioli $E$, Anzalone N, Nicolosi A, Polli $E$. Analysis of diagnostic procedure costs for cerebrovascular disease admission to a highly specialized hospital. Ital I Neurol Sci 1991;12:397-405.

51. Lanska DJ. Length of hospital stay for cerebrovascular disease in the United States: Professional Activity Study, 1963-1991. I Neurol Sci 1994;127:214-20.

52. Osberg IS, Haley SM, McGinnis GE, Delong G. Characteristics of cost outliers who did not benefit from stroke rehabilitation. Am I Phys Med Rehabil 1990;69:117-25.

53. van Straten $A$, van der Meulen $\mathrm{H}$, wan den Bos GA, Limburg M. Length of hospital stay and discharge delays in stroke patients. Stroke 1997,28:137-40.

54. Galski T, Bruno RL, Zorowitz $R$, Walker J. Predicting length of stay, functional outcome, and aftercare in the rehabilitation of stroke patients. The dominant role of higher-order cognition. Stroke 1993;24:1794-800.

55. Finocchi C, Gandolfo C, Gasparetto B, Del Sette M, Croce R, Loeb C. Value of early variables as predictors of short-term outcome in patients with acute focal cerebral ischemia. Ital | Neurol Sci 1996:17:341-6.

56. Hartz A., Guse C, Sigmann P, Krakauer H, Goldman RS, Hagen TC. Severity of illness measures derived from the Uniform Clinical Data Set (UCDSS). Med Care 1994:32:881-901.

57. Harvey RL, Roth El, Heinemann AW, Lovell LL, McGuire $\mathbb{R}$, Diaz S. Stroke rehabilitation: clinical predictors of resource utilization. Arch Phys Med Rehabil 1998;79:1349-55.

58. SPSS Inc. Chicago, Illinois.

59. Stroke Unit Trialists' Collaboration. Collaborative systematic review of the randomized trials of organized inpatient (stroke unit) care after stroke. BMII $1997 ; 314: 1151-9$.

60. Goldstein LB. Accuracy of ICD-9.CNM Coding for the identification of patients with acute ischemic stroke. Stroke 1998;29:1602-4.

61. Hasan $M$, Meara RJ, Bhowmick BK. The quality of diagnostic coding in cerebrowascullar disease. Int I Qual Health Care 1995;7:407-10.

62. Bamford I, Sandercock P. Dennis M. Burn J. Warlow C. Classification and natural history of clinically identifiable subtypes of cerebral infarction. The Lancet $1991 ; 337: 1521-6$. 
. 


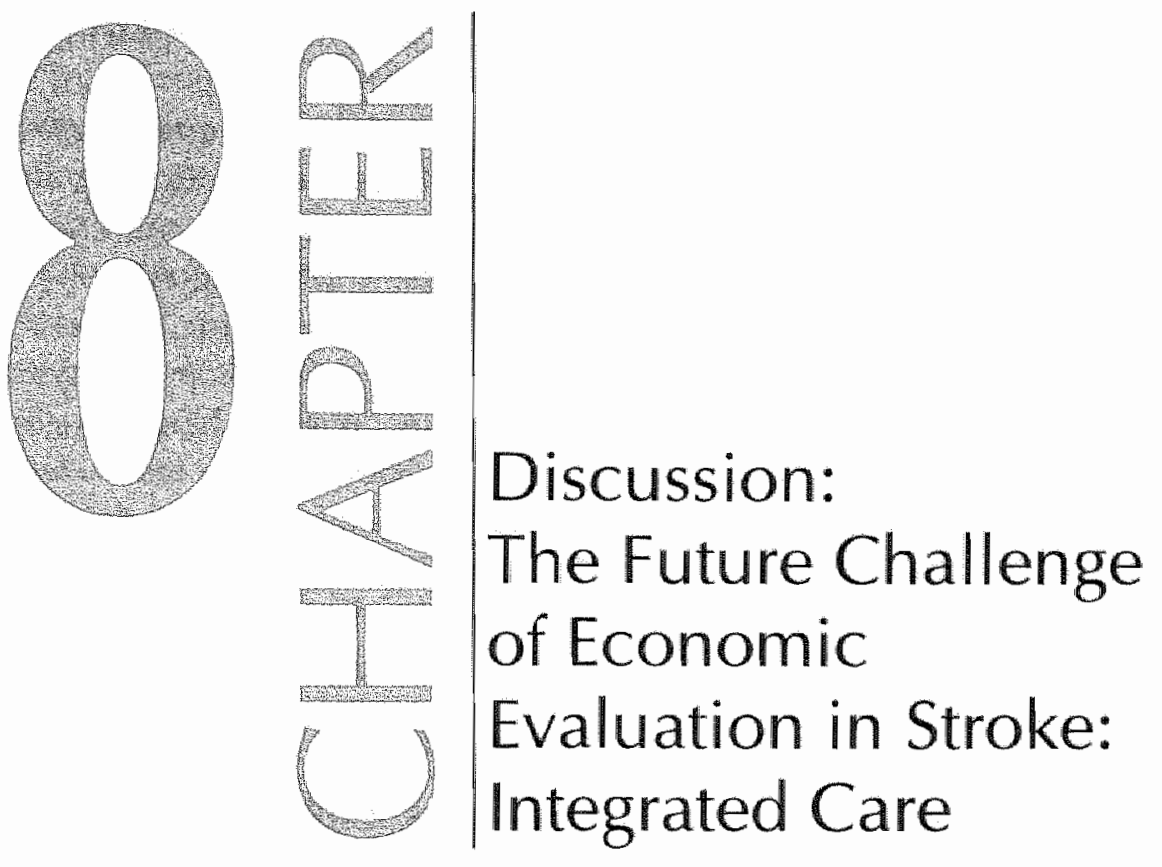




\subsection{Introduction}

The starting point of the thesis is to provide insight into the methodology of economic evaluation in stroke and to highlight some aspects of costs which are relevant when looking at the care of patients with stroke. A thesis is always imbued with the spirit of the times. In this thesis, full economic evaluation studies based on randomised controlled trials, which analyse one intervention as opposed to another intervention from a broad societal perspective, are regarded as the gold standard. This thesis has identified certain methodological aspects which are relevant when looking at the economic evaluation of stroke intervention. A broad holistic approach was chosen for the total concept of this thesis. As a result, several chapters of the thesis highlight some aspects which are often ignored in economic evaluation studies, such as the costs of psychiatric comorbidity for stroke patients.

However, in many countries stroke care is changing, and the focus is no longer on one intervention as opposed to another, but more on the coordination, integration and interrelation of various stroke care arrangements. This so-called integrated care arrangement will become increasingly important in the care of stroke patients, as it is a primary means of overcoming several bottlenecks in stroke care. The challenge of integrated care is that the implementation and economic evaluation of integrated care is performed from an angle other than the one described in this thesis. The problem is that the methodological standards discussed in this thesis cannot be applied directly when performing economic evaluation studies of integrated stroke care. Therefore, in this discussion chapter, special attention is given to the challenges which integrated care presents to economic evaluation studies in the future.

In this chapter, recommendations for policy makers are made, based on the results of the thesis. Next, there is a discussion of why the possibilities for good evidence-based economic evaluation are limited in stroke research. The following section begins with a description of the bottlenecks in stroke care, which will lead to the implementation of integrated care. The chapter concludes that integrated care will be a new challenge for future economic evaluators. 


\subsection{Recommendation for policy making}

As stated throughout the thesis, the results of economic evaluation studies can be important for policy makers. However, it is essential, before applying these economic evaluation results in policy making, that policy makers be aware of the fundamental concepts of economic evaluation studies (chapter 2) and that economic evaluators base their studies on a sound methodology (Chapters 3 and 4). Interactions between the various parties and a multidisciplinary approach can improve the likelihood that economic evaluation results are successfully applied in policy making.

Chapter 5 gives an impression of the cost of stroke for Dutch society. It has value for Dutch policy makers as this chapter gives insight into the magnitude and distribution of the costs of stroke in the Netherlands. Furthermore, crossnational comparisons (chapter 2) show that similar results for stroke are found in other countries. One of the main limitations is that in this cost-of-illness study, as in other economic evaluation studies, the cost of comorbidity is ignored. Chapter 6 investigates the costs of psychiatric comorbidity in Dutch society. This study, in conjunction with the literature, makes clear that psychiatric comorbidity is a very common and compelling problem for surviving stroke patients, leading to additional resource consumption in all countries. Economic evaluators should therefore be encouraged to consider the costs of relevant comorbidities in all future analysis, as it is obvious that information on comorbidity can provide important insights into the overall cost of a certain illness, leading to other policy decisions.

Finally, in recent years it has become obvious that the current fixed functional budgeting system does not meet current needs. The main problems are that the current system is not transparent and that its components are not congruent with the actual activities'. In chapter 7 it is shown that the implementation of an output-pricing system based on DRGs for stroke patients may be possible in hospital settings. In order to be useful for hospital financing, the DRG-system must include factors like age, discharge destination, complications, risk profile and level of functioning in its definition. The advantage of the DRG-system above the current Dutch output-pricing system is that it is based on case-mix characteristics and its components leave more room for the provision of integrated and dynamic care. 


\subsection{Major problems in economic evaluation research on stroke}

The overall conclusion of the first part of this thesis is that the technical execution and methodology of existing economic evaluation studies are limited. Although it is always easy to comment on other studies, we would like to stress that a number of additional problems limit the possibilities for performing a solid full economic evaluation study in stroke research.

First, stroke has an acute onset, which restricts the possibilities for a good baseline measurement. In addition, a large number of stroke patients die within the first year, which may lead to non-random missing values. Furthermore, stroke is not a homogeneous disease-entity, which may hamper the inclusion and selection of patient groups. Due to selection bias, often it is not possible to generalise the results of economic evaluation studies. Also, for the measurement of research data, both costs and outcomes, it is relevant that many stroke survivors have cognitive and communicative disorders, so that self-reported information cannot be obtained. In addition, a number of interventions lead to small improvements in disease severity, so that sensitive and disease-specific instruments must be used. These disease-specific health outcomes are ordinal scales and therefore are not suitable for the calculation of ratios, which can be used for allocation decisions. Finally, in their history patients might utilise a large chain of institutions, which may complicate the measurement of costs.

\subsection{Changing stroke care}

In recent years, much stress has been laid on the implementation of evidencebased medicine, in which the cost and effects of one intervention are opposed to the costs and effects of another intervention in a randomised controlled setting ${ }^{2}$. In stroke care, however, the focus is no longer on one intervention as opposed to another, but more and more on integrated care models. The narrow confines of the economic evaluation of clinical interventions are difficult to apply to integrated care models. In this section, the bottlenecks in Dutch stroke care are first highlighted, and then several integrated stroke care facilities are described, the use of which can resolve some of these problems. Although integrated care provides a solution for some care problems, it raises 
additional questions on how to continue with economic evaluation when studying integrated care models.

\subsubsection{BOTLLENECKS IN THE CARE OF STROKE PATIENTS}

Integrated care is seen as a possible solution for several of the problems presented by the care of chronic, i.e. stroke, patients. In 1995 the Dutch Heart Foundation published a report ${ }^{3}$ which gives an overview of the main bottlenecks in the treatment and care of stroke patients. The list below gives a summary of these weak areas, where problems can be resolved by the implementation of integrated care models.

If a patient has a stroke it is not immediately clear which care is best for him/her at the moment: home care, hospital care, or nursing home care. Primary care in the home situation is often provided by a GP alone; only rarely is a neurologist or a nursing home physician consulted.

One-third of patients in the acute phase are treated at home, even though it is especially difficult to organise home care at night, during weekends, and during public holidays.

If stroke patients stay at home during the acute phase, diagnostic examinations (CT-scans) are often insufficient, whereas stroke patients in hospital often receive too many diagnostic examinations.

Hospital stays due to non-medical reasons (blocked beds) are a major problem, when stroke patients in hospitals cannot be discharged to the home situation (shortage of home care), or to a nursing home (insufficient capacity). Most stroke patients are discharged to the home situation, where neither the formal nor the informal caregivers are prepared for the patients' home return. Nursing aids and home adaptation are often late. Furthermore, at the end of their recovery, when the frequency of GP visits decreases, stroke patients and their informal caregivers feel lost, and some patients and their caregivers do not dare to ask for help.

At the end of their recovery stroke patients develop cognitive and emotional problems, and their behaviour often changes. This is not understood by their informal caregivers, nor recognised by their formal caregivers.

Regarding rehabilitation, only physiotherapy and speech therapy are available for patients at home. Speech therapy is not tailored to the needs of the stroke patients. Occupational therapy is available only on a limited basis and often is not reimbursed. 
Finally, care activities of the several disciplines and health care echelons are not coordinated with one another.

\subsubsection{INTEGRATED STROKE CARE AS AN ANSWER}

Most of the above bottlenecks have to do with providing the proper stroke care facility at the proper time $e^{4,5}$. In stroke a number of integrated care models are emerging. Integrated care can be defined as the strategy for linking and coordinating the various aspects of care delivered by different care systems, such as the work of general practitioners, primary and specialised care, preventive and curative services, acute and long-term care, as well as physical and mental health services ${ }^{6}$. Irrespective of the type of integrated care, the main purpose of each arrangement is to link or tailor supply structures (in terms of the type, time and number of services and products delivered) to specific features of care demand. The orientation of integrated care toward demand explains why this type of care is also often referred to as tailor-made care ${ }^{y}$. Since these arrangements are directly tailored to demand for care, it is generally expected that integrated health care will enhance efficiency.

The Dutch Heart Foundation and the Dutch stroke consensus guidelines aim at some fundamental changes in the organization of stroke care by implementing stroke services, stroke units and TIA-outpatients' clinics $^{\text {s.14. }}$. A stroke service is defined by the Dutch Heart Foundation as a regional chain of care providers, which in a joint network guarantee an integral, professional and integrated treatment and care for stroke patients in all stages of the disease. The members of the network have joint responsibility for the adequate transfer of patients between health care facilities and have joint responsibility for the quality of the care chain at large. Coaching the informal caregiver is a main feature of the medical treatment in each link of the chain. A stroke unit is part of the stroke service $^{8}$. A large number of Dutch hospitals currently have a stroke unit ${ }^{13}$. In addition to hospital stroke units, some rehabilitation centres as well as some nursing homes have a rehabilitation stroke unit. A hospital stroke unit aims at the acute diagnosis, treatment and care of patients with an acute stroke ${ }^{13}$. The advice of the Dutch Heart Foundation is that every hospital should have a stroke unit, incorporated in a stroke service. The teams should incorporate the following stroke experts: a neurologist, specialised nurses, a rehabilitation specialist, a physiotherapist, a speech therapist, an occupational therapist, a social worker, and a transfer nurse. Ideally, a nursing home physician, a neuropsychologist, a geriatrician, an activity counsellor, and a psychiatrist 
should also be members of the multi-disciplinary team. The team should be able to consult a cardiologist, an internist, and a dietician within due time. The hospital stroke unit should be a separate unit within the hospital, with at least 4 beds providing care according to a protocol ${ }^{13}$. A relatively new phenomenon in stroke care is the TIA-outpatients' clinic, which atms at the early diagnosis of stroke (within one day by a neurologist) and prevention of secondary stroke (by changing lifestyles and if necessary providing medication $)^{14}$.

Stroke units, TIA-outpatients' clinics and stroke services are examples of integrated care facilities. An important aspect of these facilities is the remaining strong emphasis on evidence-based clinical practice and guidelines, so that the several decision makers can make informed decisions regarding care for stroke patients ${ }^{15,16}$. In integrated care facilities one has to put more emphasis on patient logistics and care chains, and consequently on the development of suitable information systems with a more flexible financial structure. However, patient logistics, care chains, and improved information systems cannot be seen as a replacement, but rather as a support for, economic evaluation, which remains the primary tool for performing efficient decisions ${ }^{4}$.

\subsection{Evaluation of integrated care: a new challenge for future research}

The problems described in paragraph 8.4.1 increasingly force care providers, insurers and governments to make financial, organizational and investment decisions on the development, introduction or prolongation of integrated care. However, the economic evaluation of integrated care is challenging and may raise many methodological questions ${ }^{\gamma}$.

Integrated care is tailor-made; therefore different stroke patients need different stroke models. This limits the possibilities of protocolised controlled designs and of standardised cost-and effect measurement. Integrated care has more processing characteristics: co-operation, co-ordination, re-evaluation and sharing of responsibility are the core features of integrated care. These aspects induce additional processing costs, which are normally not included in an economic evaluation study. Furthermore, integrated care models have to be continuously re-developed and fine-tuned, leading to structural transition costs. 
In many instances integrated care also involves different substitution processes. The substitution of outpatient for inpatient care is a well-known example. Substitution of this kind is stimulated by technological innovations that enlarge the possibilities for treating patients at home. For many integrated care services, the presence of informal care or other facilitating services at home can be indispensable for the realisation of integrated care types that encompass substitution. In a number of integrated care models, much emphasis is placed on the valuation of informal care. The costs of informal caregiving are often not included in economic evaluation studies. For a solid economic evaluation of integrated care models, it is necessary to value the time and effort which family and friends spend on the stroke patient.

In conclusion, the development of integrated care models in stroke results in new challenges for economic evaluation studies in stroke research. These involve the determination of the costs and effects of continuously changing integrated care arrangements and the inclusion of cost components that are uncommon to most economic evaluations studies, such as processing costs, fransition costs, and informal care costs. This calls for a more process-oriented determination of costs and effects, such as activity-based costing and the continuing development of standardised generic and sensitive quality of life instruments ${ }^{17.18}$.

\section{References}

1. Tweede Kamer der Staten-Generaal vergaderjaar 1999-2000. Positionering algemene ziekentivizen. "s-Gravenhage: Sdu Uitgeverij; 2000.

2. Maynard A, Sheldon TA. 7 Health economics: has it fulfilled its potential? In: Maynard A, Chalmers I, editors. Non-random Relections on Health Services Research: On the 25th anniversary of Archie Cochrane's Effectiveness and Efficiency. London: BMI Publishing Group; 1997.

3. Meyboom-de Jong B, Buis J. Zorg na een beroente; een publikatie van de Nederlandse Hartstichiing over de gevolgen en de daamee samenhangende zorg: bevindingen, knelpunten en aanbevelingen. Den Haag: Nederlandse Hartstichting; 1995.

4. Tuinstra J, Matthesius D, I.W. C, Post D. Disease Management, een eerste verkenning. Groningen: Rijksuniversiteit Groningen: Gezondheidswetenschappen, Sociale Geneeskunde, Noordelijk Centrum woor Gezondheidsvraagstukken; 1998. 
5. Brouwer de Koning 1. Patienten op het juiste moment op de juiste plek. WW bulletin 1997:27 maant 1997:11-3

6. Mission Statement International Journal of Integrated Care. Mission statement. IIC 2000.

7. Paulus A, van Raak A, van Merode $F$, Adang $\mathbb{E}$. Integrated health care from an economic point of view. I Econ Stud 2000;27:200-9.

8. Nederlandse Hartstichting. Stappenplan stroke service; een zeven-stappenmdel om te komen tot regionale samenwerking in de CVA-zorg. Den Haag: Nederlandse Hartstichting; 1999.

9. Nederlandse Hartstichting, CBO kwaliteitsinstituut woor de gezondheidszorg. Beroerte. Alphen aan den Rijn: 2000 Van Zuiden Commumications BV; 2000.

10. Nederlandse Hartstichting. CVA/Stroke Services Nieuwsbrief. Den Haag: Nederlandse Hartstichting; 2000.

11. Kwaliteitsinstituut woor de Gezondheidszorg (CBO). Richtlijn Beroerte. Utrecht: Kwaliteitsinstituut voor de Gezondheidszorg (CBO); 2000.

12. Limburg $M$. Tuut MK. CBO-richtlijn 'Beroerte' (herziening). NTvG 2000; 144:1058-62.

13. Nederlandse Hartstichting Commissie Ontwikkeling Richtlijnen Stroke Unit (CORSU). Advies Opzet Stroke Unit. Den Haag: Nederlandse Hartstichting; 2001.

14. Nederlandse Hartstichting Commissie Ontwikkeling Richtlijnen TIA-Poli (CORTIP). Advies Opzet Tia-Poli. Den Haag: Nederlandse Hartstichting; 2001.

15. Ellrodt $G$, Cook DJ, Lee I, Cho M, Hunt D, Weingarten S. Evidence-based disease management. JAMA 1997;278:1687-92.

16. Rohrbach J. Critical pathways as an essential part of a disease management program. J Nurs Care Qual 1999;14:11-5.

17. Baker Jl. Activity-based costing for integrated delivery systems. I Health Care Finance $1995 ; 22: 57-61$.

18. Huijsman R. Economic evaluation of care for the chronically ill: a literature review. Eur f Public Health 1995:5:8-17. 
Summary 
- 


\section{Summary 'Economic evaluation of stroke'}

In recent years, due to the increasing growth of the developments in health care, a tension field has emerged between medical possibilities and the available financial means. This has led to an increasing interest in economic evaluation studies, in which a comparative analysis between alternatives in terms of costs and effects is the main issue. This thesis describes the application of economic evaluation studies in the field of stroke lor Cerebrovasculair Diseases (CVD)).

Stroke is an important disease both in medical and in socio-economic terms. In the Netherlands about 30,000 people a year suffer a stroke for the first time. Of these stroke patients one third dies within the first year after the stroke and $41 \%$ of the survivors experience limitations in their daily activities.

The aim of this thesis is twofold. Firstly, the methodological aspects regarding economic evaluation in stroke are evaluated. Secondly, this thesis is the first to make mention of in-depth studies regarding some aspects of costs in stroke research, such as the cost of psychiatric comorbidity in stroke and the use of Diagnosis Related Groups as a tool to explain the different stroke costs within the hospital.

Chapter 1 outlines the backgrounds of economic evaluation and of stroke. Initially, stroke as a disease is introduced. Then, some major epidemiological aspects of stroke are described. Third, the overall health care utilisation based on an average stroke patient's career is described. Fourth, the economic burden of stroke, as well as the concept of economic evaluation, is discussed. Finally, the major points of the thesis are presented in outline.

The purpose of chapter 2 is to provide insight into economic evaluation studies in the field of stroke, so that these studies become easier for nonexperts to understand and to apply. Crucial aspects in economic evaluation research are addressed successively, such as inclusion of costs and outcomes, sensitivity analysis, discounting, incremental analysis and ratios, and the collection of data in economic evaluation research. The chapter notes that economic evaluation analyses of stroke are less accessible than they may be for other disorders, because of the typical characteristics of stroke and stroke research. Further emphasis is placed on the transparent reporting of methods and study results. Clear reporting facilitates the interpretation of the results of 
published studies and may enable one to assess the generalisability of results from one setting to another.

Chapter 3 systematically analyses the quality of economic evaluation in the field of stroke, with a review of 23 trial-based full economic evaluation studies. The chapter presents a cletailed summary of the economic evaluation data given by each of these studies and provides insight into the quality of the economic evaluations in the field of stroke. The quality of the studies was independently assessed by two reviewers using a checklist. The overall conclusion of this review is that the technical execution and methodology were limited in most of the economic evaluation studies in stroke. Little attention was paid in these studies to the measurement of patient and family costs and health-related quality of life. This chapter shows that the small number economic evaluations of comparable stroke interventions, combined with the large differences and low quality of the costing methodologies used, render it impossible to draw conclusions in favour of any one type of intervention for the care of stroke patients.

Chapter 4 reports the use of ratios for allocation decisions in stroke. The results of economic evaluation can be expressed in cost per QALY gained, which enables policy makers to compare the relative efficiency of different interventions regarding different diseases. One QALY is equal to one year in full health. Although using the concept of QALY is preferable from a theoretical point of view, for practical reasons cost-effectiveness analysis (CEA) rather than cost-utility analysis (CUA), is more often applied in medical practice. One of the main limitations of CEA is that the results may be compared only with results of other CEAs using the same effect parameter. The chapter shows that in many cases the calculation of cost-effectiveness ratios (CERs) is misleading for resource allocation.

Chapter 5 presents the cost of stroke in the Netherlands from a societal perspective. The chapter calculates that in 1993 the cost of stroke in the Netherlands amounted to 1.1 billion Euros, of which 0.9 billion were spent on medical consumption. This is over $3 \%$ of the annual Dutch healthcare budget. It was found that direct costs are generated mainly by the long-term care of inpatients (nursing homes and hospitals). The productivity losses were relatively low in comparison with other diseases, probably due to the fact that most patients with stroke are elderly. 
Chapter 6 analyses stroke patients' use of mental health care. Although psychiatric comorbidity is relevant for a number of diseases, it is often ignored in technology assessment. This chapter examines the service use rate in mental health care facilities and related costs for stroke patients discharged from University Hospital Maastricht between 1987 and $1995.16 \%$ of stroke patients used mental health services during the 10-year period around the stroke lfive years before and five years after), Of the users group, $88 \%$ had a mental health care contact following stroke. Regression analysis shows that age, length of hospital stay, and mental health care contact before stroke are associated with mental health care use after stroke. It is remarkable that there is already an increase in mental health care consumption in the prodromal phase just before the stroke. Extrapolating these mental health care costs to the Netherlands shows that stroke patients have a high psychiatric comorbidity, inducing about $1.3 \%$ of total mental health care costs.

Chapter 7 examines the prediction of hospital stay costs for stroke patients by the use of Diagnosis Related Groups (DRGs). The results of this chapter show that using current DRGs, which include operation, patient's age and discharge status, the variance explained in the costs amounts to $34 \%$. Adding other predictors to the DRGs, the variance explained increases to about $61 \%$. Additional factors highly predictive of inpatient costs are the level of functioning after stroke, comorbidity, complications, and "blocked beds". Costs decreased for stroke patients discharged during the latter part of the years studied, and if stroke patients happened to die during their hospital stay. The results do suggest that future implementation of output-pricing based on the DRG casemix measures is only feasible for stroke patients if it is enhanced with information on complications and the level of functioning.

Chapter 8 presents the most important findings of the different studies addressed in this thesis and based on the results of this thesis recommendations for policy makers are given. Furthermore, the chapter discusses integrated care as a future challenge for the economic evaluation of stroke. It is argued that the methodological standards formulated in this thesis cannot be applied directly and simply when performing economic evaluation studies of integrated stroke care. Consequently, special attention must be given to the problems which integrated care puts upon the future of economic evaluation studies in stroke research. 


\section{.}

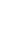

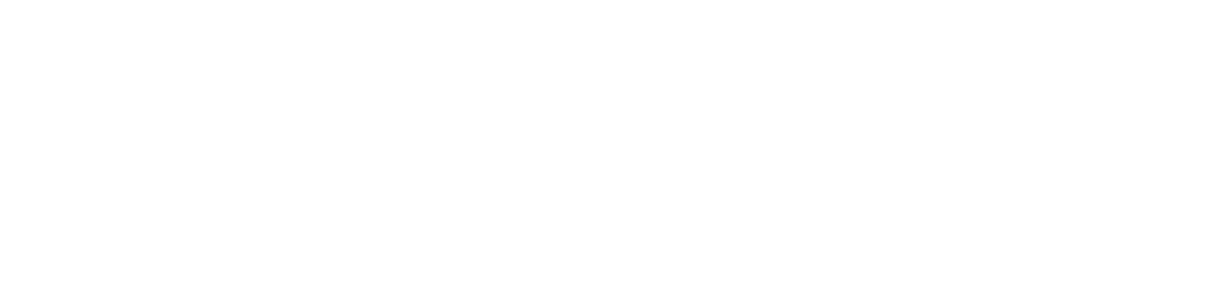


Samenvatting 


\section{Samenvatting 'Economisch evaluatieonderzoek bij beroerte'}

De afgelopen decennia is, mede door een toenemende groei van de ontwikkelingen in de gezondheidszorg, een spaniningsveld ontstaan tussen de medische mogelijkheden en de beschikbare financiën. Dit heeft onder meer geleid tot een toenemende belangstelling voor economisch evaluatieonderzoek, waarin een vergelijkende analyse van altematieven in temen van kosten en effecten centraal staat. In dit proefschpift wordt economisch evaluatieonderzoek toegepast op het gebied van beroerte loftewel cerebro Vasculair Accident (CVA)). Een beroerte is zowel in medisch als in sociaaleconomisch opzicht een belangrijke aandoening. Per jaar worden in Nederland ongeveer 30.000 personen voor de eerste keer getroffen door een beroerte. Van alle patiënten met een beroerte oveflijd eenderde binnen het eerste jaar na de beroerte. Van alle overlevenden ondervindt $41 \%$ als gevolg van de beroerte beperkingen bij het witvoeren van activiteiten in het dagelijks leven.

Het doel van dit proefschrift is tweeledig. Ten eerste worden de methodologische aspecten van economische evaluaties op het gebied van beroerte geanalyseerd. Ten tweede, wordt binnen dit proefschrift als eerste dieper ingegaan op enkele economische aspecten die relevant zijn voor onderzoek op het gebied van de beroente, zoals onderzoek naar de kosten van psychiatrische comorbiditeit bij een beroerte en het gebruik van Diagnosis Related Groups (DRGs) als instrument om de verschillen in kosten van een beroente binnen het ziekenhuis te verklaren.

Hoofdstuk 1 geeft een beschouwing van de achtergronden van zowel economisch evaluatieonderzoek, als wan beroerte. Om te beginnen, wordt beroente als ziekte geintroduceend. Vervolgens worden enkele epidemiologische kerngegevens weergegeven. Ten derde wordt het gebruik van voor zieningen beschreven, gebaseerd op de gemiddelde zorgketen van patiënten met een beroerte. Als vierde wordt de economische ziektelast van beroerte besproken en wordt het concept van economisch evaluatieonderzoek verder toegelicht. Ten slotte, worden de belangrijkste onderwerpen van dit proefschrift gepresenteerd.

Het doel van hoofdstuk 2 is om inzicht te verschaffen in het economisch evaluatieonderzoek op het gebied van beroerte, zodat deze ecomomische evaluatiestudies beter kunnen worden begrepen en kunnen worden toegepast 
door niet deskundigen op dit onderzoeksgebied. Cruciale aspecten van het economisch evaluatieonderzoek komen achtereenvolgens aan de orde, zoals meting van kosten en effecten, sensitiviteitsanalyse, discontering, incrementele analyses, ratio's en de dataverzameling binnen economisch evaluatie-onderzoek. In dit hoofdstuk wordt opgemerkt dat economisch evaluatie-onderzoek soms moeilijker is toe te passen bij beroerte in vergelijking met andere ziekten, vanwege de typische karakteristieken van beroerte. Verder wordt er nadruk gelegd op een transparante verslaglegging van de methoden en de resultaten van het onderzoek. Heldere verslaglegging vergemakkelijkt de interpretatie van resultaten van gepubliceerde economische evaluatie-onderzoeken en bevordert de generaliseerbaarheid van de ene setting naar de andere setting.

Hoofdstuk 3 analyseert de kwaliteit van het bestaande economisch evaluatieonderzoek op het gebied van beroerte door middel van een systematische review van 23 economische evaluatiestudies. Het hoordstuk geeft een gedetailleerde samenvatting van de economische evaluatie gegevens van iedere studie en geeft inzicht in de methodologische kwaliteit van de afzonderlijke studies. De kwaliteit van de studies is onafhankelijk door twee reviewers vastgesteld, waarbij gebruik werd gemaakt van een checklist. De algehele conclusie van deze systematische review is dat de technische uitvaering en methodologie van de meeste economische evaluatie-onderzoeken op het gebied van beroerte beperkt is. Verder wordt er binnen deze onderzoeken weinig aandacht besteed aan de kosten van een beroerte voor de patiënt en zijn of haar familie en aan gezondheidsgerelateerde kwaliteit van leven. Door het geringe aantal economische evaluatiestudies per afzonderlijke interventie, in combinatie met de grote methodologische verschillen en de beperkte methoden, is het onmogelijk om conclusies te trekken ten aanzien van de kosten-effectiviteit van de ene interventie ten opzichte van de andere in relatie tot de zorg voor patiënten met een beroerte.

Hoofdstuk 4 gaat verder in op het gebruik van ratio's bij allocatie beslissingen op hel gebied van beroerte. De resultaten van een economische evaluatiestudie kunnen worden uitgedrukt in kosten per gewonnen QALY (Quality Adjusted Life Year). Eén QALY is gelijk aan één jaar in volledige gezondheid. Het gebruik van QALYs maakt het voor beleidsmakers mogelijk om de relatieve efficiëntie van verschillende interventies bij verschillende aandoeningen met elkaar te vergelijken. Alhoewel thet QALY concept vanuit theoretisch oogpunt de voorkeur verdient, wordt in de dagelijkse medische 
toepassing vanwege praktische redenen vaak gekozen woot een kosteneffectiviteitsanalyse (KEA) in plaats van een kosten-utiliteitsanalyse (KUA). Een van de belangrijkste beperkingen van een KEA is dat de resultaten slechts kunnen worden vergeleken met de resultaten van een andere KEA indien dezelfde uitkomstmaten worden gebruikt. Het hoofdstuk toont aan dat het gebruik van kosten-effectiviteitsratio's vaak misleidend kan zijn bij het nemen van allocatiebeslissingen.

In hoofdstuk 5 worden de kosten van beroerte in Nederland vanuit een maatschappelijk perspectief gepresenteerd. In dit hoofdstuk wordt berekend dat de kosten voor beroerte in Nederland 1,1 miljard euro bedragen, waarvan 0,9 miljard euro wordt uitgegeven aan medische consumptie. Dit is ongeveer $3 \%$ van het jaarlijkse Nederlandse gezondheidszorgbudget. De directe gezondheidszorgkosten worden met name gegenereerd door de langdurige intramurale zorg voor patiënten met een beroerte (ziekenhuizen, verpleeghuizen). De productiviteitsverliezen zijn relatief laag in vergelijking met andere ziekten, waarschijnlijk door het feit dat patiënten met een beroerte over het algemeen ouder zijn.

Hoofdstuk 6 analyseert het gebruik van geestelijke gezondheids-zorgvoorzieningen door patiënten met een beroerte. Alhoewel psychiatrische comorbiditeit relevant is voor een aantal aandoeningen wordt het vaak buiten beschouwing gelaten in economisch evaluatieonderzoek. Het hoordstuk onderzoekt het gebruik van voorzieningen in geestelijke gezondheidszorg en de daaraan gerelateerde kosten voor patiënten met een beroerte die zijn ontslagen uit het Academisch Ziekenhuis Maastricht in de periode 1987 tot en met 1995. Van de patiënten met een beroente maakt $16 \%$ gebruik van de geestelijke gezondheidszorg in een 10-jaars periode rondom de beroente (vijf jaar ervoor en vijf jaar erna). Van deze gebruikersgroep had $88 \%$ contact met de geestelijke gezondheidszorg na de beroerte. Een regressie analyse laat zien dat leeftijd, duur van het verblijf in het ziekenhuis en het gebruik van de geestelijke gezondheidszorg voor een beroerte geassocieerd zijn met het gebruik van geestelijke gezondheidszorgvoorzieningen na een beroerte. Het is opmerkelijk dat er al een toename is in het gebruik van voorzieningen in de geestelijke gezondheidszorg in de prodromale fase, vlak voor de beroente. Indien de gegevens worden geëxtrapoleerd naar alle geestelijke gezondheidszorgkosten in Nederland dan blijkt dat de kosten van de psychiatrische 
comorbiditeit ten gevolge van een beroerte ongeveer gelik is aan $1,3 \%$ van de kosten in de geestelijke gezondheidszorg.

Hoofdstuk 7 gat verder in op vraag hoe ziekenhuiskosten voor patiënten met een beroerte voorspeld kunnen worden op basis wan Diagnosis Related Groups. (DRGS). De resultaten van dit hoofdstuk geven aan dat met de huidige DRGs, waarin wordt gekeken naar operaties, leeftijd en ontslagbestemming, de verklaarde variantie ongeveer $34 \%$ bedraagt. Door andere predictoren toe te voegen aan de DRGs, neemt de verklaarde variantie toe to ongeveer $61 \%$. Additionele factoren die in hoge mate predictief zijn voor de verklaring van de intramurale kosten zijn niveau van functioneren na een beroerte, comorbiditeit, complicaties en 'verkeerde bedden'. Verder nemen de kosten voor patiënten met een beroerte af, indien patiènten in de laatste jaren van de onderzoeksperiode zijn ontslagen en als patiënten met een beroerte overlijden tijdens de ziekenhuisopname. De resultaten suggereren dat financiering van de zorg op basis van DRGs mogelijk is, echter om betrouwbaar te zijn voor patienten met een beroerte dient informatie over comorbiditeit, complicaties en het niveau van functioneren in de DRGs te worden meegenomen.

Hoofdstuk $\mathbf{8}$ geeft een overzicht van de belangrijkste bevindingen wan de verschillende studies en schetst welke implicaties de resultaten hebben voor beleidsmakers. Verder bediscussieert het hoofdstuk dat de invoering van integrale zorg een nieuwe uitdaging vormt voor het economisch evaluatieonderzoek op het gebied van beroerte. In dit hoofdstuk wordt extra aandacht geschonken aan de specifieke problemen die naar voren komen bij economische evaluatieonderzoek naar integrale zorgarrangementen. In samenhang hiermee wordt beargumenteerd warom de methodologische richtlijnen die worden gehanteerd binnen dit proefschritt niet kunnen worden toegepast bij een economische evaluatiestudie van integrale zorgarrangementen. 
Co-authors and
Affiliations 



\section{Co-authors and affiliations}

Andre J.H.A. Ament; Maastricht University, Department of Health Organisation, Policy and Economics.

Rob M.P.M. Baltussen; Formerly University Hospital Maastricht, Department of Health Organization, Policy and Economics. Currently World Health Organization Geneva, EIP/EQR.

Gerhard Blaauw; University Hospital Maastricht, Department of Neurosurgery.

Anita M.H.P. Boreas; University Hospital Maastricht, Department of Neurology.

Ger A.M. Driessen; Maastricht University, Department of Psychiatry and Neuropsychology.

Gerard L. Engel; Formerly University Hospital Maastricht, Board of Directors. Currently University Hospitals' Associations.

Mariëlle E.J.B. Goossens; iRv, Institute for Rehabilitation Research.

Tom L.C.M. Groot; Vrije Universiteit Amsterdam, Department of Accounting.

Jan Lodder; University Hospital Maastricht, Department of Neurology.

Johannes A.M. Maarse; Maastricht University, Department of Health Organisation, Policy and Economics.

Fred H. Nieman; University Hospital Maastricht, Department of Clinical Epidemiology and Medical Technology Assessment.

Gemma B.W. Voss; University Hospital Maastricht, Department of Clinical Epidemiology and Medical Technology Assessment. 
Dankwoord 



\section{Bedaaaankt !}

Nooit zou ik als onderzoeker zijn begonnen als ik in 1990 geen stage had gelopen bij het Centraal Bureau voor de Statistiek, afdeling Gezondheidsstatistieken, onderafdeling Onderzoek Gezondheid en Gebruik Voorzieningen. De gedrevenheid voor het onderzoek is daar begonnen en nog steeds niet getemd. Onderzoek doe je (gelukkig!) niet alleen. Steeds ben ik enthousiaste collega's tegenkomen bij mijn verschillende werkplekken. Dank aan iedereen waarmee ik achtereenvolgens heb samengewerkt bij de vakgroep epidemiologie (UM), de faculteit Pedagogische Wetenschappen (UVA), de RIGG Amsterdam, de GG\&GD Amsterdam, de vakgroep Economie van de Gezondheidszorg (UM), de vakgroep Medische Sociologie (UM) en de afdeling neurochirurgie (azM). Met veel plezier ben ik sinds april '99 werkzaam op verschillende projecten bij de capaciteitsgroep Beleid, Economie en Organisatie van de Zorg. Astrid, Emily, Hilde, Isel (mooie lay-out), Jan, Marianne, Peggy, Pieter en Will bedankt voor alle ondersteuning. Daanaast maken met name Aggie, Angelique, Brigitte, Femke, Frits, Gladys, Gerry, Inge, Leonardo (jammer dat je onze kamer zo abrupt moest verlaten), Maria, Sandy en Suzanne dat "Just another day at HOPE" de moeite waard is.

In een wisselende frequentie, format en samenstelling gaven de leden van MTA-werkgroep ruimte voor een diepgaande inhoudelijke gedachtenwisseling binnen mijn vakgebied. $\mathbb{k}$ ben benieuwd hoe het verder gaat binnen het Maastrichtse TA wereldje. Uit de lijst van co-auteurs en de acknowledgements mag blijken dat dit proefschrift tot stand is gekomen, dankzij de medewerking van velen. Bedankt voor deze vruchtbare samenwerking. Dank ook aan de patiënten en hun informele zorgverleners die ik heb mogen interviewen; zij gaven het onderzoek naar beroerte voor mij een gezicht. Barbara Greenberg zorgde binnen dit proefschrift voor de puntjes op de Engelse ' $i$ '. De leden van de beoordelingscommissie: prof. Trudi van den Bos, prof. Wim Groot, prof. Katrien Kesteloot, Dr. Jan Lodder en prof. Onno van Schayck ben ik erkentelijk woor het beoordelen van mijn proefschrift. Sinds afgelopen jamuari verricht ik in samenwerking met het Centrum voor Zorgonderzoek van het RIVM een post-doc studie naar de (on)mogelijkheden om economische evaluatiegegevens van het ene land naar het andere vertalen. Alhoewel ik een minder geijkte plek bij jullie heb, hoop ik dat al onze plannen uitkomen. 
Een betere copromotor dan André Ament had ik me niet kunnen wensen. André, je zorgde voor de rode draad in mijn proetschrift. Je bent een goede inhoudelijke coach en een onmisbare sparringpantner. Overleggen met jou is een genot, jouw originele en creatieve kijk op onderzoek en jouw gevoel voor humor zijn voor mij onmisbaar. Mijn andere co-promotor Gerhard Blaauw bracht me in contact met het onderwerp van het proefschrift en gaf me de vrijheid om naast het SICHPA-onderzoek ook andere studies uit te voeren. Op deze plek will ik ook de leden van de SICHPA-groep, met name Emille Beuls, Antonette Bok, Cees Franke, Fons Kessels, Pieter Leffers, Jan Lodder en Onno Teernsta bedanken voor hun steun tijdens dat moeilijke onderzoek. André en Gerhard, ik beschouw het als een eer dat jullie beide mijn co-promotoren zijn. Natuurlijk wil ook mijn beide promotoren, Hans Maarse en Tom Groot, bedanken voor alle tijd en moeite die zij aan mij hebben besteed. Jullie waren elk op jullie eigen wijze onontbeerlijk voor de totstandkoming van dit proefschrift. Tom, de reizen naar Amsterdam waren meer dan de moeite waard. Hans bedankt voor je inzet ook wanneer het mis dreigde te lopen met mijn aanstelling.

Aan een dankwoord beginnen op de $11^{*}$ september zet alles toch in een ander perspectief. Beste pap en mam, de eerste cijfers en letters heb ik van jullie geleerd. Alles daama is een verdere verfijning van jullie fundamenten. Bedankt voor jullie onvoorwaardelijke liefde en steun. Dankzij de vrijheid die jullie mij gaven en het vertrouwen dat jullie in mij hebben, ben ik geworden tot wie ik ben vandaag. Tiny; je was steeds trots op mij, jammer genoeg ben je eir 7 december (a thans lijelijk) niet bij. Als er een hemel bestaat, vrees ik dat je nu voor onze lieve heer staat met mijn proefschrift. Merci voor alle kansen die jullie mij hebben geboden. Dit boekje is voor jullie.

Een speciaal woord van dank voor mijn paranimfen, Mariëlle Goossens en Nathalie Janssen. Het is een enorme geruststelling dat jullie tijdens mijn verdediging naast mij zullen staan. Mariëlle; als lotgenoten delen we lief en leed. Van onderzoeksmaatje, eind " 91 bij $E G Z$, werd je in alle opzichten een vriendin woor het leven. Zonder jou zouden de afgelopen jaren er heel anders hebben uitgezien. Dank voor dit alles, maar vooral woor de peptalk als ik het weer eens even niet zag zitten. Nathalie; jij zorgt voor rust en gezelligheid op onze kamer en geeft ruim de gelegenheid om stoom af te blazen als me iets. (Word) of iemand tegenzat. Ik geloof erin dat jij snel op de plek kornt te staan waar ik nu sta! 
Dank ook aan al mijn vrienden en (schoon)famillie die ervoor zorgden dat ik niet verstoken bleer van andere leuke dingen in het leven. Ondanks vele omzwervingen bleef ik met velen van jullie contact houden. Hoewel mijn carrièrepad voor jullie vaak ondoorzichtig was, bleven jullie met warme belangstelling en steun mijn werkzaamheden volgen. De vraag "hoe is het met je p...?", werd altijd met veel gezucht en gekreun beantwoord. Het is af! ; althans dat denk ik. Dank voor alle gezelligheid, gesprekken, raad en wijsheid. Nu heb ik hopelijk meer tijd voor alternatieve bezigheden. Diane; die 'Nacht van Gulpen' lopen we nog eens een keer samen. De avondonderwijsgroepen van de studie rechten heb ik altijd als heel stimulerend ervaren. Dankzij mijn studiekameraden van jaargang '94, met name Hans, Julie en Martien, kreeg ik een andere 'kijk' op wetenschap.

Lieve Loek en Lara; Loek we zijn op vele gebieden tegenpolen, daardoor zien we vele kanten van het leven. Jouw humor, liefde, en relativeringsvermogen, maar ook onze taakverdeling zijn niet te onderschatten factoren bij het totstandkomen van dit proefschrift. Er zijn geen woorden genoeg om jou te bedanken. Laartje 7 december is het precies zeven maanden geleden dat jij (op 7 mei dus) in ons midden kwam. Meer getallensymboliek is er niet nodig. Ik ben benieuwd welke avonturen we nog samen gaan beleven!

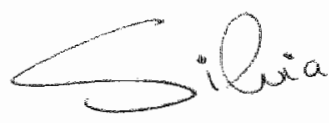




$$
\text { " }
$$




\section{List of Publications Curriculum Vitae}




\section{List of Publications}

This thesis is based on the following publications:

\section{Chapter 2}

Evers SMAA, Goossens MEIB, Ament AJHA, Maarse JAM. Economic evaluation in stroke research: an introduction. Cerebrovascular diseases 2001;11:82-91.

\section{Chapter 3}

Evers SMAA, Ament AJHA, Blaauw G. Economic evaluation of patients with cerebrovascular diseases; a review. Stroke 2000;31:1046-1053.

\section{Chapter 4}

Ament AIHA, Evers SMAA. The usefulness of ratios for allocation decisions: the case of stroke. Cerebrovascular Diseases 2000;10:283-288.

\section{Chapter 5}

Evers SMAA, Engel GL, Ament AJHA. Cost of stroke in the Netherlands from a societal perspective. Stroke 1997;28:1375-1381.

\section{Chapter 6}

Evers SMAA, Ament AlHA, Driessen GAM. The use of mental health care by patients with cerebrovascular diseases: a cost-analysis. International journal of Technology Assessment in Health Care: accepted for publication.

\section{Chapter 7}

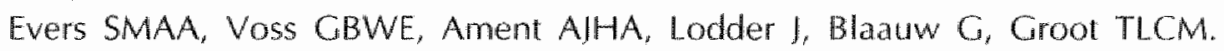
Predicting the costs of hospital stay for patients with cerebrovascular diseases: the use of diagnoses related groups. Health Policy: accepted for publication.

* Reprinted with kind permission of Lippincott Williams \& Wilkins (Chapter 3 and Chapter 5) and Karger, Basel (Chapter 2 and Chapter 4). 


\title{
Publications outside this thesis
}

\author{
INTERNATIONAL ARTICLES
}

- Evers SMAA. Health for All indicators in Health Interview Surveys: an overview of the coverage of Health for All indicators in population surveys inside the European Region and some selected countries outside the Region. Health Policy 1993;23:205-218.

- Ament AJHA, Evers SMAA. Cost-of-illness studies in health care: a comparison of two cases. Health Policy 1993;26:29-42.

- Evers SMAA, Ament AJHA. Costs of schizophrenia in the Netherlands. Schizophrenia Bulletin 1995;21;141-153.

- Evers SMAA, van Wijk AS, Ament AJHA. Economic evaluation of mental health care interventions, A review. Health Economics 1997;6:161-177.

- Goossens MEIB, Evers SMAA. Economic Assessment of Back Pain Interventions. Journal of occupational rehabilitation 1997;7:15-32.

- Evers SMAA, Stevens FCl, Diederiks JPM, Ponds RWHM, Kaplan C, Drop MI, Metsemakers JFM, Jolles J. Age-related differences in cognition: lifestyle, perceived health status, and socio-demographic factors. European Journal of Public Health 1998;2:133-139.

- Goossens MEJB, Evers SMAA, Vlaeyen JWS, Rutten-van Mölken MPMH, van der Linden SMID. Principles of economic evaluation for interventions of chronic musculoskeletal pain. European Journal of Pain 1999;3:343-353.

- Evers S, Paulus A, Boonen A. Integrated Care across Borders: Possibilities and Complexities. International Journal of Integrated Care 2001;1:http:/www.ijic.org/.

- Kotsopoulos IAW, Evers SMAA, Ament AJHA, de Krom MCTFM. Estimating the cost of epilepsy: an international comparison of epilepsy cost studies. Epilepsia 2001;42:634-640.

- Aldenkamp AP, Van de Veerdonk SHA, Majoie HIM, Berfelo MW, Evers SMAA, Kessels AGH, Renier WO, Wilmink J. Effects of 6 months treatment with vagus nerve stimulation on behavior in children with the Lennox-Gastaut syndrome in an open clinical and non-randomized study. Epilepsy and Behaviour 2001;2:343-350.

- Paulus A, Fecher F, van der Made J, Evers S, Boonen A. The effectiveness of tailor-made care: cross border care between Belgium 
and the Netherlands. European Journal of Law and Economics: submitted for publication: submitted for publication.

- van den Bemt L. Evers S, Ament A. Cost of hard drug abuse in the Netherlands from a societal perspective. British Journal of Addiction: submitted for publication.

- Majole HIM, Berfelo MW, Aldenkamp AP. Evers SMAA, Kessels AGH, Renier WO. Vagus Nerve Stimulation for Children with therapy resistant epilepsy diagnosed as Lennox-Gastaut syndrome. Neurology: submitted for publication.

- Kotsopoulos IAW, Evers SMAA, Ament AJHA, Kessels FGH, de Krom MCTFM, Knottnerus IA. Twellaar $M$. The costs of epilepsy in three different populations of patients with epilepsy. Epilepsy Research: submitted for publication.

- Kerssens IJ. Evers SMAA, Verhaak PFM, van Merode GG, Paulus ATH, Bensing IM. Costs of chronic benign pain disorders in The Netherlands. Pain: submitted for publication.

- Driessen G, Evers S, Verhey F, van Os I. Stroke and Mental Health Care: A record linkage study. Social Psychiatry and Psychiatric Epidemiology: submitted for publication.

INTERNATIONAL BOOK CHAPTERS

- Evers SMAA, Haveman MJ, Jacobs CMVW, Bijl RV. Chapter 10 The Netherlands. In: Kemp DR. International Handbook of Mental Health Policy. Westport/Connecticut/London: Greenwood Press Inc; 1993.

- Evers SMAA, Stevens FCI, Diederiks IPM, Drop Mi. Chapter 10 Life styles and cognitive aging. In: Jolles 1, Houx PJ, van Boxtel MPI, Ponds RWHM. Maastricht Aging Study: Determinants of Cognitive Aging. Maastricht: Neuropsych Publishers; 1995.

- Evers SMAA, Ament AlHA. Chapter 37 The economic impact of schizophrenia on the Dutch society. In: Moscarelli M, Rupp A, Sartorius N. The economics of schizophrenia. Sussex, John Wiley \& Sons Ltd; 1996.

- Coossens MEJB, Evers SMAA. Chapter 18 Cost-effectiveness of treatment of neck and low back pain. In: Nachemson A, Jonsson E. Neck and Back Pain. The scientific evidence of causes, diagnosis and treatment. Stockholm/Philadelphia: SBU/Lippincott; 2000. 
- Kotsopoulos IAW. Evers SMAA, Ament AIHA, de Krom MCTFM. Chapter 29 Methodological issues in studies of the costs of epilepsy: a review. In: Pfäflin M, Fraser RT, Thorbecke R, Specht U, Wolf P. Comprehensive Care for People with Epilepsy. Eastleigh: John Libbey \& Company Ltd; 2001.

- Kotsopoulos IAW, Evers SMAA, Ament AIHA, de Krom MCTFM. Chapter 30 The economic evaluation of epilepsy care. In: Pfäflin M, Fraser RT, Thorbecke R, Specht U, Wolf P. Comprehensive Care for People with Epilepsy. Eastleigh: John Libbey \& Company Ltd; 2001.

- Ament AJHA, Evers SMAA, Goossens MEJB, de Vet HCW, van Tulder MW. Criteria list for conducting systematic reviews based on economic evaluation studies (CHEC). In: Donaldson C. Mugford M, Vale L. Economics and Systematic Review BMIJ-books;in press.

\section{DUTCH ARTICLES}

- Evers SMAA. Een vergelijkend onderzoek naar het meten van 'Health for All' indicatoren in de Europese Regio. Maandbericht Gezondheidsstatistiek 1992:4:4m16.

- Evers SMAA, Ament AIHA. De kosten van schizofrenie in Nederland. Tijdschrift voor Socialle Gezondheidszorg 1993;71:393-400.

- Ament. AlHA, Evers SMAA. Schizofrenie, ook een financiële belasting. lanssen Medisch-Wetenschappelijk 1994;april:121-124.

- Groot TLCM, Evers SMAA, Wenemoser RAS. Management Accounting praktijk in Nederlandse Ziekenhuizen. Tijdschrift voor Bedrijfsadministratie (\%BA) 1996;100: 1181-1187.

- Majoie HIM, Bertelo MW. Aldenkamp AP, Evers SMAA, Kessels AGH, Renier WO, Weber IW, Wilmink IT. Nervus vagus stimulatie bij kinderen met farmacotherapieresistente epilepsie. Nederlands tijdschrift voor Epileptologie 2000;28:37-38.

- Blaauw G, Evers S, Franke C, Leffers P, Lodder I, Teernstra O. Effectiviteit van chirurgische behandeling van het niet-aneurysmatische, spontane, supratentoriele, intracerebrale hematoom. Nederlands Tijdschrift voor Neurologie 2000;6:418-421.

- Majoie HIM, Berfelo MW, Aldenkamp AP, Evers SMAA, Rouss MHG, Kessels AGH, Ament AHHA, Renier WO. Nervus vagus stimulatie bij kinderen met farmacotherapie resistente epilepsie van het type Lennox- 
Gastaut; klinische resultaten, neuropsychologische effecten en kosteneffectiviteit. Nederlands tijdschrift voor Neurologie 2001;4:315-324.

\section{DUTCH BOOK CHAPTERS}

- Evers S, Ament A. Hoofdstuk 20 Economische evaluatie in de geestelijke

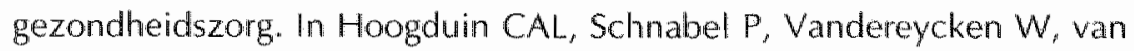
der Velden K, Verhulst FC. Jaarboek psychiatrie en psychotherapie 4, 1994-1995. Houten/Diegem: Bohn Stafleu Van Loghum; 1995.

- Evers S, Wiersma D, Ament A. Hoofdstuk 24 Kosten van schizofrenie in Nederland.In Dingemans PMAJ, van den Bosch RJ, Kahn RS, Schene $\mathrm{AH}$. Onderzoek van schizofrenie; implicaties voor behandeling. Houten/Diegem: Bohn Stafleu Van Loghum; 1995. 


\section{Curriculum Vitae}

Silvia Evers (1965, Gebrook-Echt) studied Health Sciences at Maastricht University (The Netherlands). She graduated in September 1990 with majors in Mental Health Sciences and Health Policy \& Administration. After her graduation she worked as a research fellow at Maastricht University (Epidemiology; Health Economics; Medical Sociology) and at the University of Amsterdam (Pedagogics). At the end of 1995 she started working at University Hospital Maastricht, in the Department of Neurosurgery, on a cost-effectiveness study concerning treatments for patients with intracerebral haemorrhage. In addition, she conducted the trials presented in this thesis. In 1997 she obtained a MSc in epidemiology. Since April 1999 she has been working in the Department of Health Organisation, Policy and Economics at Maastricht University, where she combined several Medical Technology Assessment (MTA) projects with work on her PhD. Currently the author is working as a postdoctoral research affiliate in the same department. In cooperation with the National Institute of Public Health and the University Hospital Maastricht she is looking at the cross-national transferability of cost-effectiveness data. Besides her research activities, she is involved as an MTA-advisor in several research projects and as a lecturer in MTA-courses. In the near future she will complete her Master of Laws with health, labour and public law as her primary field of interest. 